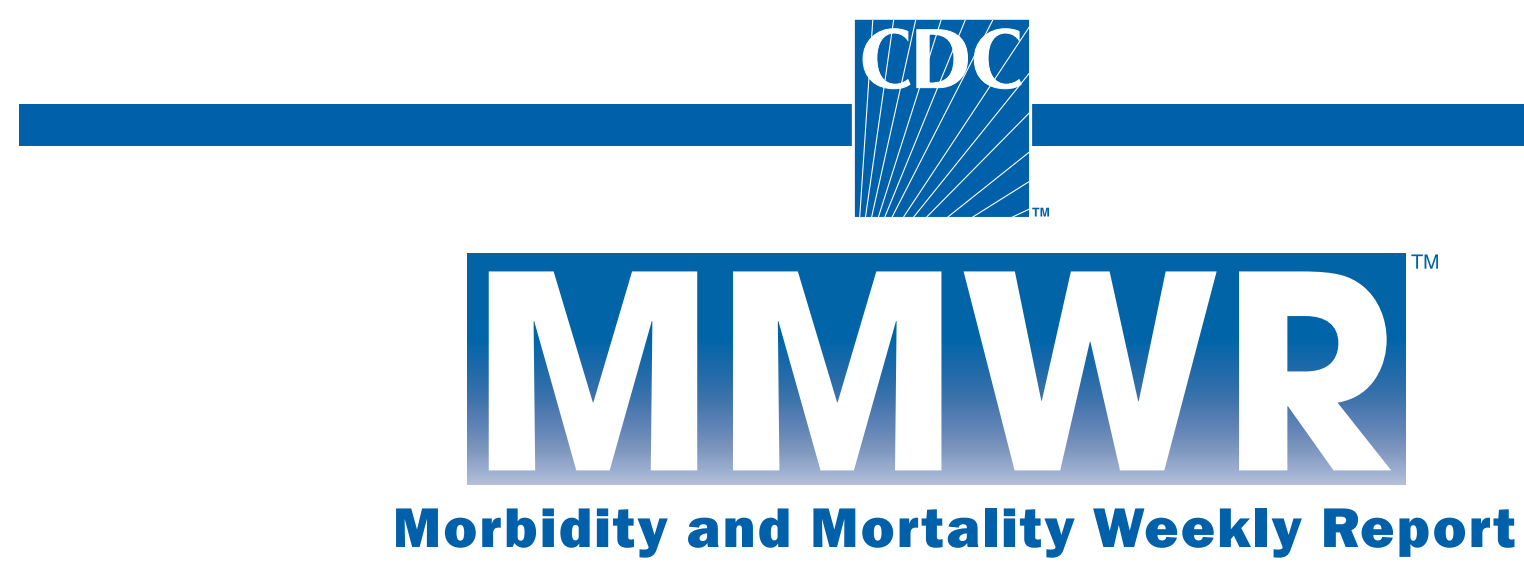

Weekly

July 21, 2006 / Vol. 55 / No. 28

\title{
Trends in Strength Training - United States, 1998-2004
}

Strength training is physical activity intended to increase muscle strength and mass. Adults who engage in strength training are less likely to experience loss of muscle mass (1), functional decline (2), and fall-related injuries than adults who do not strength train (3). Studies on strength-training interventions have indicated that inactive older adults who begin regular strength training achieve substantial strength gains within a few months (4). Because certain health benefits are linked to strength training, a national health objective for 2010 is to increase to $30 \%$ the proportion of adults who perform physical activities that enhance and maintain muscular strength and endurance on $\geq 2$ days per week (objective 22-4) (5). This objective is also recommended by the American College of Sports Medicine (6). CDC analyzed 1998-2004 data from the National Health Interview Survey (NHIS) ( 7 ) to determine the annual prevalence of strength training among U.S. adults by age group and race/ethnicity. This report describes the results of that analysis, which demonstrated that although the national prevalence of strength training for U.S. adults increased slightly during $1998-2004$, only $21.9 \%$ of men and $17.5 \%$ of women (age adjusted) in 2004 reported strength training two or more times per week. This is substantially lower than the national 2010 objective of $30 \%$ and underscores the need for additional programs to increase strength training among adults.

NHIS consists of face-to-face interviews regarding health status, use of health-care services, and health behaviors of the U.S. civilian, noninstitutionalized population. Data on strength training were collected every year during 1998-2004. The sample size ranged from 30,801 (1999) to 33,326 (2001), and the response rate ranged from $69.6 \%$ (1999) to $74.3 \%$ (2002) (7). Respondents were asked to report the frequency with which they engaged in strength training by answering the following question: "How often do you do physical activities designed to strengthen your muscles, such as lifting weights or doing calisthenics?" The same question was asked each year and was available in Spanish for Spanish-speaking respondents beginning in 1999. Respondents were categorized as meeting the national strength training objective if they engaged in strength training two or more times per week (5). Prevalence estimates by age and sex were weighted to account for nonresponse and were age adjusted to the 2000 U.S. standard population (8). Statistical software was used to account for the complex sampling design of the survey. Pairwise comparisons were performed to calculate $t$ statistics, and differences were considered significant at $\mathrm{p}<0.05$. When multiple comparisons were made, the Bonferroni adjustment was used $(\mathrm{p}<0.05 /$ number of comparisons). Only significant differences are reported in the results.

The age-adjusted prevalence of reported strength training two or more times per week among all respondents increased significantly, from $17.7 \%$ in 1998 to $19.6 \%$ in 2004 . The difference between 1998 and 2004 was significant for women but not for men (Figure). In 2004, the age-adjusted prevalence of those who met recommended levels of strength training was significantly higher among men than women $(21.9 \%$ versus $17.5 \%$, respectively).

In 2004, strength training was least prevalent among those aged $\geq 65$ years ( $14.1 \%$ among men; $10.7 \%$ among women).

\begin{tabular}{|c|c|}
\hline \multicolumn{2}{|c|}{ INSIDE } \\
\hline 772 & $\begin{array}{l}\text { Progress Toward Poliomyelitis Eradication - India, } \\
\text { January 2005-June } 2006\end{array}$ \\
\hline 776 & $\begin{array}{l}\text { Pseudomonas aeruginosa Infections Associated with } \\
\text { Transrectal Ultrasound-Guided Prostate Biopsies - } \\
\text { Georgia, } 2005\end{array}$ \\
\hline 777 & $\begin{array}{l}\text { West Nile Virus Activity - United States, } \\
\text { January 1-July 18, } 2006\end{array}$ \\
\hline 778 & Notices to Readers \\
\hline 779 & QuickStats \\
\hline
\end{tabular}


The MMWR series of publications is published by the Coordinating Center for Health Information and Service, Centers for Disease Control and Prevention (CDC), U.S. Department of Health and Human Services, Atlanta, GA 30333.

Suggested Citation: Centers for Disease Control and Prevention. [Article title]. MMWR 2006;55:[inclusive page numbers].

\section{Centers for Disease Control and Prevention}

Julie L. Gerberding, MD, MPH Director

Tanja Popovic, MD, PhD

(Acting) Chief Science Officer

James W. Stephens, PhD

(Acting) Associate Director for Science

Steven L. Solomon, MD

Director, Coordinating Center for Health Information and Service Jay M. Bernhardt, PhD, MPH

Director, National Center for Health Marketing Judith R. Aguilar

(Acting) Director, Division of Health Information Dissemination (Proposed)

\section{Editorial and Production Staff}

Frederic E. Shaw, MD, JD

(Acting) Editor, MMWR Series

Suzanne M. Hewitt, MPA

Managing Editor, MMWR Series

Douglas W. Weatherwax

(Acting) Lead Technical Writer-Editor

Catherine H. Bricker, MS

Jude C. Rutledge

Writers-Editors

Beverly J. Holland

Lead Visual Information Specialist

Lynda G. Cupell

Malbea A. LaPete

Visual Information Specialists

Quang M. Doan, MBA

Erica R. Shaver

Information Technology Specialists

\section{Editorial Board}

William L. Roper, MD, MPH, Chapel Hill, NC, Chairman

Virginia A. Caine, MD, Indianapolis, IN

David W. Fleming, MD, Seattle, WA

William E. Halperin, MD, DrPH, MPH, Newark, NJ

Margaret A. Hamburg, MD, Washington, DC

King K. Holmes, MD, PhD, Seattle, WA

Deborah Holtzman, PhD, Atlanta, GA

John K. Iglehart, Bethesda, MD

Dennis G. Maki, MD, Madison, WI

Sue Mallonee, MPH, Oklahoma City, OK

Stanley A. Plotkin, MD, Doylestown, PA

Patricia Quinlisk, MD, MPH, Des Moines, IA

Patrick L. Remington, MD, MPH, Madison, WI

Barbara K. Rimer, DrPH, Chapel Hill, NC

John V. Rullan, MD, MPH, San Juan, PR Anne Schuchat, MD, Atlanta, GA

Dixie E. Snider, MD, MPH, Atlanta, GA John W. Ward, MD, Atlanta, GA
FIGURE. Age-adjusted prevalence* of strength training two or more times per week, by sex and survey year - National Health Interview Survey, United States, 1998-2004

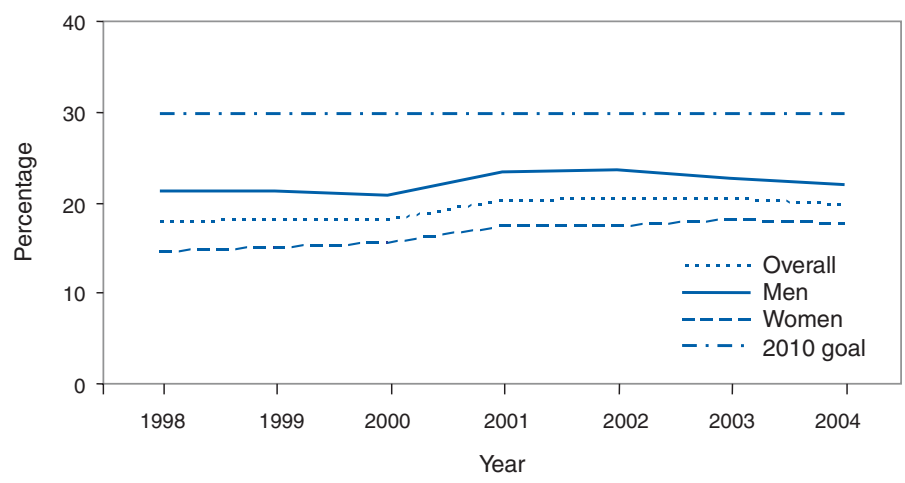

* Weighted percentages have been age adjusted to the 2000 U.S. standard population.

Prevalence of strength training among men and women decreased significantly as age increased $(\mathrm{p}<0.001)$ (Table). However, men aged $\geq 65$ years had a significant increase in prevalence during 1998-2004, and women aged 25-34, 4564 , and $\geq 65$ years had significant increases during the same period.

During 1998-2004, the prevalence of strength training increased significantly among non-Hispanic white men and women. In 2004, the prevalence of strength training among men was similar for non-Hispanic whites (23.1\%), nonHispanic blacks $(22.9 \%)$, and those classified as "other" $(21.3 \%)$. Strength training was least prevalent among Hispanic men (15.0\%). In 2004, strength training among women was significantly higher among non-Hispanic whites (20.4\%) than among non-Hispanic blacks (11.3\%), Hispanics (9.1\%), and those classified as "other" (12.9\%).

Reported by: J Kruger, PhD, S Carlson, MPH, H Kohl III, PhD, Div of Nutrition and Physical Activity, National Center for Chronic Disease Prevention and Health Promotion, CDC.

Editorial Note: The findings in this report demonstrate that the national prevalence of strength training for U.S. adults increased slightly during 1998-2004. Nonetheless, only $21.9 \%$ of men and $17.5 \%$ of women (age adjusted) in 2004 reported strength training two or more times per week, which is substantially lower than the national 2010 objective of $30 \%$. In addition, the greatest yearly increase was from 2000 to 2001 $(\mathrm{p}<0.001)$; however, since 2001, no further progress has been made. Although women experienced a significant increase during 1998-2004 and men did not, overall strength training levels among women remained lower than among men.

The prevalence of strength training was lowest among respondents aged $\geq 65$ years; nonetheless, respondents in this age group experienced the largest increase overall during 1998 2004. The factors that led to the increase in strength training in this group cannot be determined from this analysis, but 
TABLE. Age-adjusted prevalence* of strength training two or more times per week, by age group, sex, and race/ethnicity — National Health Interview Survey, United States, 1998-2004

\begin{tabular}{|c|c|c|c|c|c|c|c|c|c|c|c|c|c|c|}
\hline \multirow[b]{2}{*}{ Characteristic } & \multicolumn{2}{|r|}{1998} & \multicolumn{2}{|r|}{1999} & \multicolumn{2}{|r|}{2000} & \multicolumn{2}{|r|}{2001} & \multicolumn{2}{|r|}{2002} & \multicolumn{2}{|r|}{2003} & \multicolumn{2}{|r|}{2004} \\
\hline & $\%$ & $\left(95 \% \mathrm{Cl}^{\dagger}\right)$ & $\%$ & $(95 \% \mathrm{Cl})$ & $\%$ & $(95 \% \mathrm{Cl})$ & $\%$ & $(95 \% \mathrm{Cl})$ & $\%$ & $(95 \% \mathrm{Cl})$ & $\%$ & $(95 \% \mathrm{Cl})$ & $\%$ & $(95 \% \mathrm{Cl})$ \\
\hline Overall & 17.7 & $(17.2-18.3)$ & 18.1 & $(17.5-18.7)$ & 18.1 & $(17.4-18.7)$ & 20.2 & (19.6-20.8) & 20.4 & $(19.8-21.1)$ & 20.4 & $(19.8-21.1)$ & 19.6 & (19.0-20.3) \\
\hline $\begin{array}{l}\text { Men } \\
\text { Age (yrs) }\end{array}$ & 21.2 & (20.4-22.1) & 21.4 & $(20.6-22.2)$ & 20.9 & $(20.1-21.7)$ & 23.4 & $(22.6-24.2)$ & 23.7 & $(22.8-24.6)$ & 22.8 & (21.9-23.8) & 21.9 & $(21.0-22.7)$ \\
\hline $18-24$ & 36.3 & $(33.5-39.2)$ & 35.8 & (32.9-38.9) & 34.7 & $(31.9-37.6)$ & 37.9 & $(35.0-40.9)$ & 37.5 & $(34.4-40.8)$ & 37.0 & $(34.0-40.1)$ & 35.8 & (32.5-39.2) \\
\hline $25-34$ & 28.2 & $(26.3-30.2)$ & 27.8 & $(25.8-29.8)$ & 27.7 & $(25.8-29.7)$ & 31.1 & $(29.2-33.1)$ & 31.3 & $(29.2-33.6)$ & 28.6 & $(26.6-30.7)$ & 27.2 & (25.1-29.3) \\
\hline $35-44$ & 21.0 & (19.4-22.7) & 22.3 & $(20.7-24.1)$ & 20.6 & (19.1-22.3) & 24.7 & $(23.1-26.5)$ & 24.3 & (22.6-26.2) & 22.8 & $(21.0-24.7)$ & 21.6 & (19.7-23.6) \\
\hline $45-64$ & 16.5 & $(15.2-18.0)$ & 16.2 & $(14.9-17.7)$ & 16.4 & $(15.1-17.8)$ & 17.6 & $(16.3-19.0)$ & 18.3 & $(16.8-19.9)$ & 18.5 & $(17.1-20.0)$ & 17.3 & $(16.0-18.6)$ \\
\hline$\geq 65$ & 11.0 & $(9.7-12.5)$ & 11.3 & $(9.8-12.9)$ & 11.4 & $(10.0-12.9)$ & 12.6 & $(11.1-14.2)$ & 13.6 & $(12.1-15.3)$ & 13.5 & (11.9-15.4) & 14.1 & $(12.5-15.9)$ \\
\hline $\begin{array}{l}\text { Race/Ethnicity } \\
\text { White, } \\
\text { non-Hispanic }\end{array}$ & 21.7 & & 22.0 & $(21.1-22.9)$ & 21.5 & & 24.5 & 采 & 24.2 & 1 & 23.8 & 1 & 23.1 & 1 \\
\hline $\begin{array}{l}\text { Black, } \\
\text { non-Hispanic }\end{array}$ & 22.9 & (20.7-25.3) & 23.7 & (21.2-26.3) & 23.2 & (20.9-25.7) & 23.5 & $(21.3-25.8)$ & 25.6 & $(23.1-28.3)$ & 25.0 & $(22.5-27.8)$ & 22.9 & $(20.6-25.4)$ \\
\hline Hispanic & 16.1 & $(14.3-18.0)$ & 15.1 & $(13.3-17.0)$ & 15.0 & (13.2-17.0) & 15.7 & $(14.0-17.5)$ & 17.0 & $(15.2-18.9)$ & 16.7 & $(14.8-18.7)$ & 15.0 & (13.2-16.9) \\
\hline Other§ & 22.3 & $(18.2-27.0)$ & 20.9 & $(16.9-25.5)$ & 21.6 & $(17.5-26.2)$ & 21.6 & $(17.3-26.7)$ & 24.6 & $(20.2-29.6)$ & 23.2 & $(19.3-27.6)$ & 21.3 & $(17.4-25.8)$ \\
\hline $\begin{array}{l}\text { Women } \\
\text { Age (yrs) }\end{array}$ & 14.4 & $(13.7-15.0)$ & 15.0 & $(14.3-15.7)$ & 15.4 & $(14.7-16.2)$ & 17.2 & $(16.5-17.9)$ & 17.4 & $(16.6-18.1)$ & 18.1 & $(17.3-18.9)$ & 17.5 & $(16.7-18.3)$ \\
\hline $18-24$ & 19.6 & $(17.3-22.1)$ & 21.0 & (18.6-23.5) & 20.1 & (18.1-22.3) & 22.2 & (19.8-24.9) & 20.4 & $(18.1-22.8)$ & 22.4 & $(19.9-25.1)$ & 20.1 & $(17.8-22.5)$ \\
\hline $25-34$ & 18.1 & $(16.5-19.7)$ & 17.8 & $(16.4-19.4)$ & 18.3 & (16.6-20.2) & 21.1 & $(19.5-22.7)$ & 21.5 & (19.8-23.3) & 21.6 & (19.8-23.5) & 20.8 & (18.9-22.9) \\
\hline $35-44$ & 16.9 & $(15.5-18.4)$ & 17.7 & $(16.2-19.3)$ & 16.5 & $(15.1-18.1)$ & 19.7 & $(18.2-21.2)$ & 19.7 & (18.3-21.1) & 19.9 & $(18.4-21.5)$ & 18.2 & $(16.7-19.7)$ \\
\hline $45-64$ & 12.3 & $(11.3-13.4)$ & 13.1 & $(11.9-14.3)$ & 14.6 & $(13.5-15.8)$ & 15.6 & $(14.4-16.8)$ & 16.6 & (15.4-17.8) & 17.2 & $(16.1-18.5)$ & 17.6 & (16.4-18.9) \\
\hline$\geq 65$ & 6.8 & $(5.9-7.9)$ & 7.4 & (6.5-8.3) & 8.7 & $(7.7-9.8)$ & 9.0 & $(8.0-10.1)$ & 9.2 & $(8.1-10.4)$ & 10.3 & $(9.1-11.7)$ & 10.7 & $(9.5-12.0)$ \\
\hline $\begin{array}{l}\text { Race/Ethnicity } \\
\text { White, } \\
\text { non-Hispanic }\end{array}$ & 16.2 & $(15.4-17.0)$ & 16.5 & $(15.6-17.4)$ & 17.5 & $(16.5-18.4)$ & 19.3 & $(18.4-20.2)$ & 19.8 & $(18.8-20.7)$ & 20.6 & $(19.7-21.6)$ & 20.4 & (19.3-21.5) \\
\hline $\begin{array}{l}\text { Black, } \\
\text { non-Hispanic }\end{array}$ & 9.4 & $(8.1-10.8)$ & 11.7 & $(10.3-13.1)$ & 10.3 & $(9.0-11.8)$ & 12.9 & $(11.3-14.6)$ & 11.3 & $(10.0-12.8)$ & 11.7 & $(9.9-13.9)$ & 11.3 & $(9.9-12.8)$ \\
\hline Hispanic & 8.9 & $(7.7-10.2)$ & 9.5 & $(8.2-10.9)$ & 8.7 & $(7.6-10.1)$ & 9.2 & $(8.0-20.5)$ & 9.3 & $(8.0-10.7)$ & 10.8 & $(9.4-12.4)$ & 9.1 & $(7.9-10.6)$ \\
\hline Other§ & 12.0 & $(9.0-15.8)$ & 13.8 & $(10.7-17.6)$ & 12.4 & $(9.8-15.5)$ & 17.0 & $(14.0-20.5)$ & 17.5 & (14.4-21.1) & 17.4 & $(14.5-20.8)$ & 12.9 & $(10.0-16.4)$ \\
\hline
\end{tabular}

${ }^{*}$ Weighted percentages (except for those in the age groups) have been age adjusted to the 2000 U.S. standard population.

Confidence interval.

$\S$ Includes American Indian/Alaska Native and Asian/Pacific Islander.

possible explanations include increased promotion of active lifestyles among older adults (9) and programs that specifically promote strength training, such as Growing Stronger (10) and the Strong-for-Life program (4). Despite these gains, additional measures to promote strength training among adults are needed. Strength training throughout life can sustain functional independence for activities of daily living (1), such as the ability to carry groceries, rise from a chair, or walk up a flight of stairs.

Findings from this analysis suggest that some racial/ethnic groups have a significantly lower prevalence of strength training than others. Strength-training prevalence was consistently lower among Hispanic respondents than among non-Hispanic white respondents during 1998-2004. However, all subgroups are at risk for not meeting national health objectives for 2010 . Identification of barriers to strength training among all racial/ ethnic groups, especially Hispanics, can guide the design of culturally appropriate interventions. One of the most important barriers for many adults, regardless of racial/ethnic subgroup, is initiating a strength-training program. Including another person in the program, such as a coworker, spouse, neighbor, or friend, can provide encouragement and motivation.
The findings in this report are subject to at least two limitations. First, information on strength training is self reported and subject to response and recall bias. Second, misclassification errors in reporting might have affected prevalence estimates of strength training. For example, respondents might have interpreted the survey question differently or might not have understood the definitions of strength training and calisthenics. The survey question specified weight lifting and calisthenics, but because respondents were not asked to provide details, activities such as stair climbing might have been missed.

Although the NHIS data indicate that the prevalence of strength training increased from $17.7 \%$ to $19.6 \%$, the 2004 prevalence falls far short of the 2010 objective of $30 \%$. Evidence-based studies have indicated that strength-training programs for older adults, such as Strong-for-Life (4), have resulted in strength improvements among participants; more programs like this are needed. Additional opportunities for adults to engage in strength training (e.g., in places where adults already pursue leisure-time physical activity, such as schools and community centers) could increase the prevalence of strength training. Additional opportunities are especially 
important for racial/ethnic groups with lower prevalences (9). The findings in this report also underscore the need to increase education on the benefits of strength training among targeted adult populations.

\section{References}

1. Seguin R, Nelson ME. The benefits of strength training for older adults. Am Prev Med 2003;25(Suppl 2):S14-9.

2. Chandler JM, Duncan PW, Kochersberger G, Studenski S. Is lower extremity strength gain associated with improvement in physical performance and disability in frail, community-dwelling elders? Arch Phy Med Rehabil 1998;79:24-30.

3. Butler M, Norton R, Lee-Joe T, Coggan C. Preventing falls and fallrelated injuries among older people living in institutions: current practice and future opportunities. NZ Med J 1998;111:359-61.

4. Jette A, Lachman M, Giorgetti M, et al. Exercise: it's never too late: the strong-for-life program. Am J Public Health 1999;89:66-72.

5. US Department of Health and Human Services. Healthy people 2010, 2nd ed. With understanding and improving health and objectives for improving health. 2 vols. Washington, DC: US Government Printing Office; 2000.

6. American College of Sports Medicine. American College of Sports Medicine Position Stand. The recommended quantity and quality of exercise for developing and maintaining cardiorespiratory and muscular fitness, and flexibility in healthy adults. Med Sci Sports Exerc 1998;30:975-91.

7. US Department of Health and Human Services. National Health Interview Survey (NHIS): public use data release. Hyattsville, MD: US Department of Health and Human Services; 2006. Available at http://www.cdc.gov/nchs/nhis.htm.

8. Klein RJ, Shoenborn CA. Age adjustment using the 2000 projected U.S. population. Healthy people statistical notes, No. 20. Hyattsville, MD: National Center for Health Statistics; 2001.

9. Robert Wood Johnson Foundation. National blueprint: increasing physical activity among adults age 50 and older. Princeton, NJ: Robert Wood Johnson Foundation; 2001.

10. Seguin R, Epping J, Bloch R, Buchner D, Nelson M. Growing stronger: strength training for older adults. Washington, DC: Tufts University; 2002. Available at http://www.cdc.gov/nccdphp/dnpa/physical/ growing_stronger/growing_stronger.pdf.

\section{Progress Toward Poliomyelitis Eradication - India, January 2005-June 2006}

The global eradication of poliomyelitis has reached a critical stage. The disease remains endemic in only four countries (Afghanistan, India, Nigeria, and Pakistan), which have reported most of the cases in 2006 (1). India is the most populous of the polio-endemic countries. Beginning in 2005, the Government of India (GOI) and its partners intensified eradication efforts by implementing additional immunization and surveillance strategies, including introduction of monovalent oral poliovirus vaccine types 1 and 3 (mOPV1 and mOPV3, respectively)* (2). The number of reported cases decreased from 134 in 2004 to 66 in 2005. However, cases have resurged in 2006; as of June 25, 2006, a total of 60 cases had been reported. Although intense local transmission continues in certain areas (i.e., western Uttar Pradesh [UP]), interruption of wild poliovirus (WPV) transmission in India is feasible with continued effective interventions. This report summarizes progress toward polio eradication in India from January 2005 through June 2006.

\section{Acute Flaccid Paralysis (AFP) Surveillance}

AFP surveillance is essential to polio eradication. AFP surveillance in India continues at high levels of sensitivity, with surveillance indicators above current World Health Organization (WHO) operational targets. ${ }^{\dagger}$ In UP and Bihar, the only two Indian states where polio remains endemic, the annual nonpolio AFP rate was $>10$ cases per 100,000 population aged $<15$ years, and adequate stool specimen collection was above 80\% from January 2005 through June 2006.

Virologic testing of stool specimens from AFP patients in India is conducted at eight national laboratories, all of which are accredited by WHO as part of the Global Polio Laboratory Network (3). Despite an increased workload (55,535 specimens tested in 2005 compared with 35,885 in 2004), the laboratories sustained high levels of performance. Results of primary virus isolation were communicated to India's National Polio Surveillance Project within 28 days of specimen receipt at the laboratory for $99 \%$ of specimens tested in 2005. The mean interval from receipt of primary culture results to final poliovirus categorization (i.e., wild or vaccine related) was 6 days.

\section{WPV Epidemiology}

India reported 66 polio cases from 35 districts with onset of paralysis in 2005, of which $62(94 \%)$ were WPV type 1 (WPV1) and four (6\%) were WPV type 3 (WPV3). All four WPV3 cases occurred in UP.

\footnotetext{
${ }^{*}$ mOPV contains polio vaccine virus against either WPV type 1 or type 3 only; it does not provide protection against other WPV types. mOPV does provide greater immunity to the specific WPV type than does the same number of doses of trivalent OPV.

$\dagger$ The current WHO operational target for countries at high risk for polio transmission is a nonpolio AFP rate of at least two cases per 100,000 population aged $<15$ years and adequate stool specimen collection from $\geq 80 \%$ of AFP cases where two specimens are collected $\geq 24$ hours apart, both within 14 days of paralysis onset, and shipped on ice or frozen ice packs to a WHO-accredited laboratory.
} 
As of June 25, India had reported 60 polio cases (57 WPV1 and three WPV3) in 2006 with onset of paralysis occurring through May 2006. These 60 cases came from 20 districts, compared with 20 cases from 18 districts for the same period in 2005 (Figure). Of the cases reported in 2006, a total of 46 were from UP state, 12 from Bihar state, one from Madhya Pradesh state bordering UP, and one from Jharkhand state bordering Bihar. Twenty-six (43\%) cases, including all three WPV3 cases, were reported from Moradabad district in UP. Forty-three $(72 \%)$ of all cases reported in 2006 occurred in underserved ${ }^{\S}$ children, compared with 31 (47\%) of all such

${ }^{\S}$ Defined as belonging to a population having low socioeconomic standing, marginalized status, high population mobility, and poor sanitation. cases reported in 2005. In Moradabad district, $>85 \%$ of cases in 2006 were in the underserved population. In India, the majority of 2006 cases have occurred in children aged < 2 years; $33 \%$ of 2006 cases have been reported in children aged $<12$ months, compared with only $15 \%$ in 2005 . In Moradabad, $>50 \%$ of 2006 cases have been reported in children aged 12-23 months (Table).

Genetic sequencing of WPVs isolated in India reveal that the number of distinct genetic clusters ${ }^{9}$ of WPV1 decreased

\footnotetext{
All WPVs isolated in India are sequenced across the interval encoding the major capsid protein (VP1) (approximately 900 nucleotides), and results are analyzed to determine the likely origin (by state and district) of the virus. Isolates within a cluster share $>95 \%$ VP1 nucleotide sequence identity.
}

FIGURE. Wild poliovirus (WPV)^ cases — India, January-December 2005 and January-June $2006^{\dagger}$

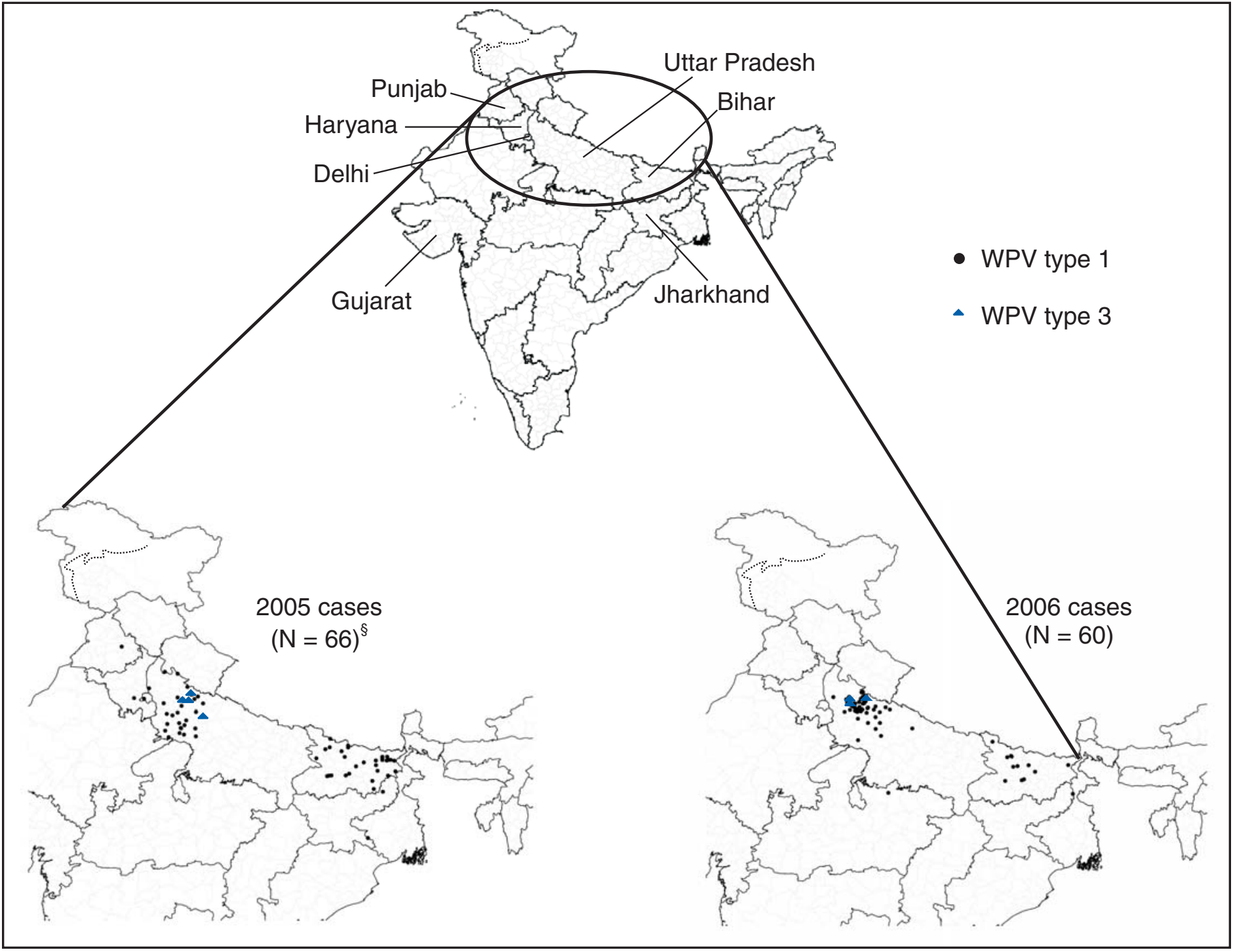

* Excludes viruses detected from environmental surveillance and vaccine-derived polioviruses.

${ }^{\dagger}$ As of June 25, 2006. Includes cases with paralysis onset occurring during May but reported in June.

$\S$ One WPV type 1 case in Gujarat state is not indicated on the map. 
TABLE. Wild poliovirus (WPV) incidence, by state and selected characteristics — India, January-June 2005 and January-June 2006 *

\begin{tabular}{|c|c|c|c|c|c|c|c|c|c|c|c|c|c|c|c|c|c|c|}
\hline \multirow{4}{*}{$\frac{\text { State }}{\text { Uttar Pradesh }}$} & \multicolumn{3}{|c|}{ No. of confirmed WPV cases } & \multicolumn{12}{|c|}{ No. and $\%$ of WPV cases by age of patient } & \multirow{2}{*}{\multicolumn{3}{|c|}{$\begin{array}{l}\text { No. and } \% \text { of WPV cases } \\
\text { in underserved }{ }^{\dagger} \text { children }\end{array}$}} \\
\hline & \multirow{2}{*}{$\begin{array}{l}\text { All of } \\
2005 \\
\end{array}$} & \multirow[b]{2}{*}{2005} & \multirow[b]{2}{*}{2006} & \multicolumn{4}{|c|}{$0-11$ mos } & \multicolumn{4}{|c|}{$12-23 \mathrm{mos}$} & \multicolumn{4}{|c|}{$\geq 24 \mathrm{mos}$} & & & \\
\hline & & & & & 005 & & 006 & & 05 & & 006 & & 005 & & 006 & 2005 & \multicolumn{2}{|c|}{2006} \\
\hline & 29 & 9 & 46 & 1 & (11) & 15 & (33) & 4 & (44) & 16 & (35) & 4 & (44) & 15 & (33) & $6(66)$ & 36 & (78) \\
\hline Moradabad & 4 & 0 & 26 & & - & 4 & (15) & & - & 15 & (58) & & - & 7 & (27) & - & 22 & (85) \\
\hline Bihar & 30 & 8 & 12 & 2 & (25) & 4 & (33) & 2 & (25) & 3 & (25) & 4 & $(50)$ & 5 & (42) & $4 \quad(50)$ & 6 & (50) \\
\hline Other states & 7 & 3 & 2 & 0 & (0) & 1 & (50) & 1 & (33) & 0 & (0) & 2 & (66) & 1 & (50) & $0 \quad(0)$ & 1 & (50) \\
\hline Total & 66 & 20 & 60 & 3 & (15) & 20 & (33) & 7 & (35) & 19 & (32) & 10 & (50) & 21 & (35) & $10(50)$ & 43 & (72) \\
\hline
\end{tabular}

* Includes cases with paralysis onset occurring during May but reported in June. For 2006, cases shown are reported as of June 25, 2006.

${ }^{\dagger}$ Defined as belonging to a population having low socioeconomic standing, marginalized social status, high population mobility, and poor sanitation.

from three in 2004 to two in 2005 to one in 2006 (as of June 25, 2006) (3). Within the surviving WPV1 cluster, distinct lineages (roughly corresponding to chains of transmission) have been reduced in UP and Bihar to two each in 2006 from five and four each, respectively, in 2005. Only one WPV3 lineage persists in India and is located in only one district (Moradabad) in UP.

Weekly environmental sewage sampling in three urban wards of Mumbai detected WPV1 in 85 (53\%) of 159 samples in 2004 , in $16(10 \%)$ of 156 samples in 2005, and in two (5\%) of 42 samples in the first half of 2006, most recently in January 2006. ${ }^{* *}$ Genetic sequencing indicated that the isolates were closely related to viruses found in Bihar and UP. Although three WPV1 cases were reported from Mumbai and nearby districts in 2004, no WPV cases were reported there from January 2005 through June 2006, despite highly sensitive surveillance.

\section{Immunization Activities}

Routine vaccination coverage with 3 doses of OPV continues to be low in the polio-endemic states (Bihar, 27\%; western UP, 38\%; and eastern UP, 45\%) (UNICEF, unpublished data, 2005). To improve these coverage rates, new strategies are being planned and gradually implemented, including hiring and training more staff dedicated to routine immunization, expanding vaccine-preventable disease surveillance, and launching immunization campaign activities specifically for all routine immunizations covered under WHO's Expanded Program on Immunization.

GOI conducted 10 supplementary immunization activity $(\mathrm{SIA})^{\dagger \dagger}$ rounds during 2005 , including two nationwide rounds

\footnotetext{
** Although sewage samples continue to be collected, no laboratory results have been available since the end of March 2006 because of a fire in April in the Global Specialized Laboratory in Mumbai.

${ }^{\dagger \dagger}$ Mass campaigns conducted during a brief period (days to weeks) in which 1 dose of OPV is administered to all children aged $<5$ years, regardless of vaccination history. The geographic extent of campaigns (national versus subnational) is determined by analysis of surveillance data. OPV can be administered at fixed sites, by mobile teams during house-to-house visits, by mobile teams at transit points (e.g., train stations or markets), or through a combination of strategies, depending on local circumstances.
}

and eight subnational rounds in states and districts where WPV was detected or where a high risk for WPV circulation existed. During the first 6 months of 2006, GOI conducted four SIAs, two nationwide and two subnational rounds; GOI is planning four more SIAs for the remainder of 2006. Continued monitoring of SIAs revealed that the percentage of missed houses increased from approximately $8 \%$ during January-April 2005 to an average of $11 \%$ in all rounds during May 2005January 2006 in the densely populated Moradabad district in UP, indicating a decline in SIA quality. ${ }^{\$ \$}$

SIAs added mOPV1 in April 2005, and it was used in most SIA rounds conducted during April-November in Bihar, UP, Mumbai (Maharashtra state), and polio-free states that had documented cases of WPV1 importation. However, mOPV1 was not used in consecutive rounds until 2006, when, for the first time, four consecutive mOPV1 rounds were conducted in western UP. In December 2005, mOPV3 was first used in eradication activities in western UP, after detection of WPV3 in Moradabad district. Trivalent OPV (tOPV) continues to be used in the routine childhood immunization program and in SIAs in states at low risk for polio transmission (1).

Reported by: Ministry of Health and Family Welfare, Government of India; National Polio Surveillance Project; Immunization and Vaccine Development Dept, WHO Regional Office for South-East Asia, New Delhi; Poliovirus Laboratory Network, Ahmedabad, Bangalore, Chennai, Coonoor, Kasauli, Kolkata, Lucknow, and Mumbai; UNICEF, New Delhi, India. Immunization, Vaccines and Biologicals Dept, WHO, Geneva, Switzerland. Div of Viral Diseases and Global Immunization Div, National Center for Immunization and Respiratory Diseases; SJ Doshi, MD, EIS Officer, CDC.

Editorial Note: The polio eradication program in India reached several milestones in 2005 and early 2006 toward the goal of ending polio transmission in India. The use of mOPV1 during large-scale SIAs had a substantial impact on virus transmission in polio-endemic areas where high coverage was maintained and achieved; mOPV1 was instrumental in stopping

\footnotetext{
\$\$ SIA quality is defined by the number of missed houses during house-to-house vaccination activities and the number of houses designated incorrectly by vaccinators.
} 
local virus transmission in Mumbai, where sewage samples indicated only imported viruses. The number of virus lineages persisting in western UP decreased from five in 2005 to two in 2006 after use of mOPV1. In Bihar, the use of mOPV1, combined with increased government support, led to a reduction in lineages from four in 2005 to two in 2006.

Although three times as many cases were reported from India during the first half of 2006 compared with the same period in 2005, genetic-sequencing data indicate that transmission is now restricted to only one circulating WPV1 genetic cluster, and over half of the chains of virus transmission present in 2004 have been eliminated. The geographic distribution of WPV1 circulation has contracted since 2005, with no WPV cases identified in the southern Indian states, West Bengal, or in the western states of Maharashtra or Rajasthan. Delhi, which is adjacent to UP, has not reported a WPV case in 2006. Even in UP, the resurgence of cases is restricted to a circumscribed area of a few districts of western UP, centered on Moradabad district. Moreover, WPV3 has been identified in only two administrative blocks in one district in western UP in 2006, compared with four administrative blocks in three districts in 2005.

The polio laboratory network remains a cornerstone of India's polio eradication program. By strengthening management techniques in 2005 and introducing new technologies in early 2006, the laboratories continued to provide rapid results. Genetic data generated by the Global Specialized Laboratory in Mumbai have been used to target immunization efforts in the most critical areas. For example, during SIAs, vaccinators are now deployed along major train routes, after genetic data and epidemiologic investigations identified these routes as channels of virus transmission across districts and states.

UP and Bihar remain the source of ongoing WPV transmission in India and exportation of WPV to other countries, including the polio-free countries of Angola (with spread to the Democratic Republic of Congo and Namibia), Bangladesh, and Nepal $(4,5)$. Data from UP and Bihar confirm that most WPV circulation is occurring in areas with inadequate SIA quality, suggesting that the early 2006 resurgence of cases has resulted from reduced community participation in vaccination campaigns and decline in the quality of vaccine program implementation. Western UP is a particularly challenging area for interrupting polio because of high population density, a large birth cohort, poor sanitation, and high population mobility. These characteristics are especially evident in areas such as Moradabad, where a large population resides with low socioeconomic standing, marginalized social status, and poor sanitation.
To improve SIA quality in areas at high risk for polio transmission, several strategies were used during 2005 and early 2006 on the basis of recommendations from the India Expert Advisory Group on Polio Eradication (IEAG), including 1) development and licensure of mOPV1 and mOPV3 for use in SIAs, 2) deployment of additional personnel to areas at high risk for polio transmission, 3) enhanced social mobilization efforts targeted to underserved population groups missed during previous SIAs, 4) use of mobile teams to vaccinate children at transit points (e.g., train stations or markets), and 5 ) increased engagement and accountability of GOI leaders and workers (2).

In May 2006, IEAG recommended increased emphasis on administering a dose of mOPV1 to all infants at birth to 1) vaccinate infants before they are infected with competing enteric pathogens that might reduce the efficacy of OPV and 2) help decrease the population immunity gap in areas of UP at high risk for polio transmission. Improved surveillance and maintenance of recent gains in SIA coverage in Bihar also were recommended ( 6 ).

As a result of these new programmatic strategies, field monitors reported improvement of SIA quality in Bihar in all four rounds in 2006, compared with the rounds held in the second half of 2005. Reports from Moradabad also indicate that the number of missed houses during vaccination activities steadily decreased, from $11 \%$ in January 2006 to $8 \%$ by April 2006. Additional monitoring measures to identify and target underserved children and those in transit will help ensure that all children are reached.

The decrease in genetic diversity and geographic spread of the virus suggests that India might be in the final stages of polio eradication. A resurgence of cases occurred in a localized area of western UP because of problems with immunization campaign quality. Improvements in SIA implementation in the remaining areas of virus transmission, effective social mobilization and communication activities targeting the underserved population, and enhanced community and political commitments are needed to eradicate the disease in India.

\section{References}

1. CDC. Progress toward interruption of wild poliovirus transmissionworldwide, January 2005-March 2006. MMWR 2006;55:458-62.

2. India Expert Advisory Group. Conclusions and recommendations: the twelfth meeting of the India Expert Advisory Group for Polio Eradication, New Delhi, India, December 5-6, 2005. New Delhi, India: National Polio Surveillance Project; 2005. Available at http:// www.npspindia.org/advisory.asp.

3. CDC. Progress toward poliomyelitis eradication-India, January 2004May 2005. MMWR 2005;54:655-9.

4. CDC. Resurgence of wild poliovirus type 1 transmission and consequences of importation-21 countries, 2002-2005. MMWR 2006;55:145-50. 
5. Roberts L. Polio experts strive to understand a puzzling outbreak. Science 2006;312:1581.

6. India Expert Advisory Group. Conclusions and recommendations: the thirteenth meeting of the India Expert Advisory Group for Polio Eradication, New Delhi, India, May 4-5, 2006. New Delhi, India: National Polio Surveillance Project; 2006. Available at http://www.npspindia.org/ advisory.asp.

\section{Pseudomonas aeruginosa Infections Associated with Transrectal Ultrasound-Guided Prostate Biopsies - Georgia, 2005}

Transrectal ultrasound (TRUS)-guided prostate biopsies are among the most common outpatient diagnostic procedures performed in urology clinics, with an estimated 624,000 performed annually in the United States (CDC, unpublished data, 2006). The procedures generally are performed in follow-up to elevated levels of prostate-specific antigen or abnormal digital rectal examinations (1). Septicemia has been reported as a rare complication of the procedure (2). This report summarizes an investigation of four cases of Pseudomonas aeruginosa infection after TRUS-guided prostate biopsies in which contamination of the equipment was the likely source. The findings underscore the need to adhere to recommendations for the cleaning and disinfection of TRUS-guided prostate biopsy equipment.

On July 28, 2005, a urologist notified the Georgia Department of Human Resources, Division of Public Health (GDPH) regarding four patients who were hospitalized with $P$. aeruginosa infections within 6 days of outpatient TRUS-guided prostate biopsies performed at a clinic. All procedures were halted at the clinic pending the investigation. The four patients were white, non-Hispanic men aged 57-71 years who had undergone the biopsy procedure during July 20-26, 2005. They were the only patients who had TRUS-guided prostate biopsies at the clinic during that period. Subsequently, all four experienced fever and chills and were admitted to the hospital 1-6 days (mean: 2.5 days) after their procedures. Three patients were admitted with diagnosed septicemia and the fourth with a diagnosis of infection. $P$. aeruginosa was recovered from cultures of blood (one patient), urine (two patients), or blood and urine specimens (one patient). The patients were treated successfully with a combination of intravenous and oral antimicrobial agents during hospitalizations of 2-12 days (mean: 5.8 days).

All procedures had been performed in the clinic by the same urologist and staff members using the following technique. Immediately before each procedure, a new finger cot was fitted over the distal tip of the ultrasound probe, filled with gel to eliminate air bubbles, and secured with an O-ring. A standard condom was then fitted over the finger cot and ultrasound probe and filled with lubricant. Next, a steel, nondisposable needle guide was fitted over the ultrasound probe, finger cot, and first condom. A second condom was fitted over these items and filled with lubricant. Once the ultrasound probe was inserted into the rectum and positioned correctly, the urologist used a spring-loaded biopsy gun to fire a sterile biopsy needle through the needle guide into the prostate, piercing the second condom, to obtain a core of tissue for pathologic analysis. The same needle was withdrawn and reinserted through the needle guide approximately eight times to obtain the needed tissue cores from each patient.

The clinic's standard practice for perioperative prophylaxis included administration of $500 \mathrm{mg}$ of levofloxacin orally the night before the procedure, an enema per rectum 1 hour before the procedure, and $80 \mathrm{mg}$ of gentamicin intramuscularly upon arrival at the clinic on the day of the biopsy. After the procedure, patients were instructed to take $500 \mathrm{mg}$ of levofloxacin orally daily for 3 days.

After each procedure, the ultrasound probe was disinfected by wiping it with a $3.2 \%$ glutaraldehyde solution. A syringe was used to flush the steel needle guide first with soap, then with tap water, and, finally, with orthophthaldehyde (OPA), a high-level disinfectant. The needle guide was then soaked in the OPA for a minimum of 15 minutes and usually overnight. Before use, the needle guide was removed from the OPA and rinsed with tap water. A review of the manufacturer's written instructions revealed that the recommended reprocessing method for the needle guide called for first cleaning biologic material from the guide and then sterilizing the guide.

A total of 16 environmental samples were obtained from surfaces, supplies, equipment, and tap water in the clinic during August 5-10, 2005. One grew $P$. aeruginosa; this was a sample obtained from the narrow lumen of the needle guide after it was removed from OPA disinfectant. This specimen was obtained by scraping the needle guide lumen with a sterile needle and then using the needle to inoculate a sterile swab. All four patient isolates and the isolate obtained from the needle guide had similar antimicrobial susceptibility patterns and were resistant to gentamicin and levofloxacin, the agents used for perioperative prophylaxis. The needle-guide isolate and the three available patient isolates were indistinguishable by pulsedfield gel electrophoresis.

Reported by: J Gillespie, MPH, KE Arnold, MD, Georgia Dept of Human Resources, Div of Public Health. MA Kainer, MBBS, Tennessee Dept of Health. J Noble-Wang, PhD, B Jensen, MMSc, M Arduino, PhD, J Hageman, MPH, A Srinivasan, MD, National Center for Preparedness, Detection, and Control of Infectious Diseases (proposed), CDC. 
Editorial Note: This report describes an investigation of $P$. aeruginosa infections that were likely related to contamination of TRUS prostate biopsy equipment that had not been adequately cleaned (i.e., by brushing) or properly sterilized and had been rinsed improperly with tap water after reprocessing. The association between the equipment and the infections was indicated by matching the strain of $P$. aeruginosa from the lumen of the reprocessed needle guide with those strains recovered from the three available patient isolates.

Although infectious complications of TRUS-guided prostate biopsies have been reported (2), contamination of the needle guide has not been previously implicated as the cause of infection. According to the Spaulding system for reprocessing medical devices (3), prostate biopsy needle guides are "critical devices" because the needles that pass through them penetrate sterile tissue. After adequate manual cleaning, critical devices must be sterilized before reuse. Steam sterilization is the preferred method for reprocessing heat-stable medical devices, including many prostate biopsy needle guides. The manufacturers of these guides provide recommendations for sterilization methods that are compatible with the specific devices, and users should review and follow these recommendations.

Manual cleaning to remove biologic material is a necessary first step in reprocessing any medical device; disinfection and sterilization protocols do not work effectively on visibly soiled surfaces. Because the lumens of needle guides and needle-guide support channels and assemblies are long and narrow, manual cleaning is difficult without the use of special equipment designed to clean the device. Manufacturers of reusable prostate needle guides recommend the use of special brushes to clean guides and support channels and assemblies. These brushes must be purchased separately from the needle guides, and a new brush should be used each time the guide is cleaned.

Another recent investigation demonstrates that the failure to properly clean the lumen of a prostate needle guide has not been limited to the cases described in this report. In April 2006, the Veterans Health Administration issued a Patient Safety Alert to all U.S. Department of Veterans Affairs (VA) hospitals stating that a routine environmental inspection at a urology clinic revealed that the lumen of a needle guide of a reusable, reprocessed, TRUS transducer assembly was soiled.* The ensuing investigation determined that brushes were not being used to clean the lumen of the needle guide. All VA hospitals were instructed to review procedures for reprocessing this equipment, and other VA facilities also reported that brushes were not being used. The VA alert has prompted

\footnotetext{
*Available at http://www.va.gov/ncps/alerts/b-kmedicaltransduceralert06011.pdf.
}

reviews by non-VA health-care systems. In Tennessee, facilities contacted the state health department to report that brushes were not being used to reprocess prostate biopsy needle guides. In response, the Tennessee Department of Health disseminated recommendations from the Food and Drug Administration (FDA) on reprocessing TRUS equipment to hospitals, surgical centers, and urologists.

In the cases described in this report, the practice of rinsing the needle guide in tap water after reprocessing might have contributed to its contamination. P. aeruginosa is well known to colonize tap water and has the ability to form biofilms on medical devices that are difficult to remove. Because tap water is not sterile, it should never be used to rinse medical equipment after reprocessing.

In June 2006, in response to the recent reports of problems with reprocessing prostate biopsy needle guides, FDA issued a Public Health Notification. This notification contains a summary of the recommendations for the proper reprocessing of reusable prostate biopsy equipment. ${ }^{\dagger}$ Health-care providers and their staffs should adhere to both the FDA recommendations and the equipment manufacturer's cleaning instructions.

\section{References}

1. Wareing M. Transrectal ultrasound and prostate biopsy clinic. Nurs Stand 2004;18:33-7.

2. Crundwell MC, Cooke PW, Wallace DM. Patients' tolerance of transrectal ultrasound-guided prostatic biopsy: an audit of 104 cases. BJU Int 1999;83:792-5.

3. Spaulding EH. Chemical disinfection of medical and surgical materials [Chapter 32]. In: Lawrence CA, Block SS, eds. Disinfection, sterilization and preservation. Philadelphia, PA: Lea \& Febiger; 1968:517-31.

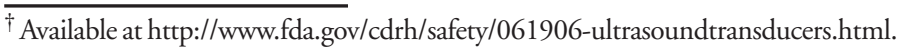

\section{West Nile Virus Activity - United States, January 1-July 18, 2006}

This report summarizes West Nile virus (WNV) surveillance data reported to CDC through ArboNET as of 3 a.m. Mountain Daylight Time, July 18, 2006. A total of 10 states had reported 15 cases of human WNV illness to CDC (Figure, Table). Nine (60\%) cases for which such data were available occurred in males; median age of patients was 50 years (range: 9-89 years). Date of illness onset ranged from January 6 to July 8; no deaths were reported.

A total of 11 presumptive West Nile viremic blood donors (PVDs) have been reported to ArboNET during 2006. Of these, two each were reported from Colorado, Kentucky, and Nebraska and one each from Idaho, Iowa, Oklahoma, South Dakota, and Texas. 
FIGURE. Areas reporting West Nile virus (WNV) activity United States, 2006*

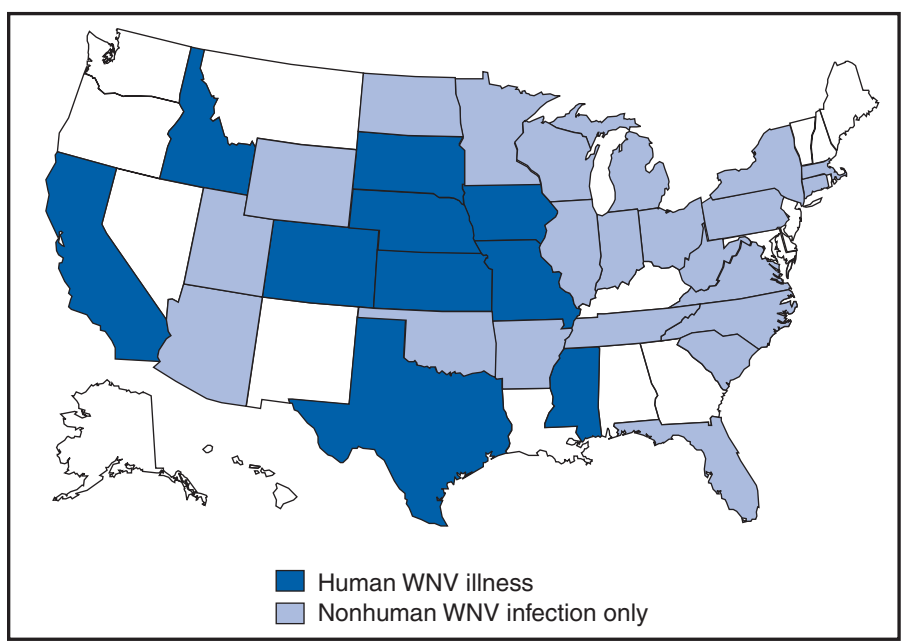

${ }^{*}$ As of July 18, 2006.

TABLE. Number of human cases of West Nile virus (WNV) illness, by state - United States, 2006*

\begin{tabular}{|c|c|c|c|c|c|}
\hline State & $\begin{array}{c}\text { Neuroinvasive } \\
\text { disease }^{\dagger}\end{array}$ & $\begin{array}{l}\text { West } \\
\text { Nile } \\
\text { fever§ }\end{array}$ & $\begin{array}{c}\text { Other } \\
\text { clinical/ } \\
\text { unspecified" }\end{array}$ & $\begin{array}{l}\text { Total } \\
\text { reported } \\
\text { to CDC** }\end{array}$ & Deaths \\
\hline California & 1 & 0 & 0 & 1 & 0 \\
\hline Colorado & 1 & 0 & 0 & 1 & 0 \\
\hline Idaho & 0 & 1 & 0 & 1 & 0 \\
\hline lowa & 0 & 1 & 0 & 1 & 0 \\
\hline Kansas & 0 & 1 & 0 & 1 & 0 \\
\hline Mississippi & 2 & 0 & 0 & 2 & 0 \\
\hline Missouri & 1 & 0 & 0 & 1 & 0 \\
\hline Nebraska & 1 & 1 & 0 & 2 & 0 \\
\hline South Dakota & 1 & 2 & 0 & 3 & 0 \\
\hline Texas & 2 & 0 & 0 & 2 & 0 \\
\hline Total & 9 & 6 & 0 & 15 & 0 \\
\hline
\end{tabular}

${ }^{*}$ As of July $18,2006$.

† Cases with neurologic manifestations (i.e., West Nile meningitis, West Nile encephalitis, and West Nile myelitis).

$\S$ Cases with no evidence of neuroinvasion.

१ Illnesses for which sufficient clinical information was not provided.

** Total number of human cases of WNV illness reported to ArboNet by state and local health departments.

In addition, 367 dead corvids and 51 other dead birds with WNV infection have been reported from 22 states during 2006. WNV infections have been reported in horses from seven states. WNV seroconversions have been reported in 33 sentinel chicken flocks from six states (Arkansas, California, Florida, Iowa, North Carolina, and North Dakota). A total of $525 \mathrm{WNV}$-positive mosquito pools have been reported from 23 states.

Additional information about national WNV activity is available from CDC at http://www.cdc.gov/ncidod/dvbid/ westnile/index.htm and at http://westnilemaps.usgs.gov.
Notice to Readers

\section{Clinical Vaccinology Course - November 3-5, 2006}

$\mathrm{CDC}$ and four other national organizations are collaborating with the National Foundation for Infectious Diseases (NFID), Emory University School of Medicine, and Emory Vaccine Center to sponsor a Clinical Vaccinology Course to be held November 3-5, 2006, at the Crowne Plaza AtlantaBuckhead in Atlanta, Georgia. The course will focus on new developments and concerns related to use of vaccines in pediatric, adolescent, and adult populations. Approximately 20 experts will present symposia on adult immunization, pediatric immunization, ensuring use of vaccines, vaccine safety and supply, the evolving adolescent immunization platform, and travel and international vaccines.

This course is specifically designed for primary-care physicians, family physicians, internal medicine specialists, pediatricians, public health specialists, nurse practitioners, physician assistants, clinical practice nurses, infectious disease specialists, and other health-care professionals involved with clinical aspects of vaccinology. The course also will be of interest to health-care professionals involved in prevention and control of infectious diseases, including federal, state, and local public health officials. Continuing education credits will be offered for physicians, nurses, and pharmacists, and prescribed credits for family physicians.

Information regarding the preliminary program, registration, and hotel accommodations is available at http:// www.nfid.org/conferences/idcourse06, or by e-mail (idcourse@nfid.org), fax (301-907-0878), telephone (301656-0003, ext. 19), and mail (NFID, Suite 750, 4733 Bethesda Avenue, Bethesda, MD 20814).

\section{Notice to Readers}

\section{Satellite Broadcast: Mobilizing Against the HIV/AIDS Crisis Among African Americans}

CDC and the Public Health Training Network will present the satellite broadcast and webcast, "Mobilizing Against the HIV/AIDS Crisis Among African Americans," on November 16, 2006, at 1 p.m. EST. The 2-hour broadcast will highlight relevant research and related programs in the United States; a panel will answer viewer questions, which can be sent via fax during the broadcast or by e-mail during and after the broadcast. 


\title{
QuickStats
}

FROM THE NATIONAL CENTER FOR HEALTH STATISTICS

\section{Percentage of Older Adults Who Engaged in Regular Leisure-Time Physical Activity, ${ }^{*}$ by Age Group and Sex — United States, 2000-2003 ${ }^{\dagger}$}

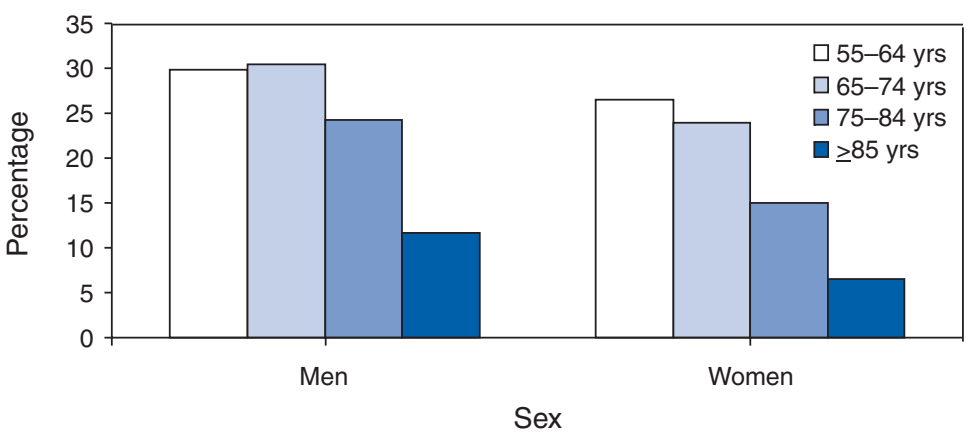

\begin{abstract}
* Defined as vigorous activity at least three times a week for $\geq 20$ minutes or lightto-moderate activity at least five times a week for $\geq 30$ minutes.

† Derived from the 2000-2003 National Health Interview Surveys. Estimates are based on household interviews of 39,990 civilian, noninstitutionalized adults aged $\geq 55$ years.
\end{abstract}

During 2000-2003, men aged $\geq 55$ years were more likely than women in the same age group to engage in regular leisure-time physical activity. For both men and women, prevalence of regular activity was nearly the same for adults aged 55-64 and 65-74 years, declined among those aged $75-84$ years, and declined further among those aged $\geq 85$ years. Among adults aged $\geq 85$ years, approximately one in 10 men and one in 20 women engaged in regular leisure-time physical activity.

SOURCE: Schoenborn CA, Vickerie JL, Powell-Griner E. Health characteristics of adults 55 years and over: United States, 2000-2003. Advance data from vital and health statistics. No. 370. Hyattsville, MD: US Department of Health and Human Services, CDC, National Center for Health Statistics; 2006. Available at http://www.cdc.gov/ nchs/data/ad/ad370.pdf.

Additional information will be available after August 10 at http://www.cdenpin.org (see Satellite Broadcasts). Organizations are responsible for setting up their own viewing locations and are encouraged to register their locations as soon as possible after August 17 so that persons who would like to view the broadcast can access information online. Directions for establishing and registering a viewing location are available at http://www.cdenpin.org. The broadcast will be available on the Internet for 3 years (Windows Media Player ${ }^{\circledR}$ required) at http://www.phppo.cdc.gov/phtn. Videotapes, DVDs, and video CD-ROMs of the broadcast can be ordered by telephone, $800-458-5231$.

\section{Erratum: Vol. 52, No. 54}

In "Summary of Notifiable Diseases - United States, 2003," on page 78, in Table 12, "Deaths from selected notifiable diseases - United States, 1996-2001," in the first column, "Cause of death," "Hepatitis B, acute" should read, Hepatitis B.

\section{Errata: Vol. 55, No. 27}

In "QuickStats: Number of Emergency Department (ED) Visits with Diagnostic Imaging Performed - United States, 1995 and 2004," page 753, the title should read "Number of Emergency Department (ED) Visits with Diagnostic Imaging Ordered or Performed — United States, 1995 and 2004," and the y-axis should read, "Number (in millions)." 
TABLE I. Provisional cases of infrequently reported notifiable diseases ( $<1,000$ cases reported during the preceding year) - United States, week ending July 15, 2006 (28th Week)

\begin{tabular}{|c|c|c|c|c|c|c|c|c|c|}
\hline \multirow[b]{2}{*}{ Disease } & \multirow{2}{*}{$\begin{array}{l}\text { Current } \\
\text { week }\end{array}$} & \multirow{2}{*}{$\begin{array}{l}\text { Cum } \\
2006\end{array}$} & \multirow{2}{*}{$\begin{array}{c}\text { 5-year } \\
\text { weekly } \\
\text { average }^{\dagger}\end{array}$} & \multicolumn{5}{|c|}{ Total cases reported for previous years } & \multirow[b]{2}{*}{ States reporting cases during current week (No.) } \\
\hline & & & & 2005 & 2004 & 2003 & 2002 & 2001 & \\
\hline Anthrax & - & 1 & 0 & - & - & - & 2 & 23 & \\
\hline \multicolumn{10}{|l|}{ Botulism: } \\
\hline foodborne & - & 3 & 1 & 19 & 16 & 20 & 28 & 39 & \\
\hline infant & - & 35 & 2 & 90 & 87 & 76 & 69 & 97 & \\
\hline other (wound \& unspecified) & 1 & 28 & 0 & 33 & 30 & 33 & 21 & 19 & CA (1) \\
\hline Brucellosis & 3 & 54 & 2 & 122 & 114 & 104 & 125 & 136 & $\mathrm{KS}(1), \mathrm{GA}(1), \mathrm{CA}(1)$ \\
\hline Chancroid & - & 18 & 1 & 17 & 30 & 54 & 67 & 38 & \\
\hline Cholera & - & 3 & 0 & 8 & 5 & 2 & 2 & 3 & \\
\hline Cyclosporiasis ${ }^{\S}$ & 6 & 45 & 10 & 734 & 171 & 75 & 156 & 147 & $\mathrm{FL}(6)$ \\
\hline Diphtheria & - & - & 0 & - & - & 1 & 1 & 2 & \\
\hline \multicolumn{10}{|l|}{ Domestic arboviral diseases $\$$,?: } \\
\hline California serogroup & - & 1 & 4 & 78 & 112 & 108 & 164 & 128 & \\
\hline eastern equine & - & - & 0 & 21 & 6 & 14 & 10 & 9 & \\
\hline Powassan & - & - & 0 & 1 & 1 & - & 1 & $\mathrm{~N}$ & \\
\hline St. Louis & - & 1 & 0 & 10 & 12 & 41 & 28 & 79 & \\
\hline western equine & - & - & - & - & - & - & - & - & \\
\hline \multicolumn{10}{|l|}{ Ehrlichiosis§: } \\
\hline human granulocytic & 18 & 101 & 19 & 790 & 537 & 362 & 511 & 261 & $\mathrm{NY}(9), \mathrm{MN}(8), \mathrm{MO}(1)$ \\
\hline human monocytic & 16 & 100 & 11 & 522 & 338 & 321 & 216 & 142 & $\mathrm{NY}(10), \mathrm{MO}(1), \mathrm{NC}(1), \mathrm{AR}(4)$ \\
\hline human (other \& unspecified) & 1 & 27 & 3 & 122 & 59 & 44 & 23 & 6 & VA (1) \\
\hline \multicolumn{10}{|l|}{$\begin{array}{l}\text { Haemophilus influenzae, } \\
\text { invasive disease (age }<5 \text { yrs): }\end{array}$} \\
\hline serotype b & - & 4 & 0 & 9 & 19 & 32 & 34 & - & \\
\hline nonserotype b & 2 & 46 & 2 & 135 & 135 & 117 & 144 & - & $\mathrm{NC}(1), \mathrm{FL}(1)$ \\
\hline unknown serotype & - & 98 & 2 & 217 & 177 & 227 & 153 & - & \\
\hline Hansen disease ${ }^{\S}$ & 1 & 32 & 2 & 88 & 105 & 95 & 96 & 79 & $\mathrm{TX}(1)$ \\
\hline Hantavirus pulmonary syndrome ${ }^{\S}$ & - & 14 & 1 & 29 & 24 & 26 & 19 & 8 & \\
\hline Hemolytic uremic syndrome, postdiarrheal ${ }^{\S}$ & 3 & 68 & 5 & 221 & 200 & 178 & 216 & 202 & CT (1), NY (1), CA (1) \\
\hline Hepatitis C viral, acute & 7 & 417 & 31 & 771 & 713 & 1,102 & 1,835 & 3,976 & NC (5), WA (1), CA (1) \\
\hline HIV infection, pediatric (age $<13 \mathrm{yrs})^{\S, t \dagger}$ & - & 52 & 7 & 380 & 436 & 504 & 420 & 543 & \\
\hline Influenza-associated pediatric mortality $\$$, १. ๆा & 1 & 39 & 1 & 49 & - & $\mathrm{N}$ & $\mathrm{N}$ & $\mathrm{N}$ & $\mathrm{NC}(1)$ \\
\hline Listeriosis & 9 & 259 & 18 & 892 & 753 & 696 & 665 & 613 & $\begin{array}{l}\text { NY (1), OH (1), MN (2), MD (1), VA (1), FL (1), } \\
\text { WA (1), CA (1) }\end{array}$ \\
\hline Measles & - $^{\star * *}$ & 22 & 2 & 66 & 37 & 56 & 44 & 116 & \\
\hline \multicolumn{10}{|l|}{ Meningococcal disease, ${ }^{\mathrm{tt \dagger}}$ invasive: } \\
\hline$A, C, Y, \& W-135$ & 1 & 127 & 4 & 297 & - & - & - & - & NY (1) \\
\hline serogroup B & 1 & 85 & 3 & 157 & - & - & - & - & $\mathrm{TN}(1)$ \\
\hline other serogroup & 2 & 14 & 0 & 27 & - & - & - & - & NC (2) \\
\hline Mumps & 25 & 5,249 & 4 & 314 & 258 & 231 & 270 & 266 & NY (2), MI (2), IA (3), SD (7), KS (10), VA (1) \\
\hline Plague & - & 4 & 0 & 8 & 3 & 1 & 2 & 2 & \\
\hline Poliomyelitis, paralytic & - & - & - & 1 & - & - & - & - & \\
\hline Psittacosis $\$$ & - & 9 & 0 & 19 & 12 & 12 & 18 & 25 & \\
\hline Q fever $§$ & 2 & 68 & 2 & 139 & 70 & 71 & 61 & 26 & $\mathrm{TN}(1), \mathrm{CA}(1)$ \\
\hline Rabies, human & - & 1 & 0 & 2 & 7 & 2 & 3 & 1 & \\
\hline Rubella & - & 4 & 0 & 11 & 10 & 7 & 18 & 23 & \\
\hline Rubella, congenital syndrome & - & 1 & - & 1 & - & 1 & 1 & 3 & \\
\hline SARS-CoV§,§§ & - & - & - & - & - & 8 & $\mathrm{~N}$ & $\mathrm{~N}$ & \\
\hline Smallpox ${ }^{\S}$ & - & - & - & - & - & - & - & - & \\
\hline Streptococcal toxic-shock syndrome $§$ & 1 & 64 & 1 & 129 & 132 & 161 & 118 & 77 & $N C(1)$ \\
\hline \multicolumn{10}{|l|}{ Streptococcus pneumoniae,,} \\
\hline invasive disease (age <5 yrs) & 5 & 606 & 10 & 1,257 & 1,162 & 845 & 513 & 498 & MA (1), NY (2), MN (1), KS (1) \\
\hline Syphilis, congenital (age < $<$ yr) & 1 & 112 & 8 & 361 & 353 & 413 & 412 & 441 & VA (1) \\
\hline Tetanus & - & 10 & 0 & 27 & 34 & 20 & 25 & 37 & \\
\hline Toxic-shock syndrome (other than streptococcal)§ & $\S 2$ & 51 & 2 & 96 & 95 & 133 & 109 & 127 & VT (1), NC (1) \\
\hline Trichinellosis & 1 & 8 & 0 & 19 & 5 & 6 & 14 & 22 & MN (1) \\
\hline Tularemia§ & 4 & 33 & 4 & 154 & 134 & 129 & 90 & 129 & ND (1), KS (1), AR (1), MT (1) \\
\hline Typhoid fever & 8 & 127 & 7 & 324 & 322 & 356 & 321 & 368 & $\mathrm{OH}(1), \mathrm{FL}(1), \mathrm{CA}(6)$ \\
\hline Vancomycin-intermediate Staphylococcus aureus & $s^{\S}-$ & 2 & - & 2 & - & $\mathrm{N}$ & $\mathrm{N}$ & $\mathrm{N}$ & \\
\hline Vancomycin-resistant Staphylococcus aureus ${ }^{\S}$ & - & - & - & 3 & 1 & $\mathrm{~N}$ & $\mathrm{~N}$ & $\mathrm{~N}$ & \\
\hline Yellow fever & - & - & - & - & - & - & 1 & - & \\
\hline
\end{tabular}

-: No reported cases. $\quad \mathrm{N}$ : Not notifiable. Cum: Cumulative year-to-date counts.

* Incidence data for reporting years 2005 and 2006 are provisional, whereas data for 2001, 2002, 2003, and 2004 are finalized.

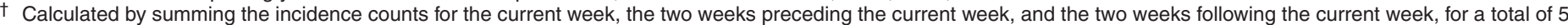
preceding years. Additional information is available at http://www.cdc.gov/epo/dphsi/phs/files/5yearweeklyaverage.pdf.

$\S$ Not notifiable in all states.

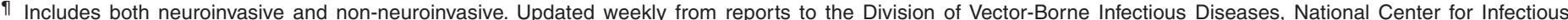
Diseases (ArboNET Surveillance).

** Data for H. influenzae (all ages, all serotypes) are available in Table II.

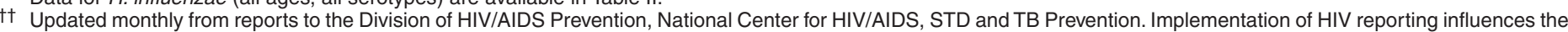
number of cases reported. Data for HIV/AIDS are available in Table IV quarterly.

$\S \S$ Updated weekly from reports to the Division of Viral and Rickettsial Diseases, National Center for Infectious Diseases.

ๆी A total of 37 cases were reported for the 2005-06 flu season (October 2, 2005 [week 40]-May 20, 2006 [week 20]).

*** No measles cases were reported for the current week.

†† Data for meningococcal disease (all serogroups and unknown serogroups) are available in Table II. 
TABLE II. Provisional cases of selected notifiable diseases, United States, weeks ending July 15, 2006, and July 16, 2005 (28th Week)*

\begin{tabular}{|c|c|c|c|c|c|c|c|c|c|c|c|c|c|c|c|}
\hline \multirow[b]{3}{*}{ Reporting area } & \multicolumn{5}{|c|}{ Chlamydia $^{\dagger}$} & \multicolumn{5}{|c|}{ Coccidioidomycosis } & \multicolumn{5}{|c|}{ Cryptosporidiosis } \\
\hline & \multirow{2}{*}{$\begin{array}{c}\text { Current } \\
\text { week }\end{array}$} & \multicolumn{2}{|c|}{$\begin{array}{c}\text { Previous } \\
52 \text { weeks } \\
\end{array}$} & \multirow{2}{*}{$\begin{array}{l}\text { Cum } \\
2006\end{array}$} & \multirow{2}{*}{$\begin{array}{l}\text { Cum } \\
2005\end{array}$} & \multirow{2}{*}{$\begin{array}{c}\text { Current } \\
\text { week }\end{array}$} & \multicolumn{2}{|c|}{$\begin{array}{l}\text { Previous } \\
52 \text { weeks }\end{array}$} & \multirow{2}{*}{$\begin{array}{l}\text { Cum } \\
2006\end{array}$} & \multirow{2}{*}{$\begin{array}{l}\text { Cum } \\
2005\end{array}$} & \multirow{2}{*}{$\begin{array}{c}\text { Current } \\
\text { week }\end{array}$} & \multicolumn{2}{|c|}{$\begin{array}{l}\text { Previous } \\
52 \text { weeks } \\
\end{array}$} & \multirow{2}{*}{$\begin{array}{l}\text { Cum } \\
2006\end{array}$} & \multirow{2}{*}{$\begin{array}{l}\text { Cum } \\
2005\end{array}$} \\
\hline & & Med & Max & & & & Med & Max & & & & $\overline{\text { Med }}$ & $\overline{M a x}$ & & \\
\hline United States & 11,186 & 18,728 & 35,170 & 486,249 & 513,069 & 75 & 126 & 1,643 & 3,765 & 2,131 & 31 & 63 & 860 & 1,263 & 1,237 \\
\hline $\begin{array}{l}\text { New England } \\
\text { Connecticut } \\
\text { Maine } \\
\text { Massachusetts } \\
\text { New Hampshire } \\
\text { Rhode Island } \\
\text { Vermont }{ }^{\S}\end{array}$ & $\begin{array}{r}880 \\
448 \\
- \\
327 \\
40 \\
43 \\
22\end{array}$ & $\begin{array}{r}627 \\
171 \\
41 \\
276 \\
35 \\
66 \\
18\end{array}$ & $\begin{array}{r}1,550 \\
1,214 \\
74 \\
432 \\
64 \\
99 \\
43\end{array}$ & $\begin{array}{r}16,660 \\
4,696 \\
1,021 \\
7,600 \\
991 \\
1,777 \\
575\end{array}$ & $\begin{array}{r}17,047 \\
5,106 \\
1,130 \\
7,523 \\
970 \\
1,796 \\
522\end{array}$ & $\begin{array}{l}\bar{N} \\
\mathrm{~N} \\
- \\
\bar{N}\end{array}$ & $\begin{array}{l}0 \\
0 \\
0 \\
0 \\
0 \\
0 \\
0\end{array}$ & $\begin{array}{l}0 \\
0 \\
0 \\
0 \\
0 \\
0 \\
0\end{array}$ & $\begin{array}{l}\bar{N} \\
\mathrm{~N} \\
- \\
\mathrm{N}\end{array}$ & $\begin{array}{l}\bar{N} \\
N \\
- \\
\bar{N}\end{array}$ & $\begin{array}{l}2 \\
- \\
\overline{1} \\
1 \\
-\end{array}$ & $\begin{array}{l}4 \\
0 \\
0 \\
2 \\
1 \\
0 \\
0\end{array}$ & $\begin{array}{r}35 \\
14 \\
3 \\
15 \\
3 \\
6 \\
5\end{array}$ & $\begin{array}{r}71 \\
9 \\
12 \\
29 \\
12 \\
4 \\
5\end{array}$ & $\begin{array}{r}71 \\
8 \\
12 \\
29 \\
9 \\
2 \\
11\end{array}$ \\
\hline $\begin{array}{l}\text { Mid. Atlantic } \\
\text { New Jersey } \\
\text { New York (Upstate) } \\
\text { New York City } \\
\text { Pennsylvania }\end{array}$ & $\begin{array}{r}1,541 \\
131 \\
432 \\
312 \\
666\end{array}$ & $\begin{array}{r}2,342 \\
373 \\
497 \\
689 \\
717\end{array}$ & $\begin{array}{r}3,696 \\
499 \\
1,727 \\
1,611 \\
1,073\end{array}$ & $\begin{array}{r}61,491 \\
9,331 \\
12,322 \\
19,405 \\
20,433\end{array}$ & $\begin{array}{l}62,624 \\
10,421 \\
12,348 \\
20,285 \\
19,570\end{array}$ & $\begin{array}{l}- \\
N \\
N \\
N \\
N\end{array}$ & $\begin{array}{l}0 \\
0 \\
0 \\
0 \\
0\end{array}$ & $\begin{array}{l}0 \\
0 \\
0 \\
0 \\
0\end{array}$ & $\begin{array}{l}- \\
N \\
N \\
N \\
N\end{array}$ & $\begin{array}{l}- \\
N \\
N \\
N \\
N\end{array}$ & $\frac{4}{\frac{1}{3}}$ & $\begin{array}{r}10 \\
0 \\
3 \\
2 \\
4\end{array}$ & $\begin{array}{r}597 \\
8 \\
561 \\
15 \\
21\end{array}$ & $\begin{array}{r}188 \\
6 \\
54 \\
31 \\
97\end{array}$ & $\begin{array}{r}165 \\
11 \\
43 \\
44 \\
67\end{array}$ \\
\hline $\begin{array}{l}\text { E.N. Central } \\
\text { Illinois } \\
\text { Indiana } \\
\text { Michigan } \\
\text { Ohio } \\
\text { Wisconsin }\end{array}$ & $\begin{array}{r}706 \\
163 \\
492 \\
51 \\
-\end{array}$ & $\begin{array}{r}3,125 \\
943 \\
393 \\
560 \\
774 \\
399\end{array}$ & $\begin{array}{r}12,578 \\
1,536 \\
552 \\
9,888 \\
1,445 \\
531\end{array}$ & $\begin{array}{r}76,558 \\
24,409 \\
8,929 \\
16,839 \\
16,866 \\
9,515\end{array}$ & $\begin{array}{l}85,560 \\
26,526 \\
10,693 \\
13,962 \\
23,571 \\
10,808\end{array}$ & $\begin{array}{l}-\bar{c} \\
\frac{\mathrm{N}}{\mathrm{N}}\end{array}$ & $\begin{array}{l}0 \\
0 \\
0 \\
0 \\
0 \\
0\end{array}$ & $\begin{array}{l}3 \\
0 \\
0 \\
3 \\
1 \\
0\end{array}$ & $\begin{array}{r}24 \\
\mathrm{~N} \\
20 \\
4 \\
\mathrm{~N}\end{array}$ & $\begin{array}{l}\frac{5}{N} \\
\frac{5}{N}\end{array}$ & $\begin{array}{l}7 \\
2 \\
2 \\
3 \\
-\end{array}$ & $\begin{array}{r}14 \\
2 \\
1 \\
2 \\
5 \\
4\end{array}$ & $\begin{array}{r}162 \\
16 \\
13 \\
7 \\
109 \\
38\end{array}$ & $\begin{array}{r}275 \\
31 \\
29 \\
49 \\
106 \\
60\end{array}$ & $\begin{array}{r}271 \\
37 \\
17 \\
37 \\
79 \\
101\end{array}$ \\
\hline $\begin{array}{l}\text { W.N. Central } \\
\text { lowa } \\
\text { Kansas } \\
\text { Minnesota } \\
\text { Missouri } \\
\text { Nebraska } \\
\text { North Dakota } \\
\text { South Dakota }\end{array}$ & $\begin{array}{r}611 \\
251 \\
- \\
213 \\
89 \\
5 \\
53\end{array}$ & $\begin{array}{r}1,135 \\
150 \\
153 \\
233 \\
429 \\
95 \\
35 \\
52\end{array}$ & $\begin{array}{r}1,448 \\
225 \\
269 \\
315 \\
525 \\
176 \\
64 \\
117\end{array}$ & $\begin{array}{r}29,933 \\
4,098 \\
4,281 \\
5,734 \\
10,860 \\
2,676 \\
904 \\
1,380\end{array}$ & $\begin{array}{r}31,350 \\
3,713 \\
3,882 \\
6,569 \\
12,136 \\
2,761 \\
841 \\
1,448\end{array}$ & $\begin{array}{l}\bar{N} \\
\mathrm{~N} \\
- \\
\bar{N} \\
\mathrm{~N} \\
\mathrm{~N}\end{array}$ & $\begin{array}{l}0 \\
0 \\
0 \\
0 \\
0 \\
0 \\
0 \\
0\end{array}$ & $\begin{array}{r}12 \\
0 \\
0 \\
12 \\
1 \\
1 \\
0 \\
0\end{array}$ & $\begin{array}{l}\bar{N} \\
\mathrm{~N} \\
- \\
\mathrm{N} \\
\mathrm{N} \\
\mathrm{N}\end{array}$ & $\begin{array}{l}3 \\
N \\
N \\
3 \\
-N \\
N \\
N\end{array}$ & $\begin{array}{l}6 \\
2 \\
1 \\
3 \\
- \\
-\end{array}$ & $\begin{array}{r}10 \\
1 \\
1 \\
3 \\
2 \\
1 \\
0 \\
0\end{array}$ & $\begin{array}{r}52 \\
11 \\
5 \\
22 \\
37 \\
4 \\
4 \\
4\end{array}$ & $\begin{array}{r}220 \\
26 \\
27 \\
82 \\
42 \\
15 \\
5 \\
23\end{array}$ & $\begin{array}{r}200 \\
55 \\
15 \\
46 \\
65 \\
6 \\
13\end{array}$ \\
\hline $\begin{array}{l}\text { S. Atlantic } \\
\text { Delaware } \\
\text { District of Columbia } \\
\text { Florida } \\
\text { Georgia } \\
\text { Maryland§ } \\
\text { North Carolina } \\
\text { South Carolina } \\
\text { Virginia§ } \\
\text { West Virginia }\end{array}$ & $\begin{array}{r}2,550 \\
59 \\
20 \\
716 \\
26 \\
359 \\
425 \\
368 \\
533 \\
44\end{array}$ & $\begin{array}{r}3,334 \\
68 \\
59 \\
898 \\
611 \\
355 \\
569 \\
276 \\
427 \\
56\end{array}$ & $\begin{array}{r}4,913 \\
92 \\
102 \\
1,089 \\
2,142 \\
519 \\
1,772 \\
1,306 \\
840 \\
226\end{array}$ & $\begin{array}{r}92,531 \\
1,893 \\
1,360 \\
25,066 \\
13,629 \\
9,439 \\
17,639 \\
9,131 \\
12,561 \\
1,813\end{array}$ & $\begin{array}{r}95,221 \\
1,729 \\
2,045 \\
23,351 \\
16,423 \\
9,648 \\
17,485 \\
10,550 \\
12,605 \\
1,385\end{array}$ & $\begin{array}{l}\bar{N} \\
\bar{N} \\
- \\
\mathrm{N} \\
\mathrm{N} \\
\mathrm{N} \\
\mathrm{N}\end{array}$ & $\begin{array}{l}0 \\
0 \\
0 \\
0 \\
0 \\
0 \\
0 \\
0 \\
0 \\
0\end{array}$ & $\begin{array}{l}1 \\
0 \\
0 \\
0 \\
0 \\
1 \\
0 \\
0 \\
0 \\
0\end{array}$ & $\begin{array}{l}2 \\
\mathrm{~N} \\
\mathrm{~N} \\
2 \\
\mathrm{~N} \\
\mathrm{~N} \\
\mathrm{~N} \\
\mathrm{~N}\end{array}$ & $\begin{array}{l}\bar{N} \\
\bar{N} \\
- \\
\mathrm{N} \\
\mathrm{N} \\
\mathrm{N} \\
\mathrm{N}\end{array}$ & $\begin{array}{l}\frac{6}{-} \\
\frac{4}{-} \\
\frac{1}{1} \\
-\end{array}$ & $\begin{array}{r}14 \\
0 \\
0 \\
6 \\
3 \\
0 \\
1 \\
0 \\
1 \\
0\end{array}$ & $\begin{array}{r}54 \\
2 \\
3 \\
28 \\
9 \\
4 \\
10 \\
4 \\
8 \\
3\end{array}$ & $\begin{array}{r}308 \\
1 \\
8 \\
132 \\
84 \\
10 \\
37 \\
16 \\
18 \\
2\end{array}$ & $\begin{array}{r}233 \\
2 \\
106 \\
55 \\
11 \\
26 \\
10 \\
19 \\
4\end{array}$ \\
\hline $\begin{array}{l}\text { E.S. Central } \\
\text { Alabama } \\
\text { Kentucky } \\
\text { Mississippi } \\
\text { Tennessee }^{\S}\end{array}$ & $\begin{array}{r}1,263 \\
-227 \\
501 \\
535\end{array}$ & $\begin{array}{r}1,391 \\
362 \\
155 \\
374 \\
489\end{array}$ & $\begin{array}{r}1,940 \\
754 \\
402 \\
609 \\
614\end{array}$ & $\begin{array}{r}38,604 \\
10,433 \\
5,180 \\
9,756 \\
13,235\end{array}$ & $\begin{array}{r}37,519 \\
7,821 \\
5,236 \\
12,091 \\
12,371\end{array}$ & $\begin{array}{l}\bar{N} \\
\frac{N}{N}\end{array}$ & $\begin{array}{l}0 \\
0 \\
0 \\
0 \\
0\end{array}$ & $\begin{array}{l}0 \\
0 \\
0 \\
0 \\
0\end{array}$ & $\begin{array}{l}\bar{N} \\
\mathrm{~N} \\
\mathrm{~N}\end{array}$ & $\begin{array}{l}\bar{N} \\
\frac{N}{N}\end{array}$ & $\begin{array}{r}3 \\
2 \\
1 \\
- \\
-\end{array}$ & $\begin{array}{l}3 \\
0 \\
1 \\
0 \\
1\end{array}$ & $\begin{array}{r}29 \\
5 \\
25 \\
1 \\
4\end{array}$ & $\begin{array}{r}55 \\
26 \\
13 \\
4 \\
12\end{array}$ & $\begin{array}{l}34 \\
12 \\
13 \\
9\end{array}$ \\
\hline $\begin{array}{l}\text { W.S. Central } \\
\text { Arkansas } \\
\text { Louisiana } \\
\text { Oklahoma } \\
\text { Texas }\end{array}$ & $\begin{array}{r}1,278 \\
231 \\
157 \\
151 \\
739\end{array}$ & $\begin{array}{r}2,153 \\
158 \\
281 \\
234 \\
1,394\end{array}$ & $\begin{array}{r}3,605 \\
340 \\
761 \\
2,159 \\
1,800\end{array}$ & $\begin{array}{r}57,277 \\
3,951 \\
8,561 \\
6,226 \\
38,539\end{array}$ & $\begin{array}{r}60,666 \\
4,702 \\
10,431 \\
5,725 \\
39,808\end{array}$ & $\begin{array}{l}- \\
\bar{N} \\
\mathrm{~N}\end{array}$ & $\begin{array}{l}0 \\
0 \\
0 \\
0 \\
0\end{array}$ & $\begin{array}{l}1 \\
0 \\
1 \\
0 \\
0\end{array}$ & $\begin{array}{l}- \\
\bar{N} \\
\mathrm{~N}\end{array}$ & $\begin{array}{l}- \\
\mathrm{N} \\
\mathrm{N} \\
\mathrm{N}\end{array}$ & $\frac{2}{-}$ & $\begin{array}{l}3 \\
0 \\
0 \\
1 \\
2\end{array}$ & $\begin{array}{r}30 \\
2 \\
21 \\
10 \\
19\end{array}$ & $\begin{array}{r}64 \\
8 \\
20 \\
36\end{array}$ & $\begin{array}{r}38 \\
2 \\
3 \\
16 \\
17\end{array}$ \\
\hline $\begin{array}{l}\text { Mountain } \\
\text { Arizona } \\
\text { Colorado } \\
\text { Idaho§ } \\
\text { Montana } \\
\text { Nevada§ } \\
\text { New Mexico§ } \\
\text { Utah } \\
\text { Wyoming }\end{array}$ & $\begin{array}{r}586 \\
463 \\
- \\
6 \\
108 \\
9 \\
- \\
-\end{array}$ & $\begin{array}{r}1,077 \\
365 \\
204 \\
52 \\
40 \\
87 \\
174 \\
89 \\
26\end{array}$ & $\begin{array}{r}1,839 \\
642 \\
482 \\
168 \\
195 \\
432 \\
338 \\
136 \\
55\end{array}$ & $\begin{array}{r}25,628 \\
9,619 \\
2,970 \\
1,744 \\
1,271 \\
2,055 \\
4,987 \\
2,231 \\
751\end{array}$ & $\begin{array}{r}33,969 \\
11,981 \\
7,838 \\
1,346 \\
1,230 \\
3,915 \\
4,724 \\
2,338 \\
597\end{array}$ & $\begin{array}{l}\frac{2}{\mathrm{~N}} \\
\mathrm{~N} \\
\mathrm{~N} \\
- \\
- \\
\end{array}$ & $\begin{array}{r}92 \\
91 \\
0 \\
0 \\
0 \\
1 \\
0 \\
1 \\
0\end{array}$ & $\begin{array}{r}452 \\
448 \\
0 \\
0 \\
0 \\
4 \\
2 \\
3 \\
2\end{array}$ & $\begin{array}{r}2,421 \\
2,359 \\
\mathrm{~N} \\
\mathrm{~N} \\
\mathrm{~N} \\
21 \\
5 \\
34 \\
2\end{array}$ & $\begin{array}{r}1,341 \\
1,284 \\
N \\
N \\
N \\
37 \\
12 \\
6 \\
2\end{array}$ & $\begin{array}{l}1 \\
- \\
- \\
- \\
- \\
-\end{array}$ & $\begin{array}{l}2 \\
0 \\
1 \\
0 \\
0 \\
0 \\
0 \\
0 \\
0\end{array}$ & $\begin{array}{l}9 \\
1 \\
3 \\
2 \\
2 \\
1 \\
3 \\
3 \\
3\end{array}$ & $\begin{array}{r}49 \\
4 \\
16 \\
5 \\
8 \\
3 \\
3 \\
6 \\
4\end{array}$ & $\begin{array}{r}67 \\
6 \\
22 \\
5 \\
12 \\
8 \\
8 \\
4 \\
2\end{array}$ \\
\hline $\begin{array}{l}\text { Pacific } \\
\text { Alaska } \\
\text { California } \\
\text { Hawaii } \\
\text { Oregon } \\
\text { Washington }\end{array}$ & $\begin{array}{r}1,771 \\
51 \\
1,393 \\
- \\
327\end{array}$ & $\begin{array}{r}3,276 \\
85 \\
2,538 \\
107 \\
177 \\
356\end{array}$ & $\begin{array}{r}5,079 \\
152 \\
4,231 \\
135 \\
315 \\
604\end{array}$ & $\begin{array}{r}87,567 \\
2,249 \\
68,325 \\
2,672 \\
4,594 \\
9,727\end{array}$ & $\begin{array}{r}89,113 \\
2,172 \\
68,940 \\
2,900 \\
4,750 \\
10,351\end{array}$ & $\begin{array}{r}73 \\
73 \\
N \\
N \\
N\end{array}$ & $\begin{array}{r}34 \\
0 \\
34 \\
0 \\
0 \\
0\end{array}$ & $\begin{array}{r}1,179 \\
0 \\
1,179 \\
0 \\
0 \\
0\end{array}$ & $\begin{array}{r}1,318 \\
\frac{-}{1,318} \\
N \\
N \\
N\end{array}$ & $\begin{array}{r}782 \\
782 \\
N \\
N \\
N\end{array}$ & $\begin{array}{l}- \\
- \\
- \\
-\end{array}$ & $\begin{array}{l}3 \\
0 \\
0 \\
0 \\
1 \\
0\end{array}$ & $\begin{array}{r}52 \\
2 \\
14 \\
1 \\
20 \\
38\end{array}$ & $\begin{array}{r}33 \\
2 \\
- \\
31 \\
\end{array}$ & $\begin{array}{r}158 \\
110 \\
26 \\
22\end{array}$ \\
\hline $\begin{array}{l}\text { American Samoa } \\
\text { C.N.M.I. } \\
\text { Guam } \\
\text { Puerto Rico } \\
\text { U.S. Virgin Islands }\end{array}$ & $\begin{array}{l}U \\
U \\
- \\
-\end{array}$ & $\begin{array}{r}0 \\
0 \\
18 \\
76 \\
2\end{array}$ & $\begin{array}{r}46 \\
0 \\
37 \\
162 \\
12\end{array}$ & 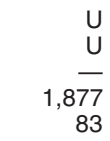 & $\begin{array}{r}U \\
U \\
410 \\
2,334 \\
173\end{array}$ & $\frac{U}{U}$ & $\begin{array}{l}0 \\
0 \\
0 \\
0 \\
0\end{array}$ & $\begin{array}{l}0 \\
0 \\
0 \\
0 \\
0\end{array}$ & $\frac{U}{U} \frac{\mathrm{U}}{\mathrm{N}}$ & $\frac{U}{U}$ & $\frac{U}{U} \frac{U}{-}$ & $\begin{array}{l}0 \\
0 \\
0 \\
0 \\
0\end{array}$ & $\begin{array}{l}0 \\
0 \\
0 \\
0 \\
0\end{array}$ & $\frac{U}{\mathrm{U}}$ & $\frac{U}{\mathrm{U}}$ \\
\hline
\end{tabular}

C.N.M.I.: Commonwealth of Northern Mariana Islands.

U: Unavailable. - No reported cases. N: Not notifiable. Cum: Cumulative year-to-date counts.

* Incidence data for reporting years 2005 and 2006 are provisional.

Med: Median. Max: Maximum.

Chlamydia refers to genital infections caused by Chlamydia trachomatis.

$\S$ Contains data reported through the National Electronic Disease Surveillance System (NEDSS). 
TABLE II. (Continued) Provisional cases of selected notifiable diseases, United States, weeks ending July 15, 2006, and July 16, 2005 (28th Week)*

\begin{tabular}{|c|c|c|c|c|c|c|c|c|c|c|c|c|c|c|c|}
\hline \multirow[b]{3}{*}{ Reporting area } & \multicolumn{5}{|c|}{ Giardiasis } & \multicolumn{5}{|c|}{ Gonorrhea } & \multicolumn{5}{|c|}{$\begin{array}{c}\text { Haemophilus influenzae, invasive } \\
\text { All ages, all serotypes }\end{array}$} \\
\hline & \multirow{2}{*}{$\begin{array}{c}\text { Current } \\
\text { week }\end{array}$} & \multicolumn{2}{|c|}{$\begin{array}{l}\text { Previous } \\
52 \text { weeks } \\
\end{array}$} & \multirow{2}{*}{$\begin{array}{l}\text { Cum } \\
2006\end{array}$} & \multirow{2}{*}{$\begin{array}{l}\text { Cum } \\
2005\end{array}$} & \multirow{2}{*}{$\begin{array}{c}\text { Current } \\
\text { week }\end{array}$} & \multicolumn{2}{|c|}{$\begin{array}{l}\text { Previous } \\
52 \text { weeks } \\
\end{array}$} & \multirow{2}{*}{$\begin{array}{l}\text { Cum } \\
2006\end{array}$} & \multirow{2}{*}{$\begin{array}{l}\text { Cum } \\
2005\end{array}$} & \multirow{2}{*}{$\begin{array}{c}\text { Current } \\
\text { week }\end{array}$} & \multicolumn{2}{|c|}{$\begin{array}{l}\text { Previous } \\
52 \text { weeks } \\
\end{array}$} & \multirow{2}{*}{$\begin{array}{l}\text { Cum } \\
2006 \\
\end{array}$} & \multirow{2}{*}{$\begin{array}{l}\text { Cum } \\
2005\end{array}$} \\
\hline & & Med & Max & & & & Med & Max & & & & Med & $\operatorname{Max}$ & & \\
\hline United States & 271 & 319 & 1,029 & 7,378 & 8,699 & 3,875 & 6,470 & 14,136 & 164,124 & 171,888 & 33 & 37 & 142 & 1,070 & 1,371 \\
\hline $\begin{array}{l}\text { New England } \\
\text { Connecticut } \\
\text { Maine }^{\dagger} \\
\text { Massachusetts } \\
\text { New Hampshire } \\
\text { Rhode Island } \\
\text { Vermont }^{\dagger}\end{array}$ & $\begin{array}{l}33 \\
21 \\
-4 \\
- \\
3 \\
5\end{array}$ & $\begin{array}{r}25 \\
0 \\
3 \\
11 \\
0 \\
0 \\
3\end{array}$ & $\begin{array}{r}75 \\
37 \\
11 \\
34 \\
3 \\
25 \\
9\end{array}$ & $\begin{array}{r}564 \\
140 \\
48 \\
249 \\
10 \\
45 \\
72\end{array}$ & $\begin{array}{r}780 \\
176 \\
95 \\
333 \\
40 \\
55 \\
81\end{array}$ & $\begin{array}{r}150 \\
91 \\
-50 \\
6 \\
\frac{6}{3}\end{array}$ & $\begin{array}{r}101 \\
42 \\
2 \\
46 \\
4 \\
8 \\
1\end{array}$ & $\begin{array}{r}288 \\
241 \\
6 \\
75 \\
9 \\
19 \\
4\end{array}$ & $\begin{array}{r}2,846 \\
1,096 \\
58 \\
1,293 \\
120 \\
250 \\
29\end{array}$ & $\begin{array}{r}3,235 \\
1,378 \\
71 \\
1,403 \\
86 \\
268 \\
29\end{array}$ & $\begin{array}{l}2 \\
2 \\
- \\
- \\
- \\
-\end{array}$ & $\begin{array}{l}2 \\
0 \\
0 \\
1 \\
0 \\
0 \\
0\end{array}$ & $\begin{array}{r}19 \\
9 \\
2 \\
4 \\
1 \\
7 \\
2\end{array}$ & $\begin{array}{r}79 \\
23 \\
8 \\
36 \\
2 \\
2 \\
8\end{array}$ & $\begin{array}{r}98 \\
29 \\
7 \\
46 \\
5 \\
7 \\
4\end{array}$ \\
\hline $\begin{array}{l}\text { Mid. Atlantic } \\
\text { New Jersey } \\
\text { New York (Upstate) } \\
\text { New York City } \\
\text { Pennsylvania }\end{array}$ & $\frac{34}{\frac{24}{10}}$ & $\begin{array}{r}60 \\
7 \\
23 \\
15 \\
15\end{array}$ & $\begin{array}{r}254 \\
18 \\
227 \\
32 \\
29\end{array}$ & $\begin{array}{r}1,277 \\
97 \\
543 \\
311 \\
326\end{array}$ & $\begin{array}{r}1,599 \\
214 \\
539 \\
451 \\
395\end{array}$ & $\begin{array}{r}457 \\
25 \\
167 \\
62 \\
203\end{array}$ & $\begin{array}{l}647 \\
107 \\
125 \\
173 \\
212\end{array}$ & $\begin{array}{r}1,014 \\
150 \\
455 \\
402 \\
391\end{array}$ & $\begin{array}{r}15,852 \\
2,594 \\
3,240 \\
4,336 \\
5,682\end{array}$ & $\begin{array}{r}17,345 \\
2,953 \\
3,413 \\
5,234 \\
5,745\end{array}$ & $\frac{7}{\frac{7}{1}}$ & $\begin{array}{l}7 \\
2 \\
2 \\
1 \\
3\end{array}$ & $\begin{array}{r}30 \\
4 \\
27 \\
4 \\
8\end{array}$ & $\begin{array}{r}203 \\
26 \\
75 \\
16 \\
86\end{array}$ & $\begin{array}{r}256 \\
46 \\
77 \\
45 \\
88\end{array}$ \\
\hline $\begin{array}{l}\text { E.N. Central } \\
\text { Illinois } \\
\text { Indiana } \\
\text { Michigan } \\
\text { Ohio } \\
\text { Wisconsin }\end{array}$ & $\begin{array}{r}13 \\
N \\
3 \\
10 \\
-\end{array}$ & $\begin{array}{r}51 \\
11 \\
0 \\
14 \\
16 \\
12\end{array}$ & $\begin{array}{r}110 \\
32 \\
0 \\
29 \\
34 \\
40\end{array}$ & $\begin{array}{r}1,084 \\
195 \\
\mathrm{~N} \\
316 \\
360 \\
213\end{array}$ & $\begin{array}{r}1,507 \\
380 \\
\mathrm{~N} \\
365 \\
326 \\
436\end{array}$ & $\begin{array}{r}208 \\
54 \\
144 \\
10 \\
-\end{array}$ & $\begin{array}{r}1,281 \\
377 \\
155 \\
235 \\
391 \\
123\end{array}$ & $\begin{array}{r}7,047 \\
567 \\
228 \\
5,880 \\
681 \\
172\end{array}$ & $\begin{array}{r}30,521 \\
9,139 \\
3,691 \\
6,819 \\
7,759 \\
3,113\end{array}$ & $\begin{array}{r}33,646 \\
10,350 \\
4,265 \\
5,285 \\
10,807 \\
2,939\end{array}$ & $\begin{array}{l}- \\
- \\
- \\
-\end{array}$ & $\begin{array}{l}5 \\
1 \\
1 \\
0 \\
1 \\
0\end{array}$ & $\begin{array}{r}14 \\
6 \\
7 \\
3 \\
6 \\
4\end{array}$ & $\begin{array}{r}146 \\
32 \\
37 \\
14 \\
48 \\
15\end{array}$ & $\begin{array}{r}239 \\
76 \\
42 \\
13 \\
81 \\
27\end{array}$ \\
\hline $\begin{array}{l}\text { W.N. Central } \\
\text { lowa } \\
\text { Kansas } \\
\text { Minnesota } \\
\text { Missouri } \\
\text { Nebraska } \\
\text { North Dakota } \\
\text { South Dakota }\end{array}$ & $\begin{array}{r}70 \\
1 \\
4 \\
59 \\
6 \\
- \\
-\end{array}$ & $\begin{array}{r}35 \\
5 \\
3 \\
4 \\
10 \\
2 \\
0 \\
1\end{array}$ & $\begin{array}{r}260 \\
14 \\
9 \\
238 \\
32 \\
6 \\
7 \\
7\end{array}$ & $\begin{array}{r}924 \\
117 \\
83 \\
403 \\
241 \\
43 \\
5 \\
32\end{array}$ & $\begin{array}{r}988 \\
127 \\
96 \\
451 \\
201 \\
60 \\
4 \\
49\end{array}$ & $\begin{array}{r}189 \\
75 \\
5 \\
82 \\
18 \\
-9\end{array}$ & $\begin{array}{r}359 \\
32 \\
47 \\
63 \\
180 \\
21 \\
3 \\
6\end{array}$ & $\begin{array}{r}461 \\
54 \\
124 \\
101 \\
240 \\
56 \\
8 \\
13\end{array}$ & $\begin{array}{r}9,167 \\
823 \\
1,192 \\
1,417 \\
4,818 \\
657 \\
61 \\
199\end{array}$ & $\begin{array}{r}9,801 \\
810 \\
1,350 \\
1,839 \\
4,901 \\
653 \\
47 \\
201\end{array}$ & $\begin{array}{l}5 \\
- \\
5 \\
- \\
- \\
-\end{array}$ & $\begin{array}{l}2 \\
0 \\
0 \\
0 \\
0 \\
0 \\
0 \\
0\end{array}$ & $\begin{array}{r}15 \\
0 \\
3 \\
9 \\
7 \\
2 \\
3 \\
0\end{array}$ & $\begin{array}{r}68 \\
12 \\
32 \\
18 \\
5 \\
1 \\
-\end{array}$ & $\begin{array}{r}63 \\
6 \\
25 \\
22 \\
9 \\
1 \\
-\end{array}$ \\
\hline $\begin{array}{l}\text { S. Atlantic } \\
\text { Delaware } \\
\text { District of Columbia } \\
\text { Florida } \\
\text { Georgia } \\
\text { Maryland }^{\dagger} \\
\text { North Carolina } \\
\text { South Carolina }^{\dagger} \\
\text { Virginia }^{\dagger} \\
\text { West Virginia }^{\text {West }}\end{array}$ & $\begin{array}{r}61 \\
\frac{-}{-} \\
37 \\
6 \\
3 \\
\mathrm{~N} \\
\frac{-15}{-}\end{array}$ & $\begin{array}{r}50 \\
1 \\
1 \\
18 \\
12 \\
4 \\
0 \\
1 \\
9 \\
0\end{array}$ & $\begin{array}{r}95 \\
3 \\
5 \\
39 \\
26 \\
10 \\
0 \\
7 \\
50 \\
6\end{array}$ & $\begin{array}{r}1,136 \\
15 \\
36 \\
496 \\
211 \\
89 \\
\mathrm{~N} \\
54 \\
223 \\
12\end{array}$ & $\begin{array}{r}1,306 \\
30 \\
22 \\
452 \\
359 \\
92 \\
\mathrm{~N} \\
70 \\
265 \\
16\end{array}$ & $\begin{array}{r}1,165 \\
34 \\
17 \\
356 \\
13 \\
109 \\
317 \\
195 \\
116 \\
8\end{array}$ & $\begin{array}{r}1,471 \\
25 \\
36 \\
418 \\
291 \\
129 \\
279 \\
125 \\
139 \\
16\end{array}$ & $\begin{array}{r}2,334 \\
44 \\
66 \\
531 \\
1,014 \\
231 \\
766 \\
748 \\
288 \\
42\end{array}$ & $\begin{array}{r}39,538 \\
789 \\
836 \\
11,801 \\
6,081 \\
3,589 \\
8,554 \\
4,050 \\
3,384 \\
454\end{array}$ & $\begin{array}{r}40,715 \\
420 \\
1,073 \\
10,304 \\
7,404 \\
3,556 \\
8,563 \\
4,666 \\
4,362 \\
367\end{array}$ & $\begin{array}{l}15 \\
- \\
3 \\
-1 \\
8 \\
1 \\
2 \\
-\end{array}$ & $\begin{array}{l}9 \\
0 \\
0 \\
3 \\
2 \\
1 \\
0 \\
1 \\
1 \\
0\end{array}$ & $\begin{array}{r}24 \\
1 \\
1 \\
9 \\
6 \\
5 \\
9 \\
3 \\
8 \\
4\end{array}$ & $\begin{array}{r}298 \\
1 \\
2 \\
99 \\
48 \\
36 \\
37 \\
23 \\
41 \\
11\end{array}$ & $\begin{array}{r}331 \\
4 \\
81 \\
73 \\
44 \\
56 \\
21 \\
33 \\
19\end{array}$ \\
\hline $\begin{array}{l}\text { E.S. Central } \\
\text { Alabama }^{\dagger} \\
\text { Kentucky } \\
\text { Mississippi } \\
\text { Tennessee }^{\dagger}\end{array}$ & $\begin{array}{r}1 \\
1 \\
N \\
- \\
-\end{array}$ & $\begin{array}{l}8 \\
4 \\
0 \\
0 \\
4\end{array}$ & $\begin{array}{r}18 \\
14 \\
0 \\
0 \\
12\end{array}$ & $\begin{array}{r}193 \\
95 \\
\mathrm{~N} \\
98\end{array}$ & $\begin{array}{r}187 \\
83 \\
N \\
104\end{array}$ & $\begin{array}{r}499 \\
- \\
82 \\
222 \\
195\end{array}$ & $\begin{array}{r}547 \\
179 \\
55 \\
139 \\
182\end{array}$ & $\begin{array}{l}724 \\
327 \\
132 \\
203 \\
279\end{array}$ & $\begin{array}{r}15,295 \\
4,796 \\
1,783 \\
3,692 \\
5,024\end{array}$ & $\begin{array}{r}14,351 \\
4,501 \\
1,690 \\
3,730 \\
4,430\end{array}$ & $\begin{array}{l}- \\
- \\
-\end{array}$ & $\begin{array}{l}2 \\
0 \\
0 \\
0 \\
1\end{array}$ & $\begin{array}{l}6 \\
4 \\
1 \\
1 \\
4\end{array}$ & $\begin{array}{r}63 \\
17 \\
2 \\
3 \\
41\end{array}$ & $\begin{array}{r}76 \\
15 \\
9 \\
52\end{array}$ \\
\hline $\begin{array}{l}\text { W.S. Central } \\
\text { Arkansas } \\
\text { Louisiana } \\
\text { Oklahoma } \\
\text { Texas }^{\dagger}\end{array}$ & $\begin{array}{l}7 \\
5 \\
2 \\
N\end{array}$ & $\begin{array}{l}4 \\
2 \\
0 \\
2 \\
0\end{array}$ & $\begin{array}{r}31 \\
6 \\
5 \\
24 \\
0\end{array}$ & $\begin{array}{r}95 \\
42 \\
53 \\
N\end{array}$ & $\begin{array}{r}124 \\
40 \\
23 \\
61 \\
\mathrm{~N}\end{array}$ & $\begin{array}{r}574 \\
117 \\
111 \\
69 \\
277\end{array}$ & $\begin{array}{r}890 \\
80 \\
171 \\
86 \\
531\end{array}$ & $\begin{array}{r}1,430 \\
186 \\
461 \\
764 \\
733\end{array}$ & $\begin{array}{r}24,242 \\
2,158 \\
5,096 \\
2,272 \\
14,716\end{array}$ & $\begin{array}{r}24,172 \\
2,433 \\
5,541 \\
2,344 \\
13,854\end{array}$ & $\begin{array}{r}2 \\
1 \\
-1 \\
-\end{array}$ & $\begin{array}{l}1 \\
0 \\
0 \\
1 \\
0\end{array}$ & $\begin{array}{r}15 \\
2 \\
2 \\
14 \\
1\end{array}$ & $\begin{array}{r}39 \\
5 \\
-34 \\
-\end{array}$ & $\begin{array}{r}82 \\
7 \\
31 \\
41 \\
3\end{array}$ \\
\hline $\begin{array}{l}\text { Mountain } \\
\text { Arizona } \\
\text { Colorado } \\
\text { Idaho }^{\dagger} \\
\text { Montana } \\
\text { Nevada }^{\dagger} \\
\text { New Mexico } \\
\text { Utah } \\
\text { Wyoming }\end{array}$ & $\begin{array}{l}\frac{12}{-} \\
3 \\
1 \\
- \\
- \\
-\end{array}$ & $\begin{array}{r}30 \\
2 \\
9 \\
3 \\
2 \\
2 \\
1 \\
7 \\
0\end{array}$ & $\begin{array}{r}57 \\
36 \\
33 \\
11 \\
7 \\
6 \\
6 \\
19 \\
3\end{array}$ & $\begin{array}{r}630 \\
33 \\
220 \\
79 \\
34 \\
29 \\
23 \\
202 \\
10\end{array}$ & $\begin{array}{r}637 \\
74 \\
221 \\
64 \\
21 \\
45 \\
36 \\
163 \\
13\end{array}$ & $\begin{array}{r}156 \\
137 \\
- \\
16 \\
3 \\
- \\
-\end{array}$ & $\begin{array}{r}220 \\
90 \\
52 \\
3 \\
2 \\
32 \\
30 \\
16 \\
2\end{array}$ & $\begin{array}{r}552 \\
201 \\
90 \\
10 \\
14 \\
194 \\
64 \\
23 \\
6\end{array}$ & $\begin{array}{r}5,441 \\
2,288 \\
879 \\
99 \\
94 \\
693 \\
901 \\
419 \\
68\end{array}$ & $\begin{array}{r}7,220 \\
2,652 \\
1,671 \\
55 \\
73 \\
1,533 \\
841 \\
360 \\
35\end{array}$ & $\begin{array}{l}1 \\
- \\
- \\
- \\
- \\
-\end{array}$ & $\begin{array}{l}3 \\
1 \\
1 \\
0 \\
0 \\
0 \\
0 \\
0 \\
0\end{array}$ & $\begin{array}{l}8 \\
7 \\
4 \\
1 \\
0 \\
1 \\
4 \\
4 \\
2\end{array}$ & $\begin{array}{r}111 \\
42 \\
34 \\
3 \\
- \\
17 \\
14 \\
1\end{array}$ & $\begin{array}{r}150 \\
78 \\
31 \\
3 \\
13 \\
16 \\
5 \\
4\end{array}$ \\
\hline $\begin{array}{l}\text { Pacific } \\
\text { Alaska } \\
\text { California } \\
\text { Hawaii } \\
\text { Oregon }^{\dagger} \\
\text { Washington }^{-}\end{array}$ & $\begin{array}{r}40 \\
1 \\
32 \\
1 \\
-6\end{array}$ & $\begin{array}{r}61 \\
1 \\
43 \\
1 \\
8 \\
8\end{array}$ & $\begin{array}{r}202 \\
7 \\
105 \\
3 \\
21 \\
90\end{array}$ & $\begin{array}{r}1,475 \\
23 \\
1,079 \\
30 \\
180 \\
163\end{array}$ & \begin{tabular}{r|}
1,571 \\
46 \\
1,186 \\
36 \\
173 \\
130
\end{tabular} & $\begin{array}{r}477 \\
9 \\
356 \\
- \\
- \\
112\end{array}$ & $\begin{array}{r}806 \\
11 \\
670 \\
19 \\
28 \\
74\end{array}$ & $\begin{array}{r}961 \\
23 \\
830 \\
36 \\
58 \\
142\end{array}$ & $\begin{array}{r}21,222 \\
291 \\
17,431 \\
484 \\
693 \\
2,323\end{array}$ & $\begin{array}{r}21,403 \\
308 \\
17,798 \\
532 \\
840 \\
1,925\end{array}$ & $\begin{array}{l}1 \\
1 \\
- \\
- \\
-\end{array}$ & $\begin{array}{l}2 \\
0 \\
0 \\
0 \\
0 \\
0\end{array}$ & $\begin{array}{r}20 \\
19 \\
9 \\
1 \\
6 \\
4\end{array}$ & $\begin{array}{r}63 \\
6 \\
15 \\
9 \\
31 \\
2\end{array}$ & $\begin{array}{r}76 \\
5 \\
30 \\
7 \\
34 \\
\end{array}$ \\
\hline $\begin{array}{l}\text { American Samoa } \\
\text { C.N.M.I. } \\
\text { Guam } \\
\text { Puerto Rico } \\
\text { U.S. Virgin Islands }\end{array}$ & $\begin{array}{l}U \\
U \\
- \\
-\end{array}$ & $\begin{array}{l}0 \\
0 \\
0 \\
3 \\
0\end{array}$ & $\begin{array}{r}0 \\
0 \\
3 \\
20 \\
0\end{array}$ & $\frac{U}{U} \frac{U}{20}$ & $\begin{array}{r}U \\
U \\
3 \\
96 \\
\end{array}$ & $\begin{array}{l}U \\
U \\
- \\
-\end{array}$ & $\begin{array}{l}0 \\
0 \\
1 \\
5 \\
0\end{array}$ & $\begin{array}{r}2 \\
0 \\
15 \\
16 \\
5\end{array}$ & $\begin{array}{r}U \\
\frac{U}{127} \\
17\end{array}$ & $\begin{array}{r}U \\
U \\
58 \\
219 \\
43\end{array}$ & $\begin{array}{l}U \\
U \\
- \\
-\end{array}$ & $\begin{array}{l}0 \\
0 \\
0 \\
0 \\
0\end{array}$ & $\begin{array}{l}0 \\
0 \\
2 \\
1 \\
0\end{array}$ & $\begin{array}{l}U \\
U \\
- \\
-\end{array}$ & $\begin{array}{l}U \\
U \\
2 \\
2 \\
-\end{array}$ \\
\hline
\end{tabular}

C.N.M.I.: Commonwealth of Northern Mariana Islands.

* Incidence data for reporting years 2005 and 2006 are provisional.

Cum: Cumulative year-to-date counts.

Med: Median

Max: Maximum.

${ }^{\dagger}$ Contains data reported through the National Electronic Disease Surveillance System (NEDSS). 
TABLE II. (Continued) Provisional cases of selected notifiable diseases, United States, weeks ending July 15, 2006, and July 16, 2005 (28th Week)*

\begin{tabular}{|c|c|c|c|c|c|c|c|c|c|c|c|c|c|c|c|}
\hline \multirow[b]{4}{*}{ Reporting area } & \multicolumn{10}{|c|}{ Hepatitis (viral, acute), by type } & \multirow{2}{*}{\multicolumn{5}{|c|}{ Legionellosis }} \\
\hline & \multicolumn{5}{|c|}{ 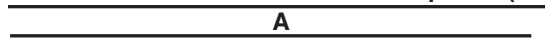 } & \multicolumn{5}{|c|}{$\mathbf{B}$} & & & & & \\
\hline & \multirow{2}{*}{$\begin{array}{c}\text { Current } \\
\text { week }\end{array}$} & \multicolumn{2}{|c|}{$\begin{array}{c}\text { Previous } \\
52 \text { weeks } \\
\end{array}$} & \multirow{2}{*}{$\begin{array}{l}\text { Cum } \\
2006 \\
\end{array}$} & \multirow{2}{*}{$\begin{array}{l}\text { Cum } \\
2005 \\
\end{array}$} & \multirow{2}{*}{$\begin{array}{c}\text { Current } \\
\text { week }\end{array}$} & \multicolumn{2}{|c|}{$\begin{array}{l}\text { Previous } \\
52 \text { weeks }\end{array}$} & \multirow{2}{*}{$\begin{array}{l}\text { Cum } \\
2006\end{array}$} & \multirow{2}{*}{$\begin{array}{l}\text { Cum } \\
2005\end{array}$} & \multirow{2}{*}{$\begin{array}{c}\text { Current } \\
\text { week }\end{array}$} & \multicolumn{2}{|c|}{$\begin{array}{l}\text { Previous } \\
52 \text { weeks }\end{array}$} & \multirow{2}{*}{$\begin{array}{l}\text { Cum } \\
2006 \\
\end{array}$} & \multirow{2}{*}{$\begin{array}{l}\text { Cum } \\
2005 \\
\end{array}$} \\
\hline & & Med & Max & & & & Med & Max & & & & Med & Max & & \\
\hline United States & 29 & 75 & 245 & 1,721 & 2,015 & 64 & 86 & 597 & 2,035 & 2,795 & 76 & 41 & 127 & 818 & 749 \\
\hline $\begin{array}{l}\text { New England } \\
\text { Connecticut } \\
\text { Maine }^{\dagger} \\
\text { Massachusetts } \\
\text { New Hampshire } \\
\text { Rhode Island } \\
\text { Vermont }^{\dagger}\end{array}$ & $\begin{array}{l}2 \\
2 \\
- \\
- \\
-\end{array}$ & $\begin{array}{l}5 \\
1 \\
0 \\
3 \\
1 \\
0 \\
0\end{array}$ & $\begin{array}{r}22 \\
3 \\
2 \\
14 \\
7 \\
4 \\
2\end{array}$ & $\begin{array}{r}99 \\
21 \\
4 \\
47 \\
15 \\
5 \\
7\end{array}$ & $\begin{array}{r}230 \\
29 \\
1 \\
137 \\
54 \\
5 \\
4\end{array}$ & $\begin{array}{l}- \\
- \\
- \\
-\end{array}$ & $\begin{array}{l}2 \\
0 \\
0 \\
1 \\
0 \\
0 \\
0\end{array}$ & $\begin{array}{l}9 \\
3 \\
2 \\
5 \\
3 \\
2 \\
1\end{array}$ & $\begin{array}{r}36 \\
11 \\
14 \\
7 \\
4 \\
-\end{array}$ & $\begin{array}{r}79 \\
28 \\
6 \\
25 \\
17 \\
1 \\
2\end{array}$ & $\begin{array}{l}9 \\
3 \\
- \\
- \\
-\end{array}$ & $\begin{array}{l}2 \\
0 \\
0 \\
1 \\
0 \\
0 \\
0\end{array}$ & $\begin{array}{r}12 \\
8 \\
1 \\
6 \\
1 \\
10 \\
10\end{array}$ & $\begin{array}{r}44 \\
16 \\
3 \\
15 \\
1 \\
7 \\
2\end{array}$ & $\begin{array}{r}37 \\
7 \\
3 \\
19 \\
4 \\
3 \\
1\end{array}$ \\
\hline $\begin{array}{l}\text { Mid. Atlantic } \\
\text { New Jersey } \\
\text { New York (Upstate) } \\
\text { New York City } \\
\text { Pennsylvania }\end{array}$ & $\begin{array}{l}\frac{3}{3} \\
- \\
-\end{array}$ & $\begin{array}{l}9 \\
2 \\
1 \\
2 \\
1\end{array}$ & $\begin{array}{r}24 \\
9 \\
14 \\
10 \\
6\end{array}$ & $\begin{array}{r}150 \\
30 \\
45 \\
45 \\
30\end{array}$ & $\begin{array}{r}332 \\
61 \\
52 \\
167 \\
52\end{array}$ & $\frac{6}{5}$ & $\begin{array}{l}9 \\
3 \\
1 \\
1 \\
3\end{array}$ & $\begin{array}{r}55 \\
10 \\
43 \\
5 \\
9\end{array}$ & $\begin{array}{r}189 \\
47 \\
35 \\
26 \\
81\end{array}$ & $\begin{array}{r}363 \\
132 \\
31 \\
75 \\
125\end{array}$ & $\frac{31}{\frac{21}{10}}$ & $\begin{array}{r}14 \\
1 \\
5 \\
1 \\
5\end{array}$ & $\begin{array}{l}53 \\
13 \\
29 \\
20 \\
17\end{array}$ & $\begin{array}{r}233 \\
8 \\
107 \\
17 \\
101\end{array}$ & $\begin{array}{r}230 \\
50 \\
52 \\
35 \\
93\end{array}$ \\
\hline $\begin{array}{l}\text { E.N. Central } \\
\text { Illinois } \\
\text { Indiana } \\
\text { Michigan } \\
\text { Ohio } \\
\text { Wisconsin }\end{array}$ & $\begin{array}{l}- \\
- \\
- \\
-\end{array}$ & $\begin{array}{l}7 \\
1 \\
0 \\
2 \\
1 \\
1\end{array}$ & $\begin{array}{r}15 \\
11 \\
5 \\
8 \\
4 \\
5\end{array}$ & $\begin{array}{r}147 \\
24 \\
17 \\
55 \\
39 \\
12\end{array}$ & $\begin{array}{r}181 \\
54 \\
11 \\
61 \\
30 \\
25\end{array}$ & $\frac{1}{-}$ & $\begin{array}{l}8 \\
1 \\
0 \\
3 \\
2 \\
0\end{array}$ & $\begin{array}{r}24 \\
6 \\
17 \\
7 \\
8 \\
6\end{array}$ & $\begin{array}{r}172 \\
7 \\
23 \\
71 \\
66 \\
5\end{array}$ & $\begin{array}{r}311 \\
90 \\
15 \\
102 \\
79 \\
25\end{array}$ & $\begin{array}{r}15 \\
1 \\
1 \\
13 \\
-\end{array}$ & $\begin{array}{l}9 \\
1 \\
0 \\
2 \\
4 \\
0\end{array}$ & $\begin{array}{r}25 \\
5 \\
6 \\
6 \\
19 \\
5\end{array}$ & $\begin{array}{r}169 \\
14 \\
11 \\
38 \\
87 \\
19\end{array}$ & $\begin{array}{r}140 \\
20 \\
10 \\
36 \\
60 \\
14\end{array}$ \\
\hline $\begin{array}{l}\text { W.N. Central } \\
\text { lowa } \\
\text { Kansas } \\
\text { Minnesota } \\
\text { Missouri } \\
\text { Nebraska }{ }^{\dagger} \\
\text { North Dakota } \\
\text { South Dakota }\end{array}$ & $\begin{array}{l}- \\
- \\
- \\
- \\
-\end{array}$ & $\begin{array}{l}2 \\
0 \\
0 \\
0 \\
1 \\
0 \\
0 \\
0\end{array}$ & $\begin{array}{r}30 \\
2 \\
5 \\
29 \\
4 \\
3 \\
2 \\
3\end{array}$ & $\begin{array}{r}76 \\
4 \\
21 \\
6 \\
29 \\
9 \\
7\end{array}$ & $\begin{array}{r}51 \\
13 \\
10 \\
3 \\
22 \\
3 \\
- \\
\end{array}$ & $\begin{array}{l}7 \\
- \\
4 \\
3 \\
- \\
-\end{array}$ & $\begin{array}{l}4 \\
0 \\
0 \\
0 \\
3 \\
0 \\
0 \\
0\end{array}$ & $\begin{array}{r}22 \\
3 \\
2 \\
13 \\
7 \\
1 \\
0 \\
1\end{array}$ & $\begin{array}{r}89 \\
9 \\
6 \\
10 \\
58 \\
6 \\
- \\
-\end{array}$ & $\begin{array}{r}144 \\
14 \\
19 \\
14 \\
77 \\
17 \\
3\end{array}$ & $\begin{array}{l}2 \\
- \\
- \\
2 \\
- \\
-\end{array}$ & $\begin{array}{l}1 \\
0 \\
0 \\
0 \\
0 \\
0 \\
0 \\
0\end{array}$ & $\begin{array}{r}12 \\
1 \\
1 \\
10 \\
3 \\
2 \\
1 \\
6\end{array}$ & $\begin{array}{r}22 \\
1 \\
1 \\
-13 \\
3 \\
\frac{3}{4}\end{array}$ & $\begin{array}{r}26 \\
3 \\
2 \\
1 \\
11 \\
2 \\
1 \\
6\end{array}$ \\
\hline 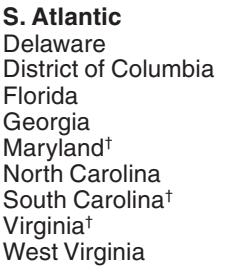 & $\begin{array}{l}\frac{13}{-} \\
\frac{5}{1} \\
\frac{5}{2} \\
\frac{2}{-}\end{array}$ & $\begin{array}{r}11 \\
0 \\
0 \\
5 \\
1 \\
1 \\
0 \\
1 \\
1 \\
0\end{array}$ & $\begin{array}{r}34 \\
2 \\
2 \\
18 \\
6 \\
6 \\
20 \\
3 \\
11 \\
3\end{array}$ & $\begin{array}{r}255 \\
9 \\
2 \\
93 \\
29 \\
30 \\
51 \\
10 \\
27 \\
4\end{array}$ & $\begin{array}{r}316 \\
4 \\
2 \\
105 \\
67 \\
29 \\
41 \\
17 \\
48 \\
3\end{array}$ & $\begin{array}{r}30 \\
- \\
13 \\
5 \\
2 \\
1 \\
4 \\
- \\
5\end{array}$ & $\begin{array}{r}23 \\
1 \\
0 \\
8 \\
3 \\
2 \\
0 \\
2 \\
1 \\
0\end{array}$ & $\begin{array}{r}66 \\
4 \\
2 \\
19 \\
8 \\
9 \\
23 \\
7 \\
18 \\
18\end{array}$ & $\begin{array}{r}615 \\
19 \\
4 \\
230 \\
89 \\
83 \\
91 \\
41 \\
20 \\
38\end{array}$ & $\begin{array}{r}802 \\
18 \\
5 \\
274 \\
126 \\
90 \\
92 \\
91 \\
84 \\
22\end{array}$ & $\begin{array}{r}13 \\
2 \\
4 \\
1 \\
1 \\
1 \\
4 \\
-\end{array}$ & $\begin{array}{l}9 \\
0 \\
0 \\
3 \\
0 \\
1 \\
0 \\
0 \\
1 \\
0\end{array}$ & $\begin{array}{r}19 \\
2 \\
2 \\
8 \\
4 \\
6 \\
5 \\
1 \\
7 \\
3\end{array}$ & $\begin{array}{r}188 \\
3 \\
8 \\
79 \\
9 \\
34 \\
20 \\
2 \\
29 \\
4\end{array}$ & $\begin{array}{r}175 \\
10 \\
2 \\
52 \\
14 \\
46 \\
14 \\
9 \\
23 \\
5\end{array}$ \\
\hline $\begin{array}{l}\text { E.S. Central } \\
\text { Alabama }^{\dagger} \\
\text { Kentucky } \\
\text { Mississippi } \\
\text { Tennessee }^{\dagger}\end{array}$ & $\begin{array}{l}- \\
- \\
-\end{array}$ & $\begin{array}{l}3 \\
0 \\
0 \\
0 \\
1\end{array}$ & $\begin{array}{r}15 \\
9 \\
5 \\
2 \\
7\end{array}$ & $\begin{array}{r}58 \\
7 \\
23 \\
3 \\
25\end{array}$ & $\begin{array}{r}132 \\
14 \\
11 \\
13 \\
94\end{array}$ & $\begin{array}{r}4 \\
2 \\
1 \\
1\end{array}$ & $\begin{array}{l}6 \\
1 \\
1 \\
0 \\
2\end{array}$ & $\begin{array}{r}18 \\
7 \\
5 \\
3 \\
12\end{array}$ & $\begin{array}{r}176 \\
63 \\
39 \\
5 \\
69\end{array}$ & $\begin{array}{r}202 \\
49 \\
40 \\
33 \\
80\end{array}$ & $\begin{array}{r}1 \\
-1 \\
-\end{array}$ & $\begin{array}{l}2 \\
0 \\
0 \\
0 \\
1\end{array}$ & $\begin{array}{l}9 \\
1 \\
4 \\
1 \\
7\end{array}$ & $\begin{array}{r}42 \\
7 \\
11 \\
1 \\
23\end{array}$ & $\begin{array}{r}39 \\
9 \\
10 \\
2 \\
18\end{array}$ \\
\hline $\begin{array}{l}\text { W.S. Central } \\
\text { Arkansas } \\
\text { Louisiana } \\
\text { Oklahoma } \\
\text { Texas }^{\dagger}\end{array}$ & $\begin{array}{l}- \\
- \\
-\end{array}$ & $\begin{array}{l}7 \\
0 \\
0 \\
0 \\
5\end{array}$ & $\begin{array}{r}77 \\
9 \\
4 \\
2 \\
73\end{array}$ & $\begin{array}{r}103 \\
29 \\
-4 \\
70\end{array}$ & $\begin{array}{r}214 \\
8 \\
36 \\
3 \\
167\end{array}$ & $\frac{2}{-}$ & $\begin{array}{r}14 \\
1 \\
0 \\
0 \\
12\end{array}$ & $\begin{array}{r}315 \\
4 \\
3 \\
17 \\
295\end{array}$ & $\begin{array}{r}317 \\
21 \\
13 \\
283\end{array}$ & $\begin{array}{r}280 \\
38 \\
46 \\
27 \\
169\end{array}$ & $\begin{array}{r}2 \\
1 \\
- \\
1\end{array}$ & $\begin{array}{l}1 \\
0 \\
0 \\
0 \\
0\end{array}$ & $\begin{array}{r}32 \\
3 \\
1 \\
3 \\
26\end{array}$ & $\begin{array}{r}20 \\
1 \\
-1 \\
18\end{array}$ & $\begin{array}{r}15 \\
4 \\
2 \\
9\end{array}$ \\
\hline $\begin{array}{l}\text { Mountain } \\
\text { Arizona } \\
\text { Colorado } \\
\text { Idaho }^{\dagger} \\
\text { Montana } \\
\text { Nevada }^{\dagger} \\
\text { New Mexico }{ }^{\dagger} \\
\text { Utah } \\
\text { Wyoming }\end{array}$ & $\begin{array}{l}2 \\
- \\
1 \\
1 \\
- \\
-\end{array}$ & $\begin{array}{l}6 \\
2 \\
1 \\
0 \\
0 \\
0 \\
0 \\
0 \\
0\end{array}$ & $\begin{array}{r}18 \\
16 \\
4 \\
2 \\
2 \\
2 \\
3 \\
2 \\
1\end{array}$ & $\begin{array}{r}127 \\
64 \\
24 \\
8 \\
6 \\
6 \\
6 \\
10 \\
8 \\
1\end{array}$ & $\begin{array}{r}162 \\
82 \\
19 \\
18 \\
7 \\
9 \\
13 \\
13 \\
1\end{array}$ & $\begin{array}{l}5 \\
- \\
- \\
- \\
- \\
-\end{array}$ & $\begin{array}{l}6 \\
4 \\
1 \\
0 \\
0 \\
1 \\
0 \\
0 \\
0\end{array}$ & $\begin{array}{r}39 \\
27 \\
5 \\
2 \\
7 \\
4 \\
3 \\
4 \\
1\end{array}$ & $\begin{array}{r}146 \\
86 \\
20 \\
6 \\
-13 \\
2 \\
19 \\
-\end{array}$ & $\begin{array}{r}282 \\
173 \\
33 \\
6 \\
3 \\
30 \\
12 \\
24 \\
1\end{array}$ & $\begin{array}{l}1 \\
- \\
- \\
- \\
- \\
-\end{array}$ & $\begin{array}{l}1 \\
0 \\
0 \\
0 \\
0 \\
0 \\
0 \\
0 \\
0\end{array}$ & $\begin{array}{l}7 \\
3 \\
1 \\
2 \\
1 \\
2 \\
1 \\
2 \\
1\end{array}$ & $\begin{array}{r}45 \\
14 \\
3 \\
7 \\
3 \\
3 \\
1 \\
13 \\
1\end{array}$ & $\begin{array}{r}55 \\
12 \\
15 \\
3 \\
4 \\
4 \\
10 \\
2 \\
6 \\
6\end{array}$ \\
\hline $\begin{array}{l}\text { Pacific } \\
\text { Alaska } \\
\text { California } \\
\text { Hawaii } \\
\text { Oregon }^{\dagger} \\
\text { Washington }\end{array}$ & $\begin{array}{l}\frac{9}{8} \\
\frac{-}{1}\end{array}$ & $\begin{array}{r}19 \\
0 \\
15 \\
0 \\
0 \\
1\end{array}$ & $\begin{array}{r}163 \\
1 \\
162 \\
2 \\
5 \\
13\end{array}$ & $\begin{array}{r}706 \\
645 \\
8 \\
26 \\
27\end{array}$ & $\begin{array}{r}397 \\
33 \\
331 \\
15 \\
24 \\
24\end{array}$ & $\begin{array}{l}\frac{9}{5} \\
\frac{-}{4}\end{array}$ & $\begin{array}{r}10 \\
0 \\
7 \\
0 \\
1 \\
0\end{array}$ & $\begin{array}{r}61 \\
1 \\
41 \\
1 \\
6 \\
6 \\
18\end{array}$ & $\begin{array}{r}295 \\
2 \\
232 \\
4 \\
32 \\
25\end{array}$ & $\begin{array}{r}332 \\
7 \\
225 \\
2 \\
58 \\
40\end{array}$ & $\begin{array}{l}\frac{2}{2} \\
\frac{N}{N}\end{array}$ & $\begin{array}{l}2 \\
0 \\
2 \\
0 \\
0 \\
0\end{array}$ & $\begin{array}{l}9 \\
1 \\
9 \\
1 \\
0 \\
0\end{array}$ & $\begin{array}{l}\frac{55}{55} \\
\frac{\mathrm{N}}{-}\end{array}$ & $\begin{array}{r}32 \\
31 \\
1 \\
\mathrm{~N} \\
-\end{array}$ \\
\hline $\begin{array}{l}\text { American Samoa } \\
\text { C.N.M.I. } \\
\text { Guam } \\
\text { Puerto Rico } \\
\text { U.S. Virgin Islands }\end{array}$ & $\begin{array}{l}U \\
- \\
-\end{array}$ & $\begin{array}{l}0 \\
0 \\
0 \\
0 \\
0\end{array}$ & $\begin{array}{l}0 \\
0 \\
0 \\
3 \\
0\end{array}$ & $\frac{U}{U}$ & $\begin{array}{r}1 \\
U \\
2 \\
44 \\
\end{array}$ & $\begin{array}{l}U \\
- \\
-\end{array}$ & $\begin{array}{l}0 \\
0 \\
0 \\
1 \\
0\end{array}$ & $\begin{array}{l}0 \\
0 \\
2 \\
8 \\
0\end{array}$ & $\frac{U}{\frac{U}{17}}$ & $\begin{array}{l}\bar{U} \\
16 \\
23 \\
-\end{array}$ & $\begin{array}{l}U \\
- \\
-\end{array}$ & $\begin{array}{l}0 \\
0 \\
0 \\
0 \\
0\end{array}$ & $\begin{array}{l}0 \\
0 \\
0 \\
1 \\
0\end{array}$ & $\frac{U}{U}$ & $\begin{array}{l}U \\
U \\
- \\
-\end{array}$ \\
\hline
\end{tabular}

C.N.M.I.: Commonwealth of Northern Mariana Islands.

$\mathrm{U}$ : Unavailable. $\quad-$ : No reported cases. N: Not notifiable.

Cum: Cumulative year-to-date counts.

Med: Median

Max: Maximum.

* Incidence data for reporting years 2005 and 2006 are provisional.

Contains data reported through the National Electronic Disease Surveillance System (NEDSS). 
TABLE II. (Continued) Provisional cases of selected notifiable diseases, United States, weeks ending July 15, 2006, and July 16, 2005 (28th Week)*

\begin{tabular}{|c|c|c|c|c|c|c|c|c|c|c|}
\hline \multirow[b]{4}{*}{ Reporting area } & \multicolumn{5}{|c|}{ Lyme disease } & \multicolumn{5}{|c|}{ Malaria } \\
\hline & \multirow{3}{*}{$\begin{array}{c}\text { Current } \\
\text { week }\end{array}$} & \multirow{2}{*}{\multicolumn{2}{|c|}{$\begin{array}{l}\text { Previous } \\
52 \text { weeks }\end{array}$}} & \multirow{3}{*}{$\begin{array}{l}\text { Cum } \\
2006\end{array}$} & \multirow{3}{*}{$\begin{array}{l}\text { Cum } \\
2005 \\
\end{array}$} & \multirow{3}{*}{$\begin{array}{c}\text { Current } \\
\text { week }\end{array}$} & \multirow{2}{*}{\multicolumn{2}{|c|}{$\begin{array}{l}\text { Previous } \\
52 \text { weeks }\end{array}$}} & \multirow{3}{*}{$\begin{array}{l}\text { Cum } \\
2006 \\
\end{array}$} & \multirow{3}{*}{$\begin{array}{l}\text { Cum } \\
2005 \\
\end{array}$} \\
\hline & & & & & & & & & & \\
\hline & & Med & Max & & & & Med & Max & & \\
\hline United States & 358 & 236 & 2,153 & 4,652 & 8,408 & 11 & 24 & 125 & 552 & 658 \\
\hline $\begin{array}{l}\text { New England } \\
\text { Connecticut } \\
\text { Maine }^{\dagger} \\
\text { Massachusetts } \\
\text { New Hampshire } \\
\text { Rhode Island } \\
\text { Vermont }^{\dagger}\end{array}$ & $\begin{array}{r}114 \\
96 \\
- \\
-18 \\
-\end{array}$ & $\begin{array}{r}37 \\
8 \\
2 \\
3 \\
5 \\
0 \\
1\end{array}$ & $\begin{array}{r}780 \\
753 \\
26 \\
205 \\
21 \\
12 \\
5\end{array}$ & $\begin{array}{r}704 \\
540 \\
39 \\
26 \\
84 \\
15\end{array}$ & $\begin{array}{r}1,461 \\
129 \\
94 \\
1,163 \\
62 \\
3 \\
10\end{array}$ & $\begin{array}{l}- \\
- \\
- \\
-\end{array}$ & $\begin{array}{l}1 \\
0 \\
0 \\
0 \\
0 \\
0 \\
0\end{array}$ & $\begin{array}{r}12 \\
10 \\
1 \\
3 \\
3 \\
8 \\
1\end{array}$ & $\begin{array}{r}38 \\
10 \\
3 \\
17 \\
7 \\
1\end{array}$ & $\begin{array}{r}29 \\
2 \\
20 \\
4 \\
2 \\
1\end{array}$ \\
\hline $\begin{array}{l}\text { Mid. Atlantic } \\
\text { New Jersey } \\
\text { New York (Upstate) } \\
\text { New York City } \\
\text { Pennsylvania }\end{array}$ & $\begin{array}{r}184 \\
4 \\
148 \\
32\end{array}$ & $\begin{array}{r}151 \\
23 \\
76 \\
1 \\
36\end{array}$ & $\begin{array}{r}1,176 \\
271 \\
1,150 \\
33 \\
376\end{array}$ & $\begin{array}{r}2,824 \\
588 \\
1,314 \\
1 \\
921\end{array}$ & $\begin{array}{r}4,706 \\
2,067 \\
821 \\
190 \\
1,628\end{array}$ & $\frac{2}{\frac{1}{1}}$ & $\begin{array}{l}5 \\
1 \\
1 \\
2 \\
1\end{array}$ & $\begin{array}{r}15 \\
7 \\
11 \\
8 \\
2\end{array}$ & $\begin{array}{l}84 \\
13 \\
18 \\
37 \\
16\end{array}$ & $\begin{array}{r}179 \\
42 \\
24 \\
93 \\
20\end{array}$ \\
\hline $\begin{array}{l}\text { E.N. Central } \\
\text { Illinois } \\
\text { Indiana } \\
\text { Michigan } \\
\text { Ohio } \\
\text { Wisconsin }\end{array}$ & $\begin{array}{l}\frac{2}{-} \\
- \\
-\end{array}$ & $\begin{array}{r}11 \\
0 \\
0 \\
1 \\
1 \\
9\end{array}$ & $\begin{array}{r}152 \\
13 \\
4 \\
7 \\
5 \\
139\end{array}$ & $\begin{array}{r}245 \\
6 \\
19 \\
17 \\
203\end{array}$ & $\begin{array}{r}1,015 \\
75 \\
11 \\
9 \\
24 \\
896\end{array}$ & $\begin{array}{l}\frac{1}{-} \\
\frac{1}{-}\end{array}$ & $\begin{array}{l}2 \\
1 \\
0 \\
0 \\
0 \\
0\end{array}$ & $\begin{array}{l}8 \\
5 \\
3 \\
2 \\
3 \\
3\end{array}$ & $\begin{array}{r}49 \\
12 \\
6 \\
8 \\
18 \\
5\end{array}$ & $\begin{array}{r}76 \\
40 \\
3 \\
15 \\
13 \\
5\end{array}$ \\
\hline $\begin{array}{l}\text { W.N. Central } \\
\text { lowa } \\
\text { Kansas } \\
\text { Minnesota } \\
\text { Missouri } \\
\text { Nebraska }^{\dagger} \\
\text { North Dakota } \\
\text { South Dakota }\end{array}$ & $\begin{array}{l}28 \\
- \\
28 \\
- \\
-\end{array}$ & $\begin{array}{r}11 \\
1 \\
0 \\
6 \\
0 \\
0 \\
0 \\
0\end{array}$ & $\begin{array}{r}98 \\
8 \\
2 \\
96 \\
3 \\
2 \\
3 \\
1\end{array}$ & $\begin{array}{r}158 \\
28 \\
3 \\
111 \\
8 \\
7 \\
-1\end{array}$ & $\begin{array}{r}176 \\
48 \\
2 \\
120 \\
6 \\
- \\
-\end{array}$ & $\begin{array}{l}\frac{3}{2} \\
\frac{1}{1} \\
- \\
-\end{array}$ & $\begin{array}{l}0 \\
0 \\
0 \\
0 \\
0 \\
0 \\
0 \\
0\end{array}$ & $\begin{array}{r}32 \\
1 \\
1 \\
30 \\
2 \\
2 \\
1 \\
1\end{array}$ & $\begin{array}{r}27 \\
1 \\
3 \\
14 \\
4 \\
3 \\
1 \\
1\end{array}$ & $\begin{array}{r}28 \\
4 \\
2 \\
11 \\
11 \\
- \\
-\end{array}$ \\
\hline $\begin{array}{l}\text { S. Atlantic } \\
\text { Delaware } \\
\text { District of Columbia } \\
\text { Florida } \\
\text { Georgia } \\
\text { Maryland }^{\dagger} \\
\text { North Carolina } \\
\text { South Carolina }^{\dagger} \\
\text { Virginia }^{\dagger} \\
\text { West Virginia }^{+}\end{array}$ & $\begin{array}{r}22 \\
3 \\
2 \\
- \\
\frac{11}{-} \\
-6 \\
-\end{array}$ & $\begin{array}{r}28 \\
9 \\
0 \\
1 \\
0 \\
13 \\
0 \\
0 \\
3 \\
0\end{array}$ & $\begin{array}{r}124 \\
37 \\
2 \\
5 \\
1 \\
87 \\
5 \\
3 \\
22 \\
44\end{array}$ & $\begin{array}{r}579 \\
235 \\
11 \\
14 \\
239 \\
15 \\
5 \\
57 \\
3\end{array}$ & $\begin{array}{r}937 \\
357 \\
4 \\
12 \\
3 \\
457 \\
26 \\
8 \\
67 \\
3\end{array}$ & $\begin{array}{l}\frac{3}{-} \\
\frac{1}{1} \\
\frac{1}{1} \\
-\end{array}$ & $\begin{array}{l}7 \\
0 \\
0 \\
1 \\
1 \\
1 \\
0 \\
0 \\
1 \\
0\end{array}$ & $\begin{array}{r}16 \\
1 \\
2 \\
6 \\
6 \\
9 \\
8 \\
2 \\
9 \\
2\end{array}$ & $\begin{array}{r}167 \\
5 \\
2 \\
27 \\
50 \\
36 \\
13 \\
4 \\
29 \\
1\end{array}$ & $\begin{array}{r}136 \\
2 \\
3 \\
22 \\
31 \\
48 \\
15 \\
3 \\
11 \\
1\end{array}$ \\
\hline $\begin{array}{l}\text { E.S. Central } \\
\text { Alabama }^{\dagger} \\
\text { Kentucky } \\
\text { Mississippi } \\
\text { Tennessee }^{\dagger}\end{array}$ & $\begin{array}{r}1 \\
1 \\
- \\
-\end{array}$ & $\begin{array}{l}0 \\
0 \\
0 \\
0 \\
0\end{array}$ & $\begin{array}{l}4 \\
1 \\
2 \\
0 \\
4\end{array}$ & $\begin{array}{r}4 \\
1 \\
- \\
3\end{array}$ & $\frac{15}{\frac{2}{13}}$ & $\begin{array}{l}- \\
- \\
-\end{array}$ & $\begin{array}{l}0 \\
0 \\
0 \\
0 \\
0\end{array}$ & $\begin{array}{l}3 \\
2 \\
2 \\
1 \\
2\end{array}$ & $\begin{array}{r}12 \\
7 \\
1 \\
2 \\
2\end{array}$ & $\begin{array}{r}12 \\
3 \\
4 \\
-5\end{array}$ \\
\hline $\begin{array}{l}\text { W.S. Central } \\
\text { Arkansas } \\
\text { Louisiana } \\
\text { Oklahoma } \\
\text { Texas }^{\dagger}\end{array}$ & $\begin{array}{l}- \\
- \\
-\end{array}$ & $\begin{array}{l}0 \\
0 \\
0 \\
0 \\
0\end{array}$ & $\begin{array}{l}5 \\
1 \\
0 \\
0 \\
5\end{array}$ & $\frac{3}{-}$ & $\begin{array}{r}47 \\
3 \\
3 \\
41\end{array}$ & $\begin{array}{l}- \\
- \\
-\end{array}$ & $\begin{array}{l}2 \\
0 \\
0 \\
0 \\
1\end{array}$ & $\begin{array}{r}31 \\
2 \\
1 \\
6 \\
29\end{array}$ & $\begin{array}{r}33 \\
1 \\
-3 \\
29\end{array}$ & $\begin{array}{r}50 \\
3 \\
2 \\
3 \\
42\end{array}$ \\
\hline $\begin{array}{l}\text { Mountain } \\
\text { Arizona } \\
\text { Colorado } \\
\text { Idaho }^{\dagger} \\
\text { Montana } \\
\text { Nevada }^{\dagger} \\
\text { New Mexico }{ }^{\dagger} \\
\text { Utah } \\
\text { Wyoming }\end{array}$ & $\begin{array}{l}1 \\
- \\
- \\
- \\
- \\
-\end{array}$ & $\begin{array}{l}0 \\
0 \\
0 \\
0 \\
0 \\
0 \\
0 \\
0 \\
0\end{array}$ & $\begin{array}{l}4 \\
4 \\
1 \\
1 \\
0 \\
1 \\
1 \\
1 \\
1\end{array}$ & $\begin{array}{l}7 \\
2 \\
1 \\
- \\
- \\
- \\
\\
\end{array}$ & $\begin{array}{l}7 \\
-- \\
1 \\
\\
2 \\
1 \\
1 \\
2\end{array}$ & $\begin{array}{l}- \\
- \\
- \\
z \\
- \\
-\end{array}$ & $\begin{array}{l}1 \\
0 \\
0 \\
0 \\
0 \\
0 \\
0 \\
0 \\
0\end{array}$ & $\begin{array}{l}9 \\
9 \\
2 \\
0 \\
1 \\
1 \\
1 \\
2 \\
1\end{array}$ & $\begin{array}{r}23 \\
4 \\
9 \\
1 \\
1 \\
1 \\
7 \\
-\end{array}$ & $\begin{array}{r}31 \\
5 \\
17 \\
- \\
2 \\
2 \\
4 \\
1\end{array}$ \\
\hline $\begin{array}{l}\text { Pacific } \\
\text { Alaska } \\
\text { California } \\
\text { Hawaii } \\
\text { Oregon }^{\dagger} \\
\text { Washington }^{\text {Wash }}\end{array}$ & $\begin{array}{r}6 \\
1 \\
5 \\
\mathrm{~N} \\
- \\
-\end{array}$ & $\begin{array}{l}3 \\
0 \\
3 \\
0 \\
0 \\
0\end{array}$ & $\begin{array}{r}14 \\
1 \\
14 \\
0 \\
2 \\
3\end{array}$ & $\begin{array}{r}128 \\
1 \\
126 \\
\mathrm{~N} \\
1 \\
-\end{array}$ & $\begin{array}{r}44 \\
2 \\
27 \\
N \\
13 \\
2\end{array}$ & $\begin{array}{l}\frac{2}{1} \\
\frac{1}{1}\end{array}$ & $\begin{array}{l}4 \\
0 \\
3 \\
0 \\
0 \\
0\end{array}$ & $\begin{array}{r}13 \\
4 \\
10 \\
1 \\
2 \\
5\end{array}$ & $\begin{array}{r}119 \\
14 \\
82 \\
1 \\
7 \\
15\end{array}$ & $\begin{array}{r}117 \\
3 \\
88 \\
11 \\
4 \\
11\end{array}$ \\
\hline $\begin{array}{l}\text { American Samoa } \\
\text { C.N.M.I. } \\
\text { Guam } \\
\text { Puerto Rico } \\
\text { U.S. Virgin Islands }\end{array}$ & $\frac{U}{\mathrm{U}}$ & $\begin{array}{l}0 \\
0 \\
0 \\
0 \\
0\end{array}$ & $\begin{array}{l}0 \\
0 \\
0 \\
0 \\
0\end{array}$ & $\frac{U}{U}$ & $\frac{U}{U}$ & $\begin{array}{l}U \\
U \\
- \\
-\end{array}$ & $\begin{array}{l}0 \\
0 \\
0 \\
0 \\
0\end{array}$ & $\begin{array}{l}0 \\
0 \\
0 \\
1 \\
0\end{array}$ & $\begin{array}{l}U \\
U \\
- \\
-\end{array}$ & $\begin{array}{l}U \\
\frac{U}{2} \\
\end{array}$ \\
\hline
\end{tabular}

C.N.M.I.: Commonwealth of Northern Mariana Islands.

U: Unavailable. $\quad-$ : No reported cases. N: Not notifiable.

* Incidence data for reporting years 2005 and 2006 are provisional.

Cum: Cumulative year-to-date counts.

Med: Median

Max: Maximum.

† Contains data reported through the National Electronic Disease Surveillance System (NEDSS). 
TABLE II. (Continued) Provisional cases of selected notifiable diseases, United States, weeks ending July 15, 2006, and July 16, 2005 (28th Week)*

\begin{tabular}{|c|c|c|c|c|c|c|c|c|c|c|c|c|c|c|c|}
\hline \multirow[b]{4}{*}{ Reporting area } & \multicolumn{10}{|c|}{ Meningococcal disease, invasive } & \multirow{2}{*}{\multicolumn{5}{|c|}{ Pertussis }} \\
\hline & \multicolumn{5}{|c|}{ All serogroups } & \multicolumn{5}{|c|}{ Serogroup unknown } & & & & & \\
\hline & \multirow{2}{*}{$\begin{array}{c}\text { Current } \\
\text { week }\end{array}$} & \multicolumn{2}{|c|}{$\begin{array}{l}\text { Previous } \\
52 \text { weeks }\end{array}$} & \multirow{2}{*}{$\begin{array}{l}\text { Cum } \\
2006\end{array}$} & \multirow{2}{*}{$\begin{array}{l}\text { Cum } \\
2005\end{array}$} & \multirow{2}{*}{$\begin{array}{c}\text { Current } \\
\text { week }\end{array}$} & \multicolumn{2}{|c|}{$\begin{array}{l}\text { Previous } \\
52 \text { weeks }\end{array}$} & \multirow{2}{*}{$\begin{array}{l}\text { Cum } \\
2006\end{array}$} & \multirow{2}{*}{$\begin{array}{l}\text { Cum } \\
2005\end{array}$} & \multirow{2}{*}{$\begin{array}{c}\text { Current } \\
\text { week }\end{array}$} & \multicolumn{2}{|c|}{$\begin{array}{l}\text { Previous } \\
52 \text { weeks }\end{array}$} & \multirow{2}{*}{$\begin{array}{l}\text { Cum } \\
2006\end{array}$} & \multirow{2}{*}{$\begin{array}{r}\text { Cum } \\
2005 \\
\end{array}$} \\
\hline & & Med & Max & & & & Med & Max & & & & Med & $\operatorname{Max}$ & & \\
\hline United States & 12 & 20 & 85 & 662 & 781 & 8 & 13 & 58 & 436 & 475 & 114 & 284 & 2,877 & 6,223 & 11,215 \\
\hline $\begin{array}{l}\text { New England } \\
\text { Connecticut } \\
\text { Maine }^{\dagger} \\
\text { Massachusetts } \\
\text { New Hampshire } \\
\text { Rhode Island } \\
\text { Vermont }^{\dagger}\end{array}$ & $\begin{array}{l}- \\
- \\
- \\
-\end{array}$ & $\begin{array}{l}1 \\
0 \\
0 \\
0 \\
0 \\
0 \\
0\end{array}$ & $\begin{array}{l}3 \\
2 \\
1 \\
2 \\
2 \\
1 \\
1\end{array}$ & $\begin{array}{r}29 \\
8 \\
3 \\
12 \\
4 \\
- \\
2\end{array}$ & $\begin{array}{r}50 \\
10 \\
2 \\
23 \\
9 \\
2 \\
4\end{array}$ & $\begin{array}{l}- \\
- \\
- \\
-\end{array}$ & $\begin{array}{l}0 \\
0 \\
0 \\
0 \\
0 \\
0 \\
0\end{array}$ & $\begin{array}{l}2 \\
2 \\
1 \\
2 \\
2 \\
0 \\
0\end{array}$ & $\begin{array}{r}21 \\
2 \\
3 \\
12 \\
4 \\
- \\
-\end{array}$ & $\begin{array}{r}19 \\
1 \\
2 \\
5 \\
9 \\
2\end{array}$ & $\begin{array}{l}1 \\
- \\
- \\
- \\
1\end{array}$ & $\begin{array}{r}30 \\
1 \\
1 \\
23 \\
2 \\
0 \\
1\end{array}$ & $\begin{array}{r}83 \\
5 \\
5 \\
43 \\
36 \\
17 \\
14\end{array}$ & $\begin{array}{r}636 \\
22 \\
23 \\
437 \\
77 \\
77\end{array}$ & $\begin{array}{r}661 \\
37 \\
16 \\
498 \\
32 \\
12 \\
66\end{array}$ \\
\hline $\begin{array}{l}\text { Mid. Atlantic } \\
\text { New Jersey } \\
\text { New York (Upstate) } \\
\text { New York City } \\
\text { Pennsylvania }\end{array}$ & $\begin{array}{l}\frac{2}{2} \\
- \\
-\end{array}$ & $\begin{array}{l}3 \\
0 \\
0 \\
0 \\
1\end{array}$ & $\begin{array}{r}13 \\
2 \\
7 \\
5 \\
5\end{array}$ & $\begin{array}{l}97 \\
10 \\
26 \\
27 \\
34\end{array}$ & $\begin{array}{l}96 \\
24 \\
27 \\
14 \\
31\end{array}$ & $\begin{array}{r}\frac{1}{1} \\
- \\
-\end{array}$ & $\begin{array}{l}2 \\
0 \\
0 \\
0 \\
1\end{array}$ & $\begin{array}{r}11 \\
2 \\
5 \\
5 \\
5\end{array}$ & $\begin{array}{r}72 \\
10 \\
5 \\
27 \\
30\end{array}$ & $\begin{array}{l}74 \\
24 \\
10 \\
14 \\
26\end{array}$ & $\frac{32}{\frac{25}{7}}$ & $\begin{array}{r}30 \\
4 \\
12 \\
2 \\
11\end{array}$ & $\begin{array}{r}137 \\
13 \\
123 \\
6 \\
26\end{array}$ & $\begin{array}{r}875 \\
127 \\
341 \\
28 \\
379\end{array}$ & $\begin{array}{r}735 \\
103 \\
277 \\
45 \\
310\end{array}$ \\
\hline $\begin{array}{l}\text { E.N. Central } \\
\text { Illinois } \\
\text { Indiana } \\
\text { Michigan } \\
\text { Ohio } \\
\text { Wisconsin }\end{array}$ & $\begin{array}{l}- \\
- \\
- \\
-\end{array}$ & $\begin{array}{l}3 \\
0 \\
0 \\
1 \\
1 \\
0\end{array}$ & $\begin{array}{r}11 \\
4 \\
5 \\
3 \\
5 \\
2\end{array}$ & $\begin{array}{l}74 \\
17 \\
14 \\
16 \\
27 \\
-\end{array}$ & $\begin{array}{l}97 \\
23 \\
13 \\
16 \\
28 \\
17\end{array}$ & $\begin{array}{l}- \\
- \\
- \\
-\end{array}$ & $\begin{array}{l}2 \\
0 \\
0 \\
0 \\
0 \\
0\end{array}$ & $\begin{array}{l}6 \\
4 \\
2 \\
3 \\
4 \\
2\end{array}$ & $\begin{array}{r}52 \\
17 \\
5 \\
9 \\
21 \\
-\end{array}$ & $\begin{array}{r}82 \\
23 \\
6 \\
10 \\
26 \\
17\end{array}$ & $\begin{array}{l}\frac{12}{-} \\
1 \\
11 \\
-\end{array}$ & $\begin{array}{r}49 \\
9 \\
4 \\
6 \\
16 \\
9\end{array}$ & $\begin{array}{r}133 \\
35 \\
75 \\
23 \\
30 \\
41\end{array}$ & $\begin{array}{r}833 \\
99 \\
118 \\
203 \\
317 \\
96\end{array}$ & $\begin{array}{r}2,089 \\
484 \\
161 \\
123 \\
711 \\
610\end{array}$ \\
\hline $\begin{array}{l}\text { W.N. Central } \\
\text { lowa } \\
\text { Kansas } \\
\text { Minnesota } \\
\text { Missouri } \\
\text { Nebraska }^{\dagger} \\
\text { North Dakota } \\
\text { South Dakota }\end{array}$ & $\begin{array}{l}1 \\
- \\
- \\
- \\
-\end{array}$ & $\begin{array}{l}1 \\
0 \\
0 \\
0 \\
0 \\
0 \\
0 \\
0\end{array}$ & $\begin{array}{l}4 \\
2 \\
1 \\
2 \\
2 \\
2 \\
2 \\
1 \\
1\end{array}$ & $\begin{array}{r}39 \\
9 \\
1 \\
10 \\
12 \\
5 \\
1 \\
1\end{array}$ & $\begin{array}{r}48 \\
12 \\
8 \\
7 \\
15 \\
4 \\
2\end{array}$ & $\begin{array}{l}1 \\
- \\
- \\
- \\
- \\
-\end{array}$ & $\begin{array}{l}0 \\
0 \\
0 \\
0 \\
0 \\
0 \\
0 \\
0\end{array}$ & $\begin{array}{l}3 \\
1 \\
1 \\
1 \\
1 \\
1 \\
1 \\
0\end{array}$ & $\begin{array}{r}14 \\
3 \\
1 \\
3 \\
3 \\
3 \\
1 \\
-\end{array}$ & $\begin{array}{r}20 \\
1 \\
8 \\
2 \\
6 \\
3 \\
- \\
-\end{array}$ & $\begin{array}{l}6 \\
4 \\
2 \\
- \\
- \\
-\end{array}$ & $\begin{array}{r}55 \\
12 \\
11 \\
0 \\
9 \\
4 \\
0 \\
1\end{array}$ & $\begin{array}{r}552 \\
63 \\
28 \\
485 \\
42 \\
15 \\
26 \\
8\end{array}$ & $\begin{array}{r}679 \\
152 \\
176 \\
105 \\
175 \\
58 \\
4 \\
9\end{array}$ & $\begin{array}{r}1,508 \\
397 \\
139 \\
374 \\
238 \\
160 \\
76 \\
124\end{array}$ \\
\hline $\begin{array}{l}\text { S. Atlantic } \\
\text { Delaware } \\
\text { District of Columbia } \\
\text { Florida } \\
\text { Georgia } \\
\text { Maryland }^{\dagger} \\
\text { North Carolina }^{\text {South Carolina }}{ }^{\dagger} \\
\text { Virginia }^{\dagger} \\
\text { West Virginia }^{\text {West }}\end{array}$ & $\begin{array}{l}4 \\
- \\
- \\
- \\
2 \\
1 \\
1 \\
-\end{array}$ & $\begin{array}{l}3 \\
0 \\
0 \\
1 \\
0 \\
0 \\
0 \\
0 \\
0 \\
0\end{array}$ & $\begin{array}{r}14 \\
1 \\
1 \\
6 \\
3 \\
2 \\
11 \\
2 \\
4 \\
2\end{array}$ & $\begin{array}{r}117 \\
4 \\
-45 \\
9 \\
7 \\
22 \\
13 \\
14 \\
3\end{array}$ & $\begin{array}{r}145 \\
2 \\
4 \\
55 \\
14 \\
14 \\
21 \\
12 \\
18 \\
5\end{array}$ & $\begin{array}{l}2 \\
- \\
- \\
- \\
- \\
1 \\
-\end{array}$ & $\begin{array}{l}1 \\
0 \\
0 \\
1 \\
0 \\
0 \\
0 \\
0 \\
0 \\
0\end{array}$ & $\begin{array}{l}7 \\
1 \\
1 \\
5 \\
3 \\
1 \\
3 \\
1 \\
3 \\
0\end{array}$ & $\begin{array}{r}49 \\
4 \\
-18 \\
9 \\
2 \\
5 \\
5 \\
6 \\
-\end{array}$ & $\begin{array}{r}58 \\
2 \\
3 \\
17 \\
14 \\
1 \\
4 \\
8 \\
7 \\
2\end{array}$ & $\begin{array}{l}15 \\
- \\
-8 \\
- \\
-4 \\
3 \\
-\end{array}$ & $\begin{array}{r}23 \\
0 \\
0 \\
4 \\
0 \\
3 \\
0 \\
4 \\
2 \\
0\end{array}$ & $\begin{array}{r}92 \\
1 \\
3 \\
14 \\
3 \\
9 \\
21 \\
22 \\
73 \\
9\end{array}$ & $\begin{array}{r}517 \\
3 \\
3 \\
119 \\
8 \\
72 \\
105 \\
78 \\
109 \\
20\end{array}$ & $\begin{array}{r}760 \\
14 \\
4 \\
45 \\
30 \\
124 \\
61 \\
235 \\
165 \\
32\end{array}$ \\
\hline $\begin{array}{l}\text { E.S. Central } \\
\text { Alabama }^{\dagger} \\
\text { Kentucky } \\
\text { Mississippi } \\
\text { Tennessee }^{\dagger}\end{array}$ & $\frac{1}{-}$ & $\begin{array}{l}1 \\
0 \\
0 \\
0 \\
0\end{array}$ & $\begin{array}{l}4 \\
1 \\
2 \\
1 \\
2\end{array}$ & $\begin{array}{r}26 \\
4 \\
7 \\
1 \\
14\end{array}$ & $\begin{array}{r}37 \\
4 \\
14 \\
4 \\
15\end{array}$ & $\begin{array}{l}- \\
- \\
-\end{array}$ & $\begin{array}{l}1 \\
0 \\
0 \\
0 \\
0\end{array}$ & $\begin{array}{l}4 \\
1 \\
2 \\
1 \\
2\end{array}$ & $\begin{array}{r}21 \\
4 \\
7 \\
1 \\
9\end{array}$ & $\begin{array}{r}28 \\
3 \\
14 \\
4 \\
7\end{array}$ & $\begin{array}{r}10 \\
1 \\
- \\
9\end{array}$ & $\begin{array}{l}7 \\
1 \\
1 \\
0 \\
2\end{array}$ & $\begin{array}{r}22 \\
7 \\
7 \\
4 \\
10\end{array}$ & $\begin{array}{r}151 \\
38 \\
22 \\
15 \\
76\end{array}$ & $\begin{array}{r}312 \\
44 \\
86 \\
38 \\
144\end{array}$ \\
\hline $\begin{array}{l}\text { W.S. Central } \\
\text { Arkansas } \\
\text { Louisiana } \\
\text { Oklahoma } \\
\text { Texas }^{\dagger}\end{array}$ & $\begin{array}{l}- \\
- \\
-\end{array}$ & $\begin{array}{l}1 \\
0 \\
0 \\
0 \\
1\end{array}$ & $\begin{array}{r}23 \\
3 \\
1 \\
4 \\
16\end{array}$ & $\begin{array}{r}35 \\
6 \\
- \\
8 \\
21\end{array}$ & $\begin{array}{l}81 \\
10 \\
25 \\
13 \\
33\end{array}$ & $\begin{array}{l}- \\
- \\
-\end{array}$ & $\begin{array}{l}0 \\
0 \\
0 \\
0 \\
0\end{array}$ & $\begin{array}{l}6 \\
2 \\
1 \\
0 \\
4\end{array}$ & $\begin{array}{r}12 \\
4 \\
- \\
8\end{array}$ & $\begin{array}{r}19 \\
2 \\
4 \\
2 \\
11\end{array}$ & $\begin{array}{r}1 \\
1 \\
- \\
-\end{array}$ & $\begin{array}{r}22 \\
2 \\
0 \\
0 \\
21\end{array}$ & $\begin{array}{r}360 \\
21 \\
3 \\
124 \\
215\end{array}$ & $\begin{array}{r}302 \\
40 \\
\frac{10}{10} \\
252\end{array}$ & $\begin{array}{r}1,165 \\
175 \\
33 \\
-557\end{array}$ \\
\hline $\begin{array}{l}\text { Mountain } \\
\text { Arizona } \\
\text { Colorado } \\
\text { Idaho }^{\dagger} \\
\text { Montana } \text { Nevada }^{\dagger} \\
\text { New Mexico }^{\dagger} \\
\text { Utah } \\
\text { Wyoming }\end{array}$ & $\begin{array}{l}- \\
- \\
- \\
- \\
- \\
-\end{array}$ & $\begin{array}{l}1 \\
0 \\
0 \\
0 \\
0 \\
0 \\
0 \\
0 \\
0\end{array}$ & $\begin{array}{l}4 \\
4 \\
2 \\
2 \\
1 \\
1 \\
2 \\
1 \\
1 \\
2\end{array}$ & $\begin{array}{r}39 \\
11 \\
14 \\
1 \\
3 \\
2 \\
2 \\
4 \\
2\end{array}$ & $\begin{array}{r}62 \\
29 \\
13 \\
3 \\
-6 \\
6 \\
8 \\
-\end{array}$ & $\begin{array}{l}- \\
- \\
- \\
- \\
- \\
-\end{array}$ & $\begin{array}{l}0 \\
0 \\
0 \\
0 \\
0 \\
0 \\
0 \\
0 \\
0\end{array}$ & $\begin{array}{l}4 \\
4 \\
1 \\
2 \\
1 \\
1 \\
1 \\
1 \\
2\end{array}$ & $\begin{array}{r}17 \\
11 \\
2 \\
1 \\
1 \\
- \\
- \\
2\end{array}$ & $\begin{array}{r}16 \\
9 \\
-3 \\
-1 \\
2 \\
1 \\
-\end{array}$ & $\begin{array}{l}28 \\
\frac{-}{-} \\
\frac{6}{-} \\
\frac{20}{2}\end{array}$ & $\begin{array}{r}65 \\
12 \\
23 \\
2 \\
3 \\
0 \\
2 \\
16 \\
1\end{array}$ & $\begin{array}{r}230 \\
177 \\
40 \\
13 \\
19 \\
9 \\
6 \\
39 \\
8\end{array}$ & $\begin{array}{r}1,599 \\
266 \\
524 \\
46 \\
75 \\
35 \\
40 \\
569 \\
44\end{array}$ & $\begin{array}{r}2,331 \\
626 \\
759 \\
108 \\
438 \\
35 \\
125 \\
217 \\
23\end{array}$ \\
\hline $\begin{array}{l}\text { Pacific } \\
\text { Alaska } \\
\text { California } \\
\text { Hawaii } \\
\text { Oregon }^{\dagger} \\
\text { Washington }^{\dagger}\end{array}$ & $\begin{array}{l}\frac{4}{3} \\
\frac{-}{1}\end{array}$ & $\begin{array}{l}5 \\
0 \\
3 \\
0 \\
1 \\
0\end{array}$ & $\begin{array}{r}29 \\
1 \\
14 \\
1 \\
7 \\
7\end{array}$ & $\begin{array}{r}206 \\
1 \\
130 \\
4 \\
46 \\
25\end{array}$ & $\begin{array}{r}165 \\
1 \\
107 \\
9 \\
29 \\
19\end{array}$ & $\begin{array}{l}\frac{4}{3} \\
\frac{-}{1}\end{array}$ & $\begin{array}{l}5 \\
0 \\
3 \\
0 \\
1 \\
0\end{array}$ & $\begin{array}{r}25 \\
1 \\
14 \\
14 \\
1 \\
4 \\
11\end{array}$ & $\begin{array}{r}178 \\
1 \\
130 \\
4 \\
32 \\
11\end{array}$ & $\begin{array}{r}159 \\
1 \\
107 \\
4 \\
29 \\
18\end{array}$ & $\begin{array}{l}\frac{9}{-} \\
- \\
-\end{array}$ & $\begin{array}{r}52 \\
2 \\
24 \\
2 \\
3 \\
10\end{array}$ & $\begin{array}{r}1,334 \\
15 \\
1,136 \\
10 \\
16 \\
195\end{array}$ & $\begin{array}{r}631 \\
36 \\
269 \\
38 \\
75 \\
213\end{array}$ & $\begin{array}{r}1,654 \\
23 \\
649 \\
101 \\
506 \\
375\end{array}$ \\
\hline $\begin{array}{l}\text { American Samoa } \\
\text { C.N.M.I. } \\
\text { Guam } \\
\text { Puerto Rico } \\
\text { U.S. Virgin Islands }\end{array}$ & $\begin{array}{l}U \\
U \\
- \\
-\end{array}$ & $\begin{array}{l}0 \\
0 \\
0 \\
0 \\
0\end{array}$ & $\begin{array}{l}0 \\
0 \\
1 \\
1 \\
0\end{array}$ & $\frac{-}{-}$ & $\frac{-}{-}$ & $\begin{array}{l}U \\
U \\
- \\
-\end{array}$ & $\begin{array}{l}0 \\
0 \\
0 \\
0 \\
0\end{array}$ & $\begin{array}{l}0 \\
0 \\
1 \\
1 \\
0\end{array}$ & $\frac{U}{U}$ & $\frac{U}{U} \frac{U}{6}$ & $\begin{array}{l}U \\
U \\
- \\
-\end{array}$ & $\begin{array}{l}0 \\
0 \\
0 \\
0 \\
0\end{array}$ & $\begin{array}{l}0 \\
0 \\
0 \\
1 \\
0\end{array}$ & $\begin{array}{l}U \\
U \\
- \\
-\end{array}$ & $\begin{array}{r}U \\
U \\
2 \\
4 \\
-\end{array}$ \\
\hline
\end{tabular}

C.N.M.I.: Commonwealth of Northern Mariana Islands.

U: Unavailable - No reported cases $\quad \mathrm{N}$ : Not not

Cum: Cumulative year-to-date counts.

Med: Median

Max: Maximum.

* Incidence data for reporting years 2005 and 2006 are provisional.

Contains data reported through the National Electronic Disease Surveillance System (NEDSS). 
TABLE II. (Continued) Provisional cases of selected notifiable diseases, United States, weeks ending July 15, 2006, and July 16, 2005 (28th Week)*

\begin{tabular}{|c|c|c|c|c|c|c|c|c|c|c|c|c|c|c|c|}
\hline \multirow[b]{3}{*}{ Reporting area } & \multicolumn{5}{|c|}{ Rabies, animal } & \multicolumn{5}{|c|}{ Rocky Mountain spotted fever } & \multicolumn{5}{|c|}{ Salmonellosis } \\
\hline & \multirow{2}{*}{$\begin{array}{c}\text { Current } \\
\text { week }\end{array}$} & \multicolumn{2}{|c|}{$\begin{array}{l}\text { Previous } \\
52 \text { weeks }\end{array}$} & \multirow{2}{*}{$\begin{array}{l}\text { Cum } \\
2006\end{array}$} & \multirow{2}{*}{$\begin{array}{l}\text { Cum } \\
2005\end{array}$} & \multirow{2}{*}{$\begin{array}{c}\text { Current } \\
\text { week }\end{array}$} & \multicolumn{2}{|c|}{$\begin{array}{l}\text { Previous } \\
52 \text { weeks }\end{array}$} & \multirow{2}{*}{$\begin{array}{l}\text { Cum } \\
2006\end{array}$} & \multirow{2}{*}{$\begin{array}{l}\text { Cum } \\
2005\end{array}$} & \multirow{2}{*}{$\begin{array}{c}\text { Current } \\
\text { week }\end{array}$} & \multicolumn{2}{|c|}{$\begin{array}{l}\text { Previous } \\
52 \text { weeks }\end{array}$} & \multirow{2}{*}{$\begin{array}{l}\text { Cum } \\
2006\end{array}$} & \multirow{2}{*}{$\begin{array}{l}\text { Cum } \\
2005\end{array}$} \\
\hline & & Med & Max & & & & Med & $\operatorname{Max}$ & & & & Med & Max & & \\
\hline United States & 80 & 104 & 154 & 2,860 & 3,271 & 37 & 35 & 246 & 722 & 604 & 696 & 706 & 2,291 & 15,972 & 18,412 \\
\hline $\begin{array}{l}\text { New England } \\
\text { Connecticut } \\
\text { Maine }^{\dagger} \\
\text { Massachusetts } \\
\text { New Hampshire } \\
\text { Rhode Island } \\
\text { Vermont }^{\dagger}\end{array}$ & $\begin{array}{r}5 \\
1 \\
-4 \\
- \\
-\end{array}$ & $\begin{array}{r}12 \\
3 \\
1 \\
4 \\
0 \\
0 \\
1\end{array}$ & $\begin{array}{r}26 \\
13 \\
5 \\
17 \\
3 \\
4 \\
7\end{array}$ & $\begin{array}{r}305 \\
80 \\
40 \\
140 \\
9 \\
1 \\
35\end{array}$ & $\begin{array}{r}395 \\
86 \\
35 \\
219 \\
9 \\
11 \\
35\end{array}$ & $\begin{array}{l}- \\
\bar{N} \\
- \\
-\end{array}$ & $\begin{array}{l}0 \\
0 \\
0 \\
0 \\
0 \\
0 \\
0\end{array}$ & $\begin{array}{l}2 \\
0 \\
0 \\
2 \\
1 \\
2 \\
0\end{array}$ & $\begin{array}{r}2 \\
\mathrm{~N} \\
1 \\
1 \\
-\end{array}$ & $\begin{array}{l}3 \\
\mathrm{~N} \\
2 \\
-1 \\
-\end{array}$ & $\begin{array}{r}18 \\
\overline{-} \\
13 \\
\frac{4}{1}\end{array}$ & $\begin{array}{r}33 \\
0 \\
2 \\
19 \\
2 \\
0 \\
1\end{array}$ & $\begin{array}{r}196 \\
188 \\
7 \\
40 \\
10 \\
17 \\
10\end{array}$ & $\begin{array}{r}858 \\
188 \\
41 \\
513 \\
58 \\
40 \\
18\end{array}$ & $\begin{array}{r}1,070 \\
212 \\
98 \\
581 \\
85 \\
44 \\
50\end{array}$ \\
\hline $\begin{array}{l}\text { Mid. Atlantic } \\
\text { New Jersey } \\
\text { New York (Upstate) } \\
\text { New York City } \\
\text { Pennsylvania }\end{array}$ & $\begin{array}{r}15 \\
N \\
15 \\
- \\
-\end{array}$ & $\begin{array}{r}18 \\
0 \\
11 \\
0 \\
8\end{array}$ & $\begin{array}{r}46 \\
0 \\
24 \\
3 \\
35\end{array}$ & $\begin{array}{r}536 \\
N \\
262 \\
1 \\
273\end{array}$ & $\begin{array}{r}479 \\
N \\
249 \\
16 \\
214\end{array}$ & $\begin{array}{l}- \\
- \\
-\end{array}$ & $\begin{array}{l}1 \\
0 \\
0 \\
0 \\
1\end{array}$ & $\begin{array}{l}7 \\
3 \\
1 \\
1 \\
5\end{array}$ & $\begin{array}{r}19 \\
1 \\
1 \\
4 \\
13\end{array}$ & $\begin{array}{r}41 \\
11 \\
1 \\
5 \\
24\end{array}$ & $\frac{65}{\frac{43}{22}}$ & $\begin{array}{l}76 \\
13 \\
22 \\
19 \\
27\end{array}$ & $\begin{array}{r}272 \\
41 \\
233 \\
44 \\
61\end{array}$ & $\begin{array}{r}1,821 \\
308 \\
485 \\
386 \\
642\end{array}$ & $\begin{array}{r}2,293 \\
446 \\
533 \\
554 \\
760\end{array}$ \\
\hline $\begin{array}{l}\text { E.N. Central } \\
\text { Illinois } \\
\text { Indiana } \\
\text { Michigan } \\
\text { Ohio } \\
\text { Wisconsin }\end{array}$ & $\begin{array}{l}\frac{4}{1} \\
-1 \\
3 \\
\mathrm{~N}\end{array}$ & $\begin{array}{l}2 \\
0 \\
0 \\
1 \\
0 \\
0\end{array}$ & $\begin{array}{r}12 \\
4 \\
3 \\
5 \\
6 \\
0\end{array}$ & $\begin{array}{r}54 \\
10 \\
5 \\
24 \\
15 \\
\mathrm{~N}\end{array}$ & $\begin{array}{r}105 \\
18 \\
4 \\
13 \\
70 \\
\mathrm{~N}\end{array}$ & $\begin{array}{l}- \\
- \\
- \\
-\end{array}$ & $\begin{array}{l}0 \\
0 \\
0 \\
0 \\
0 \\
0\end{array}$ & $\begin{array}{l}7 \\
4 \\
1 \\
1 \\
6 \\
1\end{array}$ & $\begin{array}{r}19 \\
1 \\
3 \\
14 \\
1\end{array}$ & $\begin{array}{r}21 \\
7 \\
2 \\
10 \\
2\end{array}$ & $\begin{array}{r}50 \\
27 \\
2 \\
21 \\
-\end{array}$ & $\begin{array}{l}94 \\
25 \\
12 \\
16 \\
23 \\
15\end{array}$ & $\begin{array}{r}219 \\
53 \\
69 \\
35 \\
50 \\
44\end{array}$ & $\begin{array}{r}2,154 \\
493 \\
299 \\
424 \\
583 \\
355\end{array}$ & $\begin{array}{r}2,743 \\
1,005 \\
265 \\
461 \\
589 \\
423\end{array}$ \\
\hline $\begin{array}{l}\text { W.N. Central } \\
\text { lowa } \\
\text { Kansas } \\
\text { Minnesota } \\
\text { Missouri } \\
\text { Nebraska } \\
\text { North Dakota } \\
\text { South Dakota }\end{array}$ & $\begin{array}{l}9 \\
2 \\
1 \\
2 \\
4 \\
- \\
-\end{array}$ & $\begin{array}{l}5 \\
0 \\
1 \\
1 \\
1 \\
0 \\
0 \\
1\end{array}$ & $\begin{array}{r}20 \\
5 \\
5 \\
6 \\
6 \\
0 \\
7 \\
4\end{array}$ & $\begin{array}{r}153 \\
25 \\
43 \\
25 \\
26 \\
13 \\
21\end{array}$ & $\begin{array}{r}191 \\
53 \\
40 \\
35 \\
\frac{13}{50}\end{array}$ & $\begin{array}{l}1 \\
- \\
- \\
- \\
-\end{array}$ & $\begin{array}{l}2 \\
0 \\
0 \\
0 \\
2 \\
0 \\
0 \\
0\end{array}$ & $\begin{array}{r}12 \\
2 \\
1 \\
1 \\
12 \\
2 \\
1 \\
1\end{array}$ & $\begin{array}{r}87 \\
1 \\
1 \\
1 \\
78 \\
6 \\
-\end{array}$ & $\begin{array}{r}78 \\
1 \\
4 \\
-69 \\
- \\
4\end{array}$ & $\begin{array}{r}67 \\
1 \\
8 \\
34 \\
21 \\
3 \\
-\end{array}$ & $\begin{array}{r}44 \\
7 \\
7 \\
10 \\
15 \\
4 \\
0 \\
2\end{array}$ & $\begin{array}{r}98 \\
18 \\
17 \\
60 \\
40 \\
12 \\
46 \\
8\end{array}$ & $\begin{array}{r}1,180 \\
177 \\
164 \\
330 \\
360 \\
91 \\
7 \\
51\end{array}$ & $\begin{array}{r}1,199 \\
198 \\
174 \\
279 \\
350 \\
99 \\
15 \\
84\end{array}$ \\
\hline $\begin{array}{l}\text { S. Atlantic } \\
\text { Delaware } \\
\text { District of Columbia } \\
\text { Florida } \\
\text { Georgia } \\
\text { Maryland }^{\dagger} \\
\text { North Carolina } \\
\text { South Carolina }^{\dagger} \\
\text { Virginia }^{\dagger} \\
\text { West Virginia }\end{array}$ & $\begin{array}{r}31 \\
- \\
- \\
- \\
- \\
5 \\
8 \\
-\end{array}$ & $\begin{array}{r}36 \\
0 \\
0 \\
0 \\
4 \\
7 \\
8 \\
3 \\
10 \\
1\end{array}$ & $\begin{array}{r}117 \\
0 \\
0 \\
98 \\
9 \\
14 \\
20 \\
11 \\
27 \\
13\end{array}$ & $\begin{array}{r}1,045 \\
- \\
- \\
98 \\
98 \\
154 \\
229 \\
79 \\
333 \\
54\end{array}$ & $\begin{array}{r}1,239 \\
- \\
201 \\
158 \\
189 \\
284 \\
114 \\
271 \\
22\end{array}$ & $\begin{array}{l}32 \\
- \\
- \\
1 \\
1 \\
27 \\
-3 \\
-\end{array}$ & $\begin{array}{r}18 \\
0 \\
0 \\
0 \\
0 \\
1 \\
12 \\
1 \\
2 \\
0\end{array}$ & $\begin{array}{r}94 \\
1 \\
1 \\
3 \\
4 \\
6 \\
87 \\
6 \\
10 \\
2\end{array}$ & $\begin{array}{r}467 \\
6 \\
12 \\
11 \\
19 \\
384 \\
8 \\
26 \\
1\end{array}$ & $\begin{array}{r}310 \\
4 \\
1 \\
9 \\
59 \\
34 \\
157 \\
26 \\
17 \\
3\end{array}$ & $\begin{array}{r}319 \\
1 \\
2 \\
139 \\
29 \\
21 \\
58 \\
24 \\
45 \\
-\end{array}$ & $\begin{array}{r}200 \\
2 \\
1 \\
95 \\
25 \\
12 \\
28 \\
19 \\
20 \\
2\end{array}$ & $\begin{array}{r}514 \\
9 \\
7 \\
230 \\
87 \\
39 \\
114 \\
73 \\
66 \\
19\end{array}$ & $\begin{array}{r}4,193 \\
49 \\
32 \\
1,865 \\
563 \\
263 \\
632 \\
354 \\
391 \\
44\end{array}$ & $\begin{array}{r}4,718 \\
52 \\
20 \\
1,733 \\
724 \\
347 \\
626 \\
711 \\
434 \\
71\end{array}$ \\
\hline $\begin{array}{l}\text { E.S. Central } \\
\text { Alabama }^{\dagger} \\
\text { Kentucky } \\
\text { Mississippi } \\
\text { Tennessee }^{\dagger}\end{array}$ & $\begin{array}{r}5 \\
1 \\
- \\
4\end{array}$ & $\begin{array}{l}4 \\
1 \\
0 \\
0 \\
2\end{array}$ & $\begin{array}{r}16 \\
7 \\
5 \\
2 \\
9\end{array}$ & $\begin{array}{r}138 \\
47 \\
7 \\
4 \\
80\end{array}$ & $\begin{array}{r}79 \\
45 \\
7 \\
27\end{array}$ & $\frac{1}{-}$ & $\begin{array}{l}5 \\
1 \\
0 \\
0 \\
3\end{array}$ & $\begin{array}{r}24 \\
9 \\
1 \\
3 \\
18\end{array}$ & $\begin{array}{l}82 \\
21 \\
- \\
-61\end{array}$ & $\begin{array}{r}102 \\
25 \\
-4 \\
73\end{array}$ & $\begin{array}{r}13 \\
5 \\
4 \\
-4\end{array}$ & $\begin{array}{r}49 \\
14 \\
8 \\
9 \\
14\end{array}$ & $\begin{array}{r}115 \\
41 \\
27 \\
62 \\
41\end{array}$ & $\begin{array}{l}954 \\
362 \\
180 \\
123 \\
289\end{array}$ & $\begin{array}{r}1,138 \\
288 \\
174 \\
300 \\
376\end{array}$ \\
\hline $\begin{array}{l}\text { W.S. Central } \\
\text { Arkansas } \\
\text { Louisiana } \\
\text { Oklahoma } \\
\text { Texas }^{\dagger}\end{array}$ & $\frac{8}{-}$ & $\begin{array}{r}14 \\
0 \\
0 \\
1 \\
12\end{array}$ & $\begin{array}{r}34 \\
3 \\
0 \\
9 \\
29\end{array}$ & $\begin{array}{r}461 \\
19 \\
-44 \\
398\end{array}$ & $\begin{array}{r}555 \\
21 \\
56 \\
478\end{array}$ & $\begin{array}{l}3 \\
3 \\
- \\
- \\
-\end{array}$ & $\begin{array}{l}1 \\
0 \\
0 \\
0 \\
0\end{array}$ & $\begin{array}{r}161 \\
32 \\
1 \\
154 \\
8\end{array}$ & $\begin{array}{r}30 \\
21 \\
-6 \\
3\end{array}$ & $\begin{array}{r}26 \\
14 \\
5 \\
5 \\
2\end{array}$ & $\begin{array}{l}25 \\
10 \\
\frac{15}{-}\end{array}$ & $\begin{array}{r}79 \\
14 \\
0 \\
7 \\
45\end{array}$ & $\begin{array}{r}922 \\
43 \\
43 \\
48 \\
839\end{array}$ & $\begin{array}{r}1,281 \\
375 \\
- \\
185 \\
721\end{array}$ & $\begin{array}{r}1,719 \\
317 \\
401 \\
179 \\
822\end{array}$ \\
\hline $\begin{array}{l}\text { Mountain } \\
\text { Arizona } \\
\text { Colorado } \\
\text { Idaho }^{\dagger} \\
\text { Montana } \\
\text { Nevada }^{\dagger} \\
\text { New Mexico }{ }^{\dagger} \\
\text { Utah } \\
\text { Wyoming }\end{array}$ & $\begin{array}{l}- \\
- \\
- \\
- \\
-\end{array}$ & $\begin{array}{l}3 \\
2 \\
0 \\
0 \\
0 \\
0 \\
0 \\
0 \\
0\end{array}$ & $\begin{array}{r}16 \\
11 \\
2 \\
12 \\
3 \\
2 \\
1 \\
5 \\
2\end{array}$ & $\begin{array}{l}70 \\
58 \\
- \\
7 \\
- \\
-3 \\
2\end{array}$ & $\begin{array}{r}140 \\
103 \\
13 \\
3 \\
5 \\
4 \\
12\end{array}$ & $\begin{array}{l}- \\
- \\
- \\
- \\
-\end{array}$ & $\begin{array}{l}0 \\
0 \\
0 \\
0 \\
0 \\
0 \\
0 \\
0 \\
0\end{array}$ & $\begin{array}{l}6 \\
6 \\
1 \\
2 \\
2 \\
0 \\
1 \\
2 \\
1\end{array}$ & $\begin{array}{r}13 \\
2 \\
-1 \\
1 \\
2 \\
3 \\
3 \\
2\end{array}$ & $\begin{array}{r}21 \\
12 \\
2 \\
1 \\
1 \\
\frac{1}{3} \\
\frac{2}{2}\end{array}$ & $\begin{array}{l}12 \\
- \\
3 \\
5 \\
- \\
- \\
-\end{array}$ & $\begin{array}{r}46 \\
12 \\
12 \\
2 \\
2 \\
3 \\
4 \\
5 \\
1\end{array}$ & $\begin{array}{r}110 \\
67 \\
45 \\
9 \\
16 \\
17 \\
13 \\
30 \\
12\end{array}$ & $\begin{array}{r}1,023 \\
197 \\
342 \\
79 \\
75 \\
65 \\
81 \\
151 \\
33\end{array}$ & $\begin{array}{r}1,077 \\
303 \\
245 \\
87 \\
47 \\
99 \\
121 \\
141 \\
34\end{array}$ \\
\hline $\begin{array}{l}\text { Pacific } \\
\text { Alaska } \\
\text { California } \\
\text { Hawaii } \\
\text { Oregon }^{\dagger} \\
\text { Washington }^{\dagger}\end{array}$ & $\begin{array}{l}\frac{3}{3} \\
\frac{-}{U}\end{array}$ & $\begin{array}{l}4 \\
0 \\
3 \\
0 \\
0 \\
0\end{array}$ & $\begin{array}{r}15 \\
4 \\
15 \\
0 \\
1 \\
0\end{array}$ & $\begin{array}{r}98 \\
13 \\
83 \\
2 \\
U\end{array}$ & $\begin{array}{r}88 \\
1 \\
85 \\
2 \\
U\end{array}$ & $\begin{array}{l}- \\
- \\
- \\
N\end{array}$ & $\begin{array}{l}0 \\
0 \\
0 \\
0 \\
0 \\
0\end{array}$ & $\begin{array}{l}1 \\
0 \\
1 \\
0 \\
0 \\
0\end{array}$ & $\begin{array}{l}\frac{3}{3} \\
\frac{-}{N}\end{array}$ & $\begin{array}{l}\frac{2}{-} \\
- \\
2 \\
N\end{array}$ & $\begin{array}{r}127 \\
1 \\
111 \\
1 \\
14\end{array}$ & $\begin{array}{r}108 \\
1 \\
86 \\
5 \\
7 \\
9\end{array}$ & $\begin{array}{r}426 \\
7 \\
292 \\
15 \\
25 \\
124\end{array}$ & $\begin{array}{r}2,508 \\
41 \\
1,925 \\
115 \\
195 \\
232\end{array}$ & $\begin{array}{r}2,455 \\
24 \\
1,844 \\
146 \\
214 \\
227\end{array}$ \\
\hline $\begin{array}{l}\text { American Samoa } \\
\text { C.N.M.I. } \\
\text { Guam } \\
\text { Puerto Rico } \\
\text { U.S. Virgin Islands }\end{array}$ & $\frac{U}{U}$ & $\begin{array}{l}0 \\
0 \\
0 \\
2 \\
0\end{array}$ & $\begin{array}{l}0 \\
0 \\
0 \\
6 \\
0\end{array}$ & $\frac{U}{\frac{U}{57}}$ & $\frac{U}{U} \frac{U}{42}$ & $\frac{U}{\mathrm{U}}$ & $\begin{array}{l}0 \\
0 \\
0 \\
0 \\
0\end{array}$ & $\begin{array}{l}0 \\
0 \\
0 \\
0 \\
0\end{array}$ & $\frac{U}{U} \frac{\mathrm{U}}{-}$ & $\frac{U}{U}$ & $\begin{array}{l}U \\
U \\
- \\
-\end{array}$ & $\begin{array}{l}0 \\
0 \\
0 \\
7 \\
0\end{array}$ & $\begin{array}{r}2 \\
0 \\
3 \\
35 \\
0\end{array}$ & $\frac{U}{U} \frac{U}{81}$ & $\begin{array}{r}1 \\
U \\
26 \\
288 \\
-\end{array}$ \\
\hline
\end{tabular}

C.N.M.I.: Commonwealth of Northern Mariana Islands.

U: Unavailable. ․: No reported cases. N: Not notifiable.

* Incidence data for reporting years 2005 and 2006 are provisional.

Cum: Cumulative year-to-date counts.

Med: Median

Max: Maximum.

Contains data reported through the National Electronic Disease Surveillance System (NEDSS). 
TABLE II. (Continued) Provisional cases of selected notifiable diseases, United States, weeks ending July 15, 2006, and July 16, 2005 (28th Week)*

\begin{tabular}{|c|c|c|c|c|c|c|c|c|c|c|c|c|c|c|c|}
\hline \multirow[b]{3}{*}{ Reporting area } & \multicolumn{5}{|c|}{ 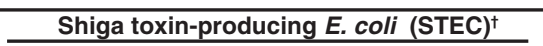 } & \multicolumn{5}{|c|}{ Shigellosis } & \multicolumn{5}{|c|}{ Streptococcal disease, invasive, group A } \\
\hline & \multirow{2}{*}{$\begin{array}{c}\text { Current } \\
\text { week }\end{array}$} & \multicolumn{2}{|c|}{$\begin{array}{l}\text { Previous } \\
52 \text { weeks }\end{array}$} & \multirow{2}{*}{$\begin{array}{l}\text { Cum } \\
2006\end{array}$} & \multirow{2}{*}{$\begin{array}{l}\text { Cum } \\
2005\end{array}$} & \multirow{2}{*}{$\begin{array}{c}\text { Current } \\
\text { week }\end{array}$} & \multicolumn{2}{|c|}{$\begin{array}{l}\text { Previous } \\
52 \text { weeks }\end{array}$} & \multirow{2}{*}{$\begin{array}{l}\text { Cum } \\
2006\end{array}$} & \multirow{2}{*}{$\begin{array}{l}\text { Cum } \\
2005\end{array}$} & \multirow{2}{*}{$\begin{array}{c}\text { Current } \\
\text { week }\end{array}$} & \multicolumn{2}{|c|}{$\begin{array}{l}\text { Previous } \\
52 \text { weeks }\end{array}$} & \multirow{2}{*}{$\begin{array}{l}\text { Cum } \\
2006\end{array}$} & \multirow{2}{*}{$\begin{array}{r}\text { Cum } \\
2005\end{array}$} \\
\hline & & Med & $\operatorname{Max}$ & & & & Med & Max & & & & Med & $\operatorname{Max}$ & & \\
\hline United States & 56 & 51 & 297 & 835 & 1,098 & 126 & 211 & 1,013 & 4,678 & 6,612 & 42 & 85 & 283 & 2,932 & 2,875 \\
\hline $\begin{array}{l}\text { New England } \\
\text { Connecticut } \\
\text { Maine } \\
\text { Massachusetts } \\
\text { New Hampshire } \\
\text { Rhode Island } \\
\text { Vermont } \$\end{array}$ & $\begin{array}{l}- \\
- \\
- \\
-\end{array}$ & $\begin{array}{l}3 \\
0 \\
0 \\
1 \\
0 \\
0 \\
0\end{array}$ & $\begin{array}{r}23 \\
22 \\
5 \\
7 \\
2 \\
2 \\
2\end{array}$ & $\begin{array}{r}67 \\
22 \\
34 \\
7 \\
2 \\
2\end{array}$ & $\begin{array}{r}98 \\
26 \\
16 \\
36 \\
9 \\
2 \\
9\end{array}$ & $\begin{array}{l}3 \\
- \\
- \\
- \\
-\end{array}$ & $\begin{array}{l}4 \\
0 \\
0 \\
4 \\
0 \\
0 \\
0\end{array}$ & $\begin{array}{r}31 \\
25 \\
3 \\
11 \\
4 \\
6 \\
4\end{array}$ & $\begin{array}{r}126 \\
25 \\
2 \\
86 \\
5 \\
5 \\
3\end{array}$ & $\begin{array}{r}134 \\
24 \\
6 \\
85 \\
4 \\
9 \\
6\end{array}$ & $\begin{array}{l}3 \\
U \\
1 \\
2 \\
-\end{array}$ & $\begin{array}{l}5 \\
0 \\
0 \\
3 \\
0 \\
0 \\
0\end{array}$ & $\begin{array}{r}15 \\
3 \\
2 \\
6 \\
9 \\
3 \\
2\end{array}$ & $\begin{array}{r}137 \\
U \\
10 \\
84 \\
30 \\
4 \\
9\end{array}$ & $\begin{array}{r}175 \\
69 \\
9 \\
72 \\
9 \\
7 \\
9\end{array}$ \\
\hline $\begin{array}{l}\text { Mid. Atlantic } \\
\text { New Jersey } \\
\text { New York (Upstate) } \\
\text { New York City } \\
\text { Pennsylvania }\end{array}$ & $\begin{array}{l}7 \\
- \\
-\end{array}$ & $\begin{array}{l}5 \\
1 \\
1 \\
0 \\
0\end{array}$ & $\begin{array}{r}107 \\
7 \\
103 \\
3 \\
8\end{array}$ & $\begin{array}{r}60 \\
3 \\
19 \\
9 \\
-\end{array}$ & $\begin{array}{r}130 \\
30 \\
52 \\
7 \\
41\end{array}$ & $\frac{7}{\frac{5}{2}}$ & $\begin{array}{r}16 \\
4 \\
4 \\
4 \\
2\end{array}$ & $\begin{array}{l}72 \\
15 \\
60 \\
14 \\
48\end{array}$ & $\begin{array}{r}337 \\
97 \\
115 \\
81 \\
44\end{array}$ & $\begin{array}{r}639 \\
186 \\
148 \\
253 \\
52\end{array}$ & $\frac{7}{\frac{5}{2}}$ & $\begin{array}{r}14 \\
2 \\
4 \\
2 \\
5\end{array}$ & $\begin{array}{r}43 \\
6 \\
32 \\
10 \\
13\end{array}$ & $\begin{array}{r}547 \\
68 \\
210 \\
65 \\
204\end{array}$ & $\begin{array}{l}618 \\
127 \\
180 \\
122 \\
189\end{array}$ \\
\hline $\begin{array}{l}\text { E.N. Central } \\
\text { Illinois } \\
\text { Indiana } \\
\text { Michigan } \\
\text { Ohio } \\
\text { Wisconsin }\end{array}$ & $\begin{array}{l}7 \\
2 \\
1 \\
4 \\
-\end{array}$ & $\begin{array}{r}10 \\
1 \\
1 \\
1 \\
3 \\
2\end{array}$ & $\begin{array}{r}38 \\
10 \\
6 \\
8 \\
14 \\
15\end{array}$ & $\begin{array}{r}176 \\
20 \\
27 \\
31 \\
62 \\
36\end{array}$ & $\begin{array}{r}214 \\
58 \\
26 \\
40 \\
48 \\
42\end{array}$ & $\begin{array}{l}3 \\
- \\
1 \\
2 \\
-\end{array}$ & $\begin{array}{r}20 \\
7 \\
2 \\
3 \\
3 \\
3\end{array}$ & $\begin{array}{l}96 \\
26 \\
56 \\
10 \\
11 \\
10\end{array}$ & $\begin{array}{r}440 \\
123 \\
73 \\
92 \\
90 \\
62\end{array}$ & $\begin{array}{r}477 \\
122 \\
44 \\
136 \\
45 \\
130\end{array}$ & $\begin{array}{l}4 \\
2 \\
1 \\
1 \\
-\end{array}$ & $\begin{array}{r}16 \\
4 \\
1 \\
3 \\
4 \\
1\end{array}$ & $\begin{array}{r}42 \\
10 \\
11 \\
11 \\
19 \\
4\end{array}$ & $\begin{array}{r}550 \\
111 \\
80 \\
148 \\
175 \\
36\end{array}$ & $\begin{array}{r}617 \\
207 \\
59 \\
153 \\
131 \\
67\end{array}$ \\
\hline $\begin{array}{l}\text { W.N. Central } \\
\text { lowa } \\
\text { Kansas } \\
\text { Minnesota } \\
\text { Missouri } \\
\text { Nebraska } \\
\text { North Dakota } \\
\text { South Dakota }\end{array}$ & $\begin{array}{l}8 \\
2 \\
5 \\
5 \\
1 \\
-\end{array}$ & $\begin{array}{l}7 \\
1 \\
0 \\
3 \\
2 \\
1 \\
0 \\
0\end{array}$ & $\begin{array}{r}35 \\
10 \\
4 \\
19 \\
9 \\
5 \\
15 \\
5\end{array}$ & $\begin{array}{r}141 \\
53 \\
71 \\
77 \\
19 \\
\frac{14}{14}\end{array}$ & $\begin{array}{r}161 \\
37 \\
17 \\
26 \\
45 \\
23 \\
1 \\
12\end{array}$ & $\begin{array}{r}22 \\
2 \\
6 \\
7 \\
7 \\
- \\
-\end{array}$ & $\begin{array}{r}42 \\
1 \\
4 \\
2 \\
20 \\
2 \\
0 \\
2\end{array}$ & $\begin{array}{r}78 \\
7 \\
20 \\
8 \\
70 \\
11 \\
2 \\
17\end{array}$ & $\begin{array}{r}712 \\
36 \\
62 \\
51 \\
456 \\
39 \\
4 \\
64\end{array}$ & $\begin{array}{r}615 \\
45 \\
53 \\
34 \\
422 \\
41 \\
2 \\
18\end{array}$ & $\begin{array}{l}1 \\
\mathrm{~N} \\
1 \\
- \\
- \\
- \\
-\end{array}$ & $\begin{array}{l}5 \\
0 \\
1 \\
0 \\
1 \\
0 \\
0 \\
0\end{array}$ & $\begin{array}{r}57 \\
0 \\
5 \\
52 \\
5 \\
4 \\
5 \\
3\end{array}$ & $\begin{array}{r}222 \\
N \\
42 \\
106 \\
42 \\
19 \\
7 \\
6\end{array}$ & $\begin{array}{r}178 \\
\mathrm{~N} \\
29 \\
64 \\
46 \\
17 \\
6 \\
16\end{array}$ \\
\hline $\begin{array}{l}\text { S. Atlantic } \\
\text { Delaware } \\
\text { District of Columbia } \\
\text { Florida } \\
\text { Georgia } \\
\text { Maryland } \\
\text { North Carolina } \\
\text { South Carolina } \\
\text { Virginia } \\
\text { West Virginia }\end{array}$ & $\begin{array}{l}\frac{19}{-} \\
\frac{5}{4} \\
4 \\
- \\
-\end{array}$ & $\begin{array}{l}7 \\
0 \\
0 \\
1 \\
1 \\
1 \\
1 \\
0 \\
0 \\
0\end{array}$ & $\begin{array}{r}39 \\
2 \\
1 \\
29 \\
6 \\
5 \\
11 \\
2 \\
8 \\
2\end{array}$ & $\begin{array}{r}153 \\
1 \\
-47 \\
28 \\
17 \\
39 \\
4 \\
- \\
\end{array}$ & $\begin{array}{r}157 \\
2 \\
60 \\
18 \\
24 \\
19 \\
3 \\
30 \\
1\end{array}$ & $\begin{array}{r}55 \\
- \\
31 \\
17 \\
1 \\
3 \\
-3 \\
-\end{array}$ & $\begin{array}{r}51 \\
0 \\
0 \\
25 \\
14 \\
2 \\
1 \\
1 \\
1 \\
0\end{array}$ & $\begin{array}{r}122 \\
2 \\
2 \\
66 \\
38 \\
8 \\
22 \\
9 \\
9 \\
1\end{array}$ & $\begin{array}{r}1,274 \\
2 \\
6 \\
612 \\
429 \\
39 \\
95 \\
59 \\
32 \\
-\end{array}$ & $\begin{array}{r}980 \\
8 \\
8 \\
479 \\
246 \\
36 \\
95 \\
53 \\
55 \\
\end{array}$ & $\begin{array}{r}20 \\
- \\
8 \\
4 \\
4 \\
1 \\
3 \\
-\end{array}$ & $\begin{array}{r}21 \\
0 \\
0 \\
5 \\
4 \\
3 \\
0 \\
0 \\
2 \\
0\end{array}$ & $\begin{array}{r}41 \\
2 \\
2 \\
12 \\
12 \\
12 \\
26 \\
6 \\
11 \\
6\end{array}$ & $\begin{array}{r}687 \\
7 \\
9 \\
158 \\
134 \\
123 \\
106 \\
43 \\
86 \\
21\end{array}$ & $\begin{array}{r}550 \\
1 \\
7 \\
145 \\
112 \\
110 \\
81 \\
27 \\
52 \\
15\end{array}$ \\
\hline $\begin{array}{l}\text { E.S. Central } \\
\text { Alabama§ } \\
\text { Kentucky } \\
\text { Mississippi } \\
\text { Tennessee }\end{array}$ & $\begin{array}{l}\frac{5}{1} \\
- \\
-\end{array}$ & $\begin{array}{l}2 \\
0 \\
1 \\
0 \\
1\end{array}$ & $\begin{array}{r}11 \\
3 \\
8 \\
2 \\
4\end{array}$ & $\begin{array}{r}50 \\
8 \\
17 \\
25\end{array}$ & $\begin{array}{r}61 \\
15 \\
19 \\
2 \\
25\end{array}$ & $\begin{array}{r}4 \\
2 \\
1 \\
1\end{array}$ & $\begin{array}{r}14 \\
3 \\
6 \\
1 \\
3\end{array}$ & $\begin{array}{r}35 \\
14 \\
23 \\
6 \\
11\end{array}$ & $\begin{array}{r}330 \\
99 \\
146 \\
28 \\
57\end{array}$ & $\begin{array}{r}769 \\
160 \\
130 \\
46 \\
433\end{array}$ & $\begin{array}{r}3 \\
\mathrm{~N} \\
- \\
3\end{array}$ & $\begin{array}{l}3 \\
0 \\
0 \\
0 \\
3\end{array}$ & $\begin{array}{r}11 \\
0 \\
5 \\
0 \\
9\end{array}$ & $\begin{array}{r}133 \\
N \\
28 \\
105\end{array}$ & $\begin{array}{r}120 \\
\mathrm{~N} \\
25 \\
95\end{array}$ \\
\hline $\begin{array}{l}\text { W.S. Central } \\
\text { Arkansas } \\
\text { Louisiana } \\
\text { Oklahoma } \\
\text { Texas }\end{array}$ & $\frac{1}{-}$ & $\begin{array}{l}1 \\
0 \\
0 \\
0 \\
1\end{array}$ & $\begin{array}{r}52 \\
2 \\
2 \\
8 \\
44\end{array}$ & $\begin{array}{r}11 \\
4 \\
-7 \\
32\end{array}$ & $\begin{array}{r}48 \\
7 \\
14 \\
12 \\
15\end{array}$ & $\begin{array}{r}2 \\
1 \\
-1 \\
-\end{array}$ & $\begin{array}{r}29 \\
1 \\
0 \\
4 \\
24\end{array}$ & $\begin{array}{r}596 \\
7 \\
11 \\
286 \\
308\end{array}$ & $\begin{array}{r}387 \\
42 \\
54 \\
291\end{array}$ & $\begin{array}{r}1,809 \\
32 \\
78 \\
405 \\
1,294\end{array}$ & $\frac{3}{-}$ & $\begin{array}{l}6 \\
0 \\
0 \\
2 \\
4\end{array}$ & $\begin{array}{r}58 \\
5 \\
1 \\
14 \\
43\end{array}$ & $\begin{array}{r}223 \\
18 \\
\frac{67}{67} \\
138\end{array}$ & $\begin{array}{r}181 \\
11 \\
4 \\
72 \\
94\end{array}$ \\
\hline $\begin{array}{l}\text { Mountain } \\
\text { Arizona } \\
\text { Colorado } \\
\text { Idaho§ } \\
\text { Montana } \\
\text { Nevada } \\
\text { New Mexico } \\
\text { Utah } \\
\text { Wyoming }\end{array}$ & $\begin{array}{l}- \\
\overline{-} \\
- \\
- \\
- \\
-\end{array}$ & $\begin{array}{l}4 \\
0 \\
1 \\
1 \\
0 \\
0 \\
0 \\
1 \\
0\end{array}$ & $\begin{array}{r}15 \\
4 \\
6 \\
7 \\
2 \\
3 \\
3 \\
7 \\
3\end{array}$ & $\begin{array}{r}70 \\
16 \\
30 \\
25 \\
7 \\
4 \\
28 \\
6\end{array}$ & $\begin{array}{r}117 \\
13 \\
28 \\
17 \\
7 \\
12 \\
14 \\
24 \\
2\end{array}$ & $\begin{array}{l}2 \\
- \\
- \\
- \\
- \\
-\end{array}$ & $\begin{array}{r}17 \\
8 \\
3 \\
0 \\
0 \\
1 \\
2 \\
1 \\
0\end{array}$ & $\begin{array}{r}47 \\
29 \\
18 \\
4 \\
1 \\
8 \\
9 \\
4 \\
1\end{array}$ & $\begin{array}{r}298 \\
131 \\
63 \\
6 \\
4 \\
28 \\
35 \\
30 \\
1\end{array}$ & $\begin{array}{r}328 \\
172 \\
49 \\
5 \\
5 \\
29 \\
48 \\
20 \\
-\end{array}$ & $\begin{array}{l}- \\
- \\
- \\
- \\
- \\
-\end{array}$ & $\begin{array}{r}10 \\
3 \\
3 \\
0 \\
0 \\
0 \\
1 \\
1 \\
0\end{array}$ & $\begin{array}{r}78 \\
57 \\
8 \\
2 \\
0 \\
6 \\
7 \\
6 \\
1\end{array}$ & $\begin{array}{r}379 \\
180 \\
92 \\
8 \\
- \\
46 \\
50 \\
3\end{array}$ & $\begin{array}{r}378 \\
166 \\
124 \\
2 \\
1 \\
48 \\
35 \\
2\end{array}$ \\
\hline $\begin{array}{l}\text { Pacific } \\
\text { Alaska } \\
\text { California } \\
\text { Hawaii } \\
\text { Oregon } \\
\text { Washington }\end{array}$ & $\begin{array}{l}\frac{9}{6} \\
\frac{-}{3}\end{array}$ & $\begin{array}{l}7 \\
0 \\
4 \\
0 \\
2 \\
2\end{array}$ & $\begin{array}{r}55 \\
2 \\
18 \\
4 \\
47 \\
32\end{array}$ & $\begin{array}{r}107 \\
70 \\
6 \\
30 \\
31\end{array}$ & $\begin{array}{r}112 \\
6 \\
48 \\
4 \\
36 \\
18\end{array}$ & $\frac{28}{\frac{27}{-}}$ & $\begin{array}{r}40 \\
0 \\
32 \\
0 \\
2 \\
2\end{array}$ & $\begin{array}{r}148 \\
2 \\
104 \\
4 \\
31 \\
43\end{array}$ & $\begin{array}{r}774 \\
7 \\
605 \\
20 \\
71 \\
71\end{array}$ & $\begin{array}{r}861 \\
10 \\
746 \\
14 \\
43 \\
48\end{array}$ & $\begin{array}{l}1 \\
- \\
1 \\
N \\
N\end{array}$ & $\begin{array}{l}2 \\
0 \\
0 \\
2 \\
0 \\
0\end{array}$ & $\begin{array}{l}9 \\
0 \\
0 \\
9 \\
0 \\
0\end{array}$ & $\begin{array}{r}54 \\
- \\
54 \\
\mathrm{~N} \\
\mathrm{~N}\end{array}$ & $\begin{array}{r}58 \\
- \\
58 \\
N \\
N\end{array}$ \\
\hline $\begin{array}{l}\text { American Samoa } \\
\text { C.N.M.I. } \\
\text { Guam } \\
\text { Puerto Rico } \\
\text { U.S. Virgin Islands }\end{array}$ & $\begin{array}{l}U \\
U \\
- \\
-\end{array}$ & $\begin{array}{l}0 \\
0 \\
0 \\
0 \\
0\end{array}$ & $\begin{array}{l}0 \\
0 \\
0 \\
1 \\
0\end{array}$ & $\begin{array}{l}\mathrm{U} \\
\mathrm{U} \\
-\end{array}$ & $\begin{array}{l}U \\
U \\
-\end{array}$ & $\begin{array}{l}U \\
U \\
- \\
-\end{array}$ & $\begin{array}{l}0 \\
0 \\
0 \\
0 \\
0\end{array}$ & $\begin{array}{l}2 \\
0 \\
3 \\
2 \\
0\end{array}$ & $\frac{U}{U}$ & $\begin{array}{l}3 \\
U \\
9 \\
2 \\
\end{array}$ & $\frac{U}{U}$ & $\begin{array}{l}0 \\
0 \\
0 \\
0 \\
0\end{array}$ & $\begin{array}{l}0 \\
0 \\
0 \\
0 \\
0\end{array}$ & $\frac{U}{\mathrm{U}}$ & $\frac{U}{\mathrm{U}}$ \\
\hline
\end{tabular}

C.N.M.I.: Commonwealth of Northern Mariana Islands.

U: Unavailable. $\quad$-: No reported cases. $\quad \mathrm{N}$ : Not notifiable.

Cum: Cumulative year-to-date counts.

Med: Median

Max: Maximum

* Incidence data for reporting years 2005 and 2006 are provisional.

Includes E. coli O157:H7; Shiga toxin positive, serogroup non-0157; and Shiga toxin positive, not serogrouped.

${ }^{\S}$ Contains data reported through the National Electronic Disease Surveillance System (NEDSS). 
TABLE II. (Continued) Provisional cases of selected notifiable diseases, United States, weeks ending July 15, 2006, and July 16, 2005 (28th Week)*

\begin{tabular}{|c|c|c|c|c|c|c|c|c|c|c|c|c|c|c|c|}
\hline \multirow[b]{3}{*}{ Reporting area } & \multicolumn{5}{|c|}{$\begin{array}{c}\text { Streptococcus pneumoniae, invasive disease } \\
\text { Drug resistant, all ages }\end{array}$} & \multicolumn{5}{|c|}{ Syphilis, primary and secondary } & \multicolumn{5}{|c|}{ Varicella (chickenpox) } \\
\hline & \multirow{2}{*}{$\begin{array}{c}\text { Current } \\
\text { week }\end{array}$} & \multicolumn{2}{|c|}{$\begin{array}{l}\text { Previous } \\
52 \text { weeks } \\
\end{array}$} & \multirow{2}{*}{$\begin{array}{l}\text { Cum } \\
2006\end{array}$} & \multirow{2}{*}{$\begin{array}{l}\text { Cum } \\
2005\end{array}$} & \multirow{2}{*}{$\begin{array}{c}\text { Current } \\
\text { week }\end{array}$} & \multicolumn{2}{|c|}{$\begin{array}{l}\text { Previous } \\
52 \text { weeks } \\
\end{array}$} & \multirow{2}{*}{$\begin{array}{l}\text { Cum } \\
2006\end{array}$} & \multirow{2}{*}{$\begin{array}{l}\text { Cum } \\
2005\end{array}$} & \multirow{2}{*}{$\begin{array}{c}\text { Current } \\
\text { week }\end{array}$} & \multicolumn{2}{|c|}{$\begin{array}{l}\text { Previous } \\
52 \text { weeks }\end{array}$} & \multirow{2}{*}{$\begin{array}{l}\text { Cum } \\
2006\end{array}$} & \multirow{2}{*}{$\begin{array}{l}\text { Cum } \\
2005 \\
\end{array}$} \\
\hline & & Med & Max & & & & Med & $\operatorname{Max}$ & & & & Med & $\operatorname{Max}$ & & \\
\hline United States & 27 & 51 & 334 & 1,574 & 1,691 & 106 & 167 & 334 & 4,312 & 4,410 & 342 & 799 & 3,204 & 26,638 & 16,612 \\
\hline $\begin{array}{l}\text { New England } \\
\text { Connecticut } \\
\text { Maine }^{\dagger} \\
\text { Massachusetts } \\
\text { New Hampshire } \\
\text { Rhode Island } \\
\text { Vermont }^{\dagger}\end{array}$ & $\begin{array}{l}\bar{U} \\
\mathrm{~N} \\
- \\
- \\
-\end{array}$ & $\begin{array}{l}1 \\
0 \\
0 \\
0 \\
0 \\
0 \\
0\end{array}$ & $\begin{array}{r}24 \\
7 \\
0 \\
6 \\
0 \\
11 \\
2\end{array}$ & $\begin{array}{r}16 \\
U \\
\mathrm{~N} \\
- \\
6 \\
10\end{array}$ & $\begin{array}{r}153 \\
64 \\
\mathrm{~N} \\
67 \\
14 \\
8\end{array}$ & $\begin{array}{l}\frac{5}{-} \\
- \\
- \\
-\end{array}$ & $\begin{array}{l}4 \\
0 \\
0 \\
2 \\
0 \\
0 \\
0\end{array}$ & $\begin{array}{r}17 \\
11 \\
2 \\
5 \\
2 \\
6 \\
1\end{array}$ & $\begin{array}{r}109 \\
22 \\
8 \\
68 \\
6 \\
3 \\
2\end{array}$ & $\begin{array}{r}111 \\
23 \\
1 \\
75 \\
7 \\
5 \\
-\end{array}$ & $\begin{array}{l}\frac{46}{U} \\
\frac{4}{-} \\
\frac{43}{3}\end{array}$ & $\begin{array}{r}43 \\
0 \\
5 \\
13 \\
5 \\
0 \\
12\end{array}$ & $\begin{array}{r}144 \\
58 \\
20 \\
54 \\
30 \\
0 \\
50\end{array}$ & $\begin{array}{r}987 \\
U \\
151 \\
92 \\
260 \\
484\end{array}$ & $\begin{array}{r}3,481 \\
980 \\
208 \\
1,558 \\
198 \\
-537\end{array}$ \\
\hline $\begin{array}{l}\text { Mid. Atlantic } \\
\text { New Jersey } \\
\text { New York (Upstate) } \\
\text { New York City } \\
\text { Pennsylvania }\end{array}$ & $\begin{array}{r}1 \\
N \\
1 \\
U \\
-\end{array}$ & $\begin{array}{l}3 \\
0 \\
1 \\
0 \\
2\end{array}$ & $\begin{array}{r}15 \\
0 \\
10 \\
0 \\
9\end{array}$ & $\begin{array}{r}102 \\
N \\
39 \\
U \\
63\end{array}$ & $\begin{array}{r}151 \\
N \\
62 \\
U \\
89\end{array}$ & $\begin{array}{l}11 \\
3 \\
3 \\
5\end{array}$ & $\begin{array}{r}21 \\
2 \\
2 \\
10 \\
5\end{array}$ & $\begin{array}{r}35 \\
7 \\
14 \\
22 \\
9\end{array}$ & $\begin{array}{r}580 \\
81 \\
82 \\
287 \\
130\end{array}$ & $\begin{array}{r}541 \\
74 \\
35 \\
340 \\
92\end{array}$ & $\frac{40}{-}$ & $\begin{array}{r}103 \\
0 \\
0 \\
0 \\
103\end{array}$ & $\begin{array}{r}183 \\
0 \\
0 \\
0 \\
183\end{array}$ & $\begin{array}{r}\frac{3,051}{-} \\
\frac{-}{3,051}\end{array}$ & $\begin{array}{r}\frac{3,062}{-} \\
\frac{-}{3,062}\end{array}$ \\
\hline $\begin{array}{l}\text { E.N. Central } \\
\text { Illinois } \\
\text { Indiana } \\
\text { Michigan } \\
\text { Ohio } \\
\text { Wisconsin }\end{array}$ & $\begin{array}{l}\frac{2}{-} \\
\frac{-}{2} \\
\mathrm{~N}\end{array}$ & $\begin{array}{r}11 \\
1 \\
2 \\
0 \\
6 \\
0\end{array}$ & $\begin{array}{r}41 \\
3 \\
21 \\
4 \\
32 \\
0\end{array}$ & $\begin{array}{r}386 \\
12 \\
103 \\
15 \\
256 \\
\mathrm{~N}\end{array}$ & $\begin{array}{r}420 \\
17 \\
133 \\
28 \\
242 \\
\mathrm{~N}\end{array}$ & $\begin{array}{l}-8 \\
- \\
6 \\
2 \\
-\end{array}$ & $\begin{array}{r}18 \\
9 \\
1 \\
2 \\
4 \\
1\end{array}$ & $\begin{array}{r}38 \\
23 \\
4 \\
19 \\
11 \\
3\end{array}$ & $\begin{array}{r}445 \\
214 \\
32 \\
62 \\
114 \\
23\end{array}$ & $\begin{array}{r}476 \\
260 \\
37 \\
40 \\
119 \\
20\end{array}$ & $\begin{array}{r}48 \\
N \\
9 \\
39 \\
\end{array}$ & $\begin{array}{r}213 \\
1 \\
0 \\
102 \\
82 \\
10\end{array}$ & $\begin{array}{r}576 \\
5 \\
347 \\
174 \\
420 \\
41\end{array}$ & $\begin{array}{r}9,736 \\
12 \\
N \\
2,976 \\
6,328 \\
420\end{array}$ & $\begin{array}{r}3,718 \\
59 \\
70 \\
2,356 \\
943 \\
290\end{array}$ \\
\hline $\begin{array}{l}\text { W.N. Central } \\
\text { lowa } \\
\text { Kansas } \\
\text { Minnesota } \\
\text { Missouri } \\
\text { Nebraska }^{\dagger} \\
\text { North Dakota } \\
\text { South Dakota }\end{array}$ & $\begin{array}{l}2 \\
N \\
N \\
2 \\
- \\
-\end{array}$ & $\begin{array}{l}1 \\
0 \\
0 \\
0 \\
1 \\
0 \\
0 \\
0\end{array}$ & $\begin{array}{r}191 \\
0 \\
0 \\
191 \\
3 \\
0 \\
1 \\
0\end{array}$ & $\begin{array}{r}31 \\
\mathrm{~N} \\
\mathrm{~N} \\
31 \\
- \\
-\end{array}$ & $\begin{array}{r}28 \\
N \\
N \\
22 \\
2 \\
1 \\
3\end{array}$ & $\begin{array}{l}2 \\
- \\
- \\
2 \\
- \\
-\end{array}$ & $\begin{array}{l}4 \\
0 \\
0 \\
1 \\
3 \\
0 \\
0 \\
0\end{array}$ & $\begin{array}{l}9 \\
3 \\
2 \\
3 \\
8 \\
1 \\
1 \\
1\end{array}$ & $\begin{array}{r}130 \\
9 \\
12 \\
16 \\
92 \\
1 \\
- \\
-\end{array}$ & $\begin{array}{r}147 \\
4 \\
12 \\
47 \\
81 \\
3 \\
-\end{array}$ & $\begin{array}{l}3 \\
\mathrm{~N} \\
- \\
-3 \\
- \\
-\end{array}$ & $\begin{array}{r}22 \\
0 \\
0 \\
0 \\
16 \\
0 \\
0 \\
1\end{array}$ & $\begin{array}{r}84 \\
0 \\
0 \\
0 \\
82 \\
0 \\
25 \\
12\end{array}$ & $\begin{array}{r}983 \\
\mathrm{~N} \\
- \\
-\overline{926} \\
-\overline{25} \\
32\end{array}$ & $\begin{array}{r}241 \\
\mathrm{~N} \\
- \\
153 \\
\frac{-}{12} \\
76\end{array}$ \\
\hline $\begin{array}{l}\text { S. Atlantic } \\
\text { Delaware } \\
\text { District of Columbia } \\
\text { Florida } \\
\text { Georgia } \\
\text { Maryland }^{\dagger} \\
\text { North Carolina } \\
\text { South Carolina }^{\dagger} \\
\text { Virginia }^{\dagger} \\
\text { West Virginia }^{\text {Westia }}\end{array}$ & $\begin{array}{r}19 \\
\frac{1}{1} \\
14 \\
2 \\
\frac{\mathrm{N}}{\mathrm{N}} \\
2\end{array}$ & $\begin{array}{r}24 \\
0 \\
0 \\
13 \\
7 \\
0 \\
0 \\
0 \\
0 \\
1\end{array}$ & $\begin{array}{r}53 \\
2 \\
3 \\
36 \\
29 \\
0 \\
0 \\
0 \\
0 \\
14\end{array}$ & $\begin{array}{r}841 \\
\overline{20} \\
458 \\
281 \\
-\mathrm{N} \\
\overline{\mathrm{N}} \\
82\end{array}$ & $\begin{array}{r}683 \\
1 \\
12 \\
360 \\
229 \\
\mathrm{~N} \\
\bar{N} \\
81\end{array}$ & $\begin{array}{r}28 \\
1 \\
2 \\
16 \\
- \\
2 \\
1 \\
1 \\
5 \\
-\end{array}$ & $\begin{array}{r}43 \\
0 \\
1 \\
14 \\
8 \\
5 \\
5 \\
1 \\
2 \\
0\end{array}$ & $\begin{array}{r}186 \\
2 \\
9 \\
29 \\
147 \\
19 \\
17 \\
7 \\
12 \\
1\end{array}$ & $\begin{array}{r}1,007 \\
14 \\
57 \\
382 \\
128 \\
163 \\
150 \\
39 \\
73 \\
1\end{array}$ & $\begin{array}{r}1,027 \\
6 \\
61 \\
382 \\
171 \\
163 \\
136 \\
31 \\
75 \\
2\end{array}$ & $\begin{array}{l}16 \\
- \\
- \\
- \\
- \\
2 \\
8 \\
6\end{array}$ & $\begin{array}{r}90 \\
1 \\
0 \\
0 \\
0 \\
0 \\
0 \\
16 \\
27 \\
26\end{array}$ & $\begin{array}{r}860 \\
5 \\
5 \\
0 \\
0 \\
0 \\
0 \\
53 \\
812 \\
70\end{array}$ & $\begin{array}{r}2,830 \\
43 \\
21 \\
- \\
- \\
- \\
- \\
726 \\
1,044 \\
996\end{array}$ & $\begin{array}{r}1,266 \\
22 \\
19 \\
- \\
- \\
- \\
- \\
346 \\
217 \\
662\end{array}$ \\
\hline $\begin{array}{l}\text { E.S. Central } \\
\text { Alabama }^{\dagger} \\
\text { Kentucky } \\
\text { Mississippi } \\
\text { Tennessee }^{\dagger}\end{array}$ & $\begin{array}{l}\bar{N} \\
- \\
-\end{array}$ & $\begin{array}{l}3 \\
0 \\
0 \\
0 \\
2\end{array}$ & $\begin{array}{r}13 \\
0 \\
5 \\
0 \\
13\end{array}$ & $\begin{array}{r}122 \\
N \\
23 \\
99\end{array}$ & $\begin{array}{r}122 \\
N \\
22 \\
1 \\
99\end{array}$ & $\frac{9}{\frac{2}{7}}$ & $\begin{array}{r}11 \\
3 \\
1 \\
0 \\
4\end{array}$ & $\begin{array}{r}21 \\
12 \\
8 \\
6 \\
12\end{array}$ & $\begin{array}{r}326 \\
124 \\
35 \\
31 \\
136\end{array}$ & $\begin{array}{r}244 \\
89 \\
19 \\
28 \\
108\end{array}$ & $\begin{array}{r}3 \\
3 \\
N \\
N\end{array}$ & $\begin{array}{l}0 \\
0 \\
0 \\
0 \\
0\end{array}$ & $\begin{array}{r}70 \\
70 \\
0 \\
0 \\
0\end{array}$ & $\begin{array}{r}65 \\
65 \\
N \\
N\end{array}$ & $\begin{array}{l}7 \\
7 \\
\mathrm{~N} \\
\mathrm{~N}\end{array}$ \\
\hline $\begin{array}{l}\text { W.S. Central } \\
\text { Arkansas } \\
\text { Louisiana } \\
\text { Oklahoma } \\
\text { Texas }^{\dagger}\end{array}$ & $\begin{array}{l}- \\
\overline{-} \\
\mathrm{N}\end{array}$ & $\begin{array}{l}0 \\
0 \\
0 \\
0 \\
0\end{array}$ & $\begin{array}{l}4 \\
3 \\
4 \\
0 \\
0\end{array}$ & $\begin{array}{l}11 \\
11 \\
\mathrm{~N} \\
\mathrm{~N}\end{array}$ & $\begin{array}{r}95 \\
12 \\
83 \\
N \\
N\end{array}$ & $\begin{array}{r}29 \\
2 \\
7 \\
3 \\
17\end{array}$ & $\begin{array}{r}25 \\
0 \\
4 \\
1 \\
18\end{array}$ & $\begin{array}{r}40 \\
6 \\
17 \\
6 \\
29\end{array}$ & $\begin{array}{r}753 \\
38 \\
109 \\
39 \\
567\end{array}$ & $\begin{array}{r}678 \\
30 \\
144 \\
21 \\
483\end{array}$ & $\begin{array}{r}182 \\
37 \\
- \\
145\end{array}$ & $\begin{array}{r}206 \\
5 \\
0 \\
0 \\
202\end{array}$ & $\begin{array}{r}1,757 \\
110 \\
7 \\
0 \\
1,647\end{array}$ & $\begin{array}{r}7,209 \\
553 \\
- \\
6,656\end{array}$ & $\begin{array}{r}3,102 \\
\frac{108}{-} \\
2,994\end{array}$ \\
\hline $\begin{array}{l}\text { Mountain } \\
\text { Arizona } \\
\text { Colorado } \\
\text { Idaho }^{\dagger} \\
\text { Montana } \\
\text { Nevada }^{\dagger} \\
\text { New Mexico } \\
\text { Utah } \\
\text { Wyoming }\end{array}$ & $\begin{array}{l}3 \\
N \\
N \\
N \\
- \\
- \\
2 \\
1\end{array}$ & $\begin{array}{l}1 \\
0 \\
0 \\
0 \\
0 \\
0 \\
0 \\
0 \\
0\end{array}$ & $\begin{array}{r}27 \\
0 \\
0 \\
0 \\
1 \\
27 \\
1 \\
8 \\
3\end{array}$ & $\begin{array}{r}65 \\
N \\
N \\
N \\
4 \\
1 \\
28 \\
32\end{array}$ & $\begin{array}{r}39 \\
N \\
N \\
N \\
\frac{2}{2} \\
\frac{17}{20}\end{array}$ & $\begin{array}{l}3 \\
3 \\
- \\
- \\
- \\
- \\
-\end{array}$ & $\begin{array}{l}7 \\
4 \\
1 \\
0 \\
0 \\
1 \\
1 \\
0 \\
0\end{array}$ & $\begin{array}{r}17 \\
13 \\
3 \\
1 \\
1 \\
12 \\
5 \\
1 \\
0\end{array}$ & $\begin{array}{r}200 \\
97 \\
20 \\
2 \\
1 \\
44 \\
34 \\
2 \\
-\end{array}$ & $\begin{array}{r}225 \\
72 \\
26 \\
18 \\
5 \\
68 \\
29 \\
7 \\
-\end{array}$ & $\begin{array}{l}4 \\
- \\
- \\
- \\
- \\
-\end{array}$ & $\begin{array}{r}52 \\
0 \\
33 \\
0 \\
0 \\
0 \\
3 \\
10 \\
0\end{array}$ & $\begin{array}{r}138 \\
0 \\
76 \\
0 \\
0 \\
2 \\
34 \\
55 \\
8\end{array}$ & $\begin{array}{r}1,777 \\
939 \\
- \\
- \\
4 \\
280 \\
526 \\
28\end{array}$ & $\begin{array}{r}1,735 \\
1,181 \\
- \\
- \\
- \\
150 \\
359 \\
45\end{array}$ \\
\hline $\begin{array}{l}\text { Pacific } \\
\text { Alaska } \\
\text { California } \\
\text { Hawaii } \\
\text { Oregon }^{\dagger} \\
\text { Washington }^{-}\end{array}$ & $\begin{array}{l}- \\
\bar{N} \\
\bar{N} \\
N\end{array}$ & $\begin{array}{l}0 \\
0 \\
0 \\
0 \\
0 \\
0\end{array}$ & $\begin{array}{l}0 \\
0 \\
0 \\
0 \\
0 \\
0\end{array}$ & $\begin{array}{l}- \\
\frac{N}{N} \\
N \\
N\end{array}$ & $\begin{array}{l}-\bar{C} \\
\frac{N}{N} \\
N\end{array}$ & $\begin{array}{l}\frac{11}{3} \\
\frac{-}{8}\end{array}$ & $\begin{array}{r}33 \\
0 \\
27 \\
0 \\
0 \\
3\end{array}$ & $\begin{array}{r}49 \\
4 \\
42 \\
2 \\
2 \\
6 \\
11\end{array}$ & $\begin{array}{r}762 \\
5 \\
628 \\
11 \\
9 \\
109\end{array}$ & $\begin{array}{r}961 \\
5 \\
869 \\
4 \\
16 \\
67\end{array}$ & $\begin{array}{l}- \\
- \\
N \\
N \\
N\end{array}$ & $\begin{array}{l}0 \\
0 \\
0 \\
0 \\
0 \\
0\end{array}$ & $\begin{array}{l}0 \\
0 \\
0 \\
0 \\
0 \\
0\end{array}$ & $\begin{array}{l}- \\
- \\
N \\
N \\
N\end{array}$ & $\begin{array}{l}- \\
- \\
N \\
N \\
N\end{array}$ \\
\hline $\begin{array}{l}\text { American Samoa } \\
\text { C.N.M.I. } \\
\text { Guam } \\
\text { Puerto Rico } \\
\text { U.S. Virgin Islands }\end{array}$ & $\begin{array}{l}- \\
\bar{N} \\
-\end{array}$ & $\begin{array}{l}0 \\
0 \\
0 \\
0 \\
0\end{array}$ & $\begin{array}{l}0 \\
0 \\
0 \\
0 \\
0\end{array}$ & $\begin{array}{l}- \\
\bar{N} \\
-\end{array}$ & $\begin{array}{l}- \\
\bar{N} \\
-\end{array}$ & $\begin{array}{l}U \\
U \\
- \\
-\end{array}$ & $\begin{array}{l}0 \\
0 \\
0 \\
3 \\
0\end{array}$ & $\begin{array}{r}0 \\
0 \\
0 \\
16 \\
0\end{array}$ & $\frac{U}{U} \frac{U}{54}$ & $\begin{array}{r}U \\
U \\
3 \\
126 \\
-\end{array}$ & $\begin{array}{l}U \\
U \\
- \\
-\end{array}$ & $\begin{array}{l}0 \\
0 \\
2 \\
8 \\
0\end{array}$ & $\begin{array}{r}0 \\
0 \\
12 \\
47 \\
0\end{array}$ & $\frac{U}{U} \frac{U}{178}$ & $\begin{array}{r}U \\
U \\
373 \\
443 \\
-\end{array}$ \\
\hline
\end{tabular}

C.N.M.I.: Commonwealth of Northern Mariana Islands.

U: Unavailable - No reported cases N: Not

* Incidence data for reporting years 2005 and 2006 are provisiona

Cum: Cumulative year-to-date counts.

Med: Median

Max: Maximum.

${ }^{\dagger}$ Contains data reported through the National Electronic Disease Surveillance System (NEDSS). 
TABLE II. (Continued) Provisional cases of selected notifiable diseases, United States, weeks ending July 15, 2006, and July 16, 2005 (28th Week)*

\begin{tabular}{|c|c|c|c|c|c|c|c|c|c|c|}
\hline \multirow[b]{4}{*}{ Reporting area } & \multicolumn{9}{|c|}{ West Nile virus disease $^{\dagger}$} & \multirow{4}{*}{$\begin{array}{l} \\
\text { Cum } \\
2005 \\
\end{array}$} \\
\hline & \multicolumn{5}{|c|}{ Neuroinvasive } & \multicolumn{4}{|c|}{ Non-neuroinvasive } & \\
\hline & \multirow{2}{*}{$\begin{array}{c}\text { Current } \\
\text { week }\end{array}$} & \multicolumn{2}{|c|}{$\begin{array}{l}\text { Previous } \\
52 \text { weeks }\end{array}$} & \multirow{2}{*}{$\begin{array}{l}\text { Cum } \\
2006\end{array}$} & & Current & & & Cum & \\
\hline & & Med & Max & & 2005 & week & Med & Max & 2006 & \\
\hline United States & - & 1 & 155 & 9 & 75 & - & 0 & 203 & 5 & 159 \\
\hline New England & - & 0 & 3 & - & - & - & 0 & 2 & - & - \\
\hline Connecticut & - & 0 & 2 & - & - & - & 0 & 1 & - & - \\
\hline Maine ${ }^{\S}$ & - & 0 & $\overline{0}$ & - & - & - & 0 & 0 & - & - \\
\hline Massachusetts & - & 0 & 3 & - & - & - & 0 & 1 & - & - \\
\hline New Hampshire & - & 0 & 0 & - & - & - & 0 & 0 & - & - \\
\hline Rhode Island & - & 0 & 1 & - & - & - & 0 & 0 & - & - \\
\hline Vermont ${ }^{\S}$ & - & 0 & 0 & - & - & - & 0 & 0 & - & - \\
\hline Mid. Atlantic & - & 0 & 10 & - & 1 & - & 0 & 4 & - & 2 \\
\hline New Jersey & - & 0 & 1 & - & - & - & 0 & 2 & - & - \\
\hline New York (Upstate) & - & 0 & 7 & - & - & - & 0 & 2 & - & - \\
\hline New York City & - & 0 & 2 & - & - & - & 0 & 2 & - & - \\
\hline Pennsylvania & - & 0 & 3 & - & 1 & - & 0 & 2 & - & 2 \\
\hline E.N. Central & - & 0 & 39 & - & 6 & - & 0 & 18 & - & 1 \\
\hline Illinois & - & 0 & 25 & - & 2 & - & 0 & 16 & - & - \\
\hline Indiana & - & 0 & 2 & - & 1 & - & 0 & 1 & - & - \\
\hline Michigan & - & 0 & 14 & - & - & - & 0 & 3 & - & - \\
\hline Ohio & - & 0 & 9 & - & 2 & - & 0 & 4 & - & - \\
\hline Wisconsin & - & 0 & 3 & - & 1 & - & 0 & 2 & - & 1 \\
\hline W.N. Central & - & 0 & 26 & 3 & 7 & - & 0 & 80 & 4 & 29 \\
\hline lowa & - & 0 & 3 & - & - & - & 0 & 5 & 1 & - \\
\hline Kansas & - & 0 & 3 & - & 1 & $\mathrm{~N}$ & 0 & 0 & $\mathrm{~N}$ & $\mathrm{~N}$ \\
\hline Minnesota & - & 0 & 5 & - & 2 & - & 0 & 5 & - & 3 \\
\hline Missouri & - & 0 & 4 & 1 & 1 & - & 0 & 3 & - & - \\
\hline Nebraska ${ }^{\S}$ & - & 0 & 9 & 1 & 1 & - & 0 & 24 & 1 & 4 \\
\hline North Dakota & - & 0 & 4 & - & - & - & 0 & 15 & - & 4 \\
\hline South Dakota & - & 0 & 7 & 1 & 2 & - & 0 & 33 & 2 & 18 \\
\hline S. Atlantic & - & 0 & 6 & - & 2 & - & 0 & 4 & - & 2 \\
\hline Delaware & - & 0 & 1 & - & - & - & 0 & 0 & - & - \\
\hline District of Columbia & - & 0 & 1 & - & - & - & 0 & 1 & - & - \\
\hline $\begin{array}{l}\text { Florida } \\
\text { Sula }\end{array}$ & - & 0 & 2 & - & 2 & - & 0 & 4 & - & 1 \\
\hline Georgia & - & 0 & 3 & - & - & - & 0 & 3 & - & 1 \\
\hline Maryland $\$$ & - & 0 & 2 & - & - & - & 0 & 1 & - & - \\
\hline North Carolina & - & 0 & 1 & - & - & - & 0 & 1 & - & - \\
\hline South Carolina ${ }^{\S}$ & - & 0 & 1 & - & - & - & 0 & 0 & - & - \\
\hline Virginia ${ }^{\S}$ & - & 0 & 0 & - & - & - & 0 & 1 & - & - \\
\hline West Virginia & - & 0 & 0 & - & - & $\mathrm{N}$ & 0 & 0 & $\mathrm{~N}$ & $\mathrm{~N}$ \\
\hline E.S. Central & - & 0 & 10 & 2 & 2 & - & 0 & 5 & - & 3 \\
\hline Alabama $\$$ & - & 0 & 1 & - & - & - & 0 & 2 & - & - \\
\hline Kentucky & - & 0 & 1 & - & - & - & 0 & 0 & - & - \\
\hline Mississippi & - & 0 & 9 & 2 & 2 & - & 0 & 5 & - & 3 \\
\hline Tennessee ${ }^{\S}$ & - & 0 & 3 & - & - & - & 0 & 1 & - & - \\
\hline W.S. Central & - & 0 & 32 & 2 & 19 & - & 0 & 22 & - & 10 \\
\hline Arkansas & - & 0 & 3 & - & - & - & 0 & 2 & - & 2 \\
\hline Louisiana & - & 0 & 20 & - & 5 & - & 0 & 9 & - & 3 \\
\hline Oklahoma & - & 0 & 6 & - & 1 & - & 0 & 3 & - & - \\
\hline Texas ${ }^{\S}$ & - & 0 & 16 & 2 & 13 & - & 0 & 13 & - & 5 \\
\hline Mountain & - & 0 & 16 & 1 & 6 & - & 0 & 39 & 1 & 25 \\
\hline Arizona & - & 0 & 8 & - & 4 & - & 0 & 8 & - & 10 \\
\hline Colorado & - & 0 & 5 & 1 & - & - & 0 & 13 & - & 11 \\
\hline Idaho§ & - & 0 & 2 & - & - & - & 0 & 3 & 1 & - \\
\hline Montana & - & 0 & 3 & - & - & - & 0 & 9 & - & - \\
\hline $\mathrm{Nevada}^{\$}$ & - & 0 & 3 & - & 1 & - & 0 & 8 & - & 2 \\
\hline New Mexico§ & - & 0 & 3 & - & 1 & - & 0 & 4 & - & 2 \\
\hline Utah & - & 0 & 6 & - & - & - & 0 & 8 & - & - \\
\hline Wyoming & - & 0 & 2 & - & - & - & 0 & 1 & - & - \\
\hline Pacific & - & 0 & 50 & 1 & 32 & - & 0 & 90 & - & 87 \\
\hline Alaska & - & 0 & 0 & - & - & - & 0 & 0 & - & - \\
\hline California & - & 0 & 50 & 1 & 32 & - & 0 & 89 & - & 86 \\
\hline Hawaii & - & 0 & 0 & - & - & - & 0 & 0 & - & - \\
\hline Oregon ${ }^{\S}$ & - & 0 & 1 & - & - & - & 0 & 2 & - & 1 \\
\hline Washington & - & 0 & 0 & - & - & - & 0 & 0 & - & - \\
\hline American Samoa & $\mathrm{U}$ & 0 & 0 & $\mathrm{U}$ & $u$ & $\mathrm{U}$ & 0 & 0 & $\mathrm{U}$ & $\mathrm{u}$ \\
\hline C.N.M.I. & U & 0 & 0 & U & u & $u$ & 0 & 0 & u & $u$ \\
\hline Guam & - & 0 & 0 & - & - & - & 0 & 0 & - & - \\
\hline Puerto Rico & - & 0 & 0 & - & - & - & 0 & 0 & - & - \\
\hline U.S. Virgin Islands & - & 0 & 0 & - & - & - & 0 & 0 & - & - \\
\hline
\end{tabular}

C.N.M.I.: Commonwealth of Northern Mariana Islands.

U: Unavailable. $\quad$ - No reported cases. N: Not notifiable.

* Incidence data for reporting years 2005 and 2006 are provisional.

Cum: Cumulative year-to-date counts.

Med: Median

Max: Maximum.

Updated weekly from reports to the Division of Vector-Borne Infectious Diseases, National Center for Infectious Diseases (ArboNet Surveillance).

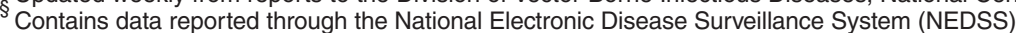


TABLE III. Deaths in 122 U.S. cities, ${ }^{*}$ week ending July 15, 2006 (28th Week)

\begin{tabular}{|c|c|c|c|c|c|c|c|c|c|c|c|c|c|c|c|}
\hline \multirow[b]{2}{*}{ Reporting Area } & \multicolumn{6}{|c|}{ All causes, by age (years) } & \multirow[b]{2}{*}{$\begin{array}{l}\text { P\&I }^{\dagger} \\
\text { Total }\end{array}$} & \multirow[b]{2}{*}{ Reporting Area } & \multicolumn{6}{|c|}{ All causes, by age (years) } & \multirow[b]{2}{*}{$\begin{array}{l}\text { P\&I }{ }^{\dagger} \\
\text { Total }\end{array}$} \\
\hline & $\begin{array}{c}\text { All } \\
\text { Ages }\end{array}$ & $\geq 65$ & $45-64$ & $25-44$ & $1-24$ & $<1$ & & & $\begin{array}{c}\text { All } \\
\text { Ages }\end{array}$ & $\geq 65$ & $45-64$ & $25-44$ & $1-24$ & $<1$ & \\
\hline New England & 487 & 342 & 94 & 30 & 5 & 16 & 31 & S. Atlantic & 1,171 & 702 & 312 & 89 & 38 & 29 & 68 \\
\hline Boston, MA & 126 & 77 & 29 & 12 & 1 & 7 & 7 & Atlanta, GA & 177 & 99 & 50 & 20 & 6 & 2 & 11 \\
\hline Bridgeport, CT & 24 & 20 & 4 & - & - & - & 1 & Baltimore, MD & 187 & 106 & 59 & 10 & 4 & 8 & 16 \\
\hline Cambridge, MA & 13 & 11 & 2 & - & - & - & 4 & Charlotte, NC & 100 & 60 & 29 & 5 & 4 & 2 & 6 \\
\hline Fall River, MA & 17 & 12 & 1 & 4 & - & - & - & Jacksonville, FL & U & U & U & $U$ & $U$ & $\bar{U}$ & U \\
\hline Hartford, CT & 44 & 27 & 8 & 3 & 2 & 4 & 4 & Miami, FL & 114 & 68 & 35 & 5 & 3 & 3 & 3 \\
\hline Lowell, MA & 22 & 16 & 3 & 3 & - & - & - & Norfolk, VA & 74 & 48 & 20 & 1 & 3 & 1 & 2 \\
\hline Lynn, MA & 8 & 7 & 1 & - & - & - & - & Richmond, VA & 69 & 42 & 17 & 5 & 3 & 2 & 5 \\
\hline New Bedford, MA & 23 & 19 & 3 & - & - & 1 & 1 & Savannah, GA & 77 & 51 & 17 & 7 & 2 & - & 5 \\
\hline New Haven, CT & 22 & 16 & 4 & - & 1 & 1 & 2 & St. Petersburg, FL & 52 & 34 & 6 & 4 & 3 & 5 & 5 \\
\hline Providence, RI & 65 & 45 & 14 & 4 & 1 & 1 & - & Tampa, FL & 199 & 122 & 50 & 21 & 5 & 1 & 12 \\
\hline Somerville, MA & 5 & 5 & - & - & - & - & - & Washington, D.C. & 105 & 61 & 26 & 8 & 5 & 5 & 2 \\
\hline Springfield, MA & 33 & 21 & 9 & 3 & - & - & 3 & Wilmington, DE & 17 & 11 & 3 & 3 & - & - & 1 \\
\hline Waterbury, CT & 24 & 20 & 4 & - & - & - & 2 & & 814 & 498 & 209 & & 37 & 13 & 47 \\
\hline Worcester, MA & 61 & 46 & 12 & 1 & - & 2 & 7 & $\begin{array}{l}\text { E.S. Central } \\
\text { Birmingham, AL }\end{array}$ & $\begin{array}{l}814 \\
183\end{array}$ & $\begin{array}{l}498 \\
126\end{array}$ & $\begin{array}{r}209 \\
33\end{array}$ & $\begin{array}{l}57 \\
12\end{array}$ & $\begin{array}{r}31 \\
9\end{array}$ & 3 & $\begin{array}{l}47 \\
13\end{array}$ \\
\hline Mid. Atlantic & 2,088 & 1,426 & 438 & 128 & 51 & 45 & 104 & Chattanooga, TN & 71 & 40 & 22 & 5 & 3 & 1 & 2 \\
\hline Albany, NY & 35 & 25 & 9 & - & 1 & - & 2 & Knoxville, TN & 84 & 54 & 22 & 6 & 1 & 1 & 5 \\
\hline Allentown, PA & 19 & 16 & 3 & - & - & - & 1 & Lexington, $\mathrm{KY}$ & 75 & 44 & 18 & 6 & 4 & 3 & 2 \\
\hline Buffalo, NY & 66 & 43 & 13 & 4 & 1 & 5 & 2 & Memphis, TN & 129 & 79 & 35 & 8 & 7 & - & 7 \\
\hline Camden, NJ & 25 & 6 & 9 & 3 & 3 & 4 & 1 & Mobile, AL & 56 & 34 & 13 & 5 & 3 & 1 & 4 \\
\hline Elizabeth, NJ & 17 & 12 & 4 & 1 & - & - & 1 & Montgomery, AL & 53 & 34 & 13 & 3 & 3 & - & 2 \\
\hline Erie, PA & 46 & 40 & 4 & 1 & 1 & - & 2 & Nashville, TN & 163 & 87 & 53 & 12 & 7 & 4 & 12 \\
\hline Jersey City, NJ & 37 & 26 & 10 & 1 & - & - & - & W.S. Central & 1,541 & 1,009 & 337 & 114 & 49 & 32 & 51 \\
\hline New York City, NY & 1,102 & 755 & 229 & 67 & 26 & 25 & 52 & $\begin{array}{l}\text { W.S. Central } \\
\text { Austin, TX }\end{array}$ & 82 & 48 & 23 & 7 & $\begin{array}{r}45 \\
2\end{array}$ & $\begin{array}{r}32 \\
2\end{array}$ & 2 \\
\hline Newark, NJ & 42 & 22 & 13 & 7 & - & - & 2 & $\begin{array}{l}\text { Austın, IX } \\
\text { Baton Rouge, LA }\end{array}$ & 58 & 37 & 12 & 7 & 1 & 1 & $\begin{array}{l}2 \\
1\end{array}$ \\
\hline Paterson, NJ & 15 & 9 & 4 & 1 & 1 & - & 1 & $\begin{array}{l}\text { Baton Rouge, LA } \\
\text { Corpus Christi. TX }\end{array}$ & $\begin{array}{l}30 \\
44\end{array}$ & 35 & 6 & 1 & 1 & 1 & 3 \\
\hline Philadelphia, PA & 279 & 164 & 74 & 23 & 9 & 9 & 14 & $\begin{array}{l}\text { Corpus Christi, IX } \\
\text { Dallas, TX }\end{array}$ & $\begin{array}{r}44 \\
210\end{array}$ & 133 & 53 & 14 & 6 & 4 & $\begin{array}{l}3 \\
6\end{array}$ \\
\hline Pittsburgh, PA $\$$ & 27 & 19 & 5 & 3 & - & - & 2 & Dallas, IX & 118 & $\begin{array}{r}130 \\
88\end{array}$ & 20 & 4 & 4 & $\begin{array}{l}4 \\
2\end{array}$ & 2 \\
\hline Reading, PA & 40 & 29 & 6 & 4 & 1 & - & 2 & El Paso, IX & $\begin{array}{r}110 \\
99\end{array}$ & $\begin{array}{l}00 \\
63\end{array}$ & 26 & 6 & - & 4 & 2 \\
\hline Rochester, NY & 140 & 112 & 18 & 5 & 4 & 1 & 6 & $\begin{array}{l}\text { Fort Worth, TX } \\
\text { Houston. TX }\end{array}$ & $\begin{array}{r}99 \\
465\end{array}$ & 276 & 109 & 50 & 17 & $\begin{array}{r}4 \\
13\end{array}$ & 14 \\
\hline Schenectady, NY & 32 & 24 & 7 & 1 & - & - & 5 & $\begin{array}{l}\text { Houston, I X } \\
\text { Little Rock AR }\end{array}$ & $\begin{array}{r}405 \\
89\end{array}$ & 52 & 23 & 7 & 6 & $\begin{array}{r}13 \\
1\end{array}$ & $\begin{array}{r}14 \\
3\end{array}$ \\
\hline Scranton, PA & 26 & 20 & 5 & - & - & 1 & 2 & LItte ROCK, AR & 89 & & U & U & U & 1 & 3 \\
\hline Syracuse, NY & 90 & 65 & 16 & 5 & 4 & - & 5 & New Urleans, LA" & $18 ?$ & 135 & 31 & 0 & 7 & 0 & $\frac{U}{8}$ \\
\hline Trenton, NJ & 15 & 9 & 6 & - & - & - & - & San Antonio, IX & 182 & 135 & 31 & 9 & 7 & - & 8 \\
\hline Utica, NY & 12 & 9 & 2 & 1 & - & - & 1 & Shreveport, LA & $\begin{array}{r}61 \\
133\end{array}$ & $\begin{array}{r}41 \\
101\end{array}$ & $\begin{array}{l}14 \\
20\end{array}$ & 3 & $\overline{5}$ & $\begin{array}{l}3 \\
1\end{array}$ & $\begin{array}{l}5 \\
5\end{array}$ \\
\hline Yonkers, NY & 23 & 21 & 1 & 1 & - & - & 3 & Tulsa, OK & 133 & 101 & 20 & 6 & 5 & 1 & 5 \\
\hline E.N. Central & 1,792 & 1,186 & 418 & 104 & 42 & 42 & 96 & Mountain & 1,110 & 719 & 229 & 93 & 39 & 30 & 61 \\
\hline Akron, $\mathrm{OH}$ & 42 & 35 & 6 & 1 & - & - & 1 & Albuquerque, NM & 120 & 70 & 27 & 13 & 4 & 6 & 9 \\
\hline Canton, $\mathrm{OH}$ & 37 & 28 & 4 & 2 & 1 & 2 & 3 & Boise, ID & 52 & 33 & 14 & 4 & - & 1 & 6 \\
\hline Chicago, IL & U & U & $\mathrm{U}$ & $\mathrm{U}$ & U & $\mathrm{U}$ & $U$ & Colorado Springs, CO & 72 & 45 & 18 & 4 & 3 & 2 & 3 \\
\hline Cincinnati, $\mathrm{OH}$ & 73 & 47 & 13 & 2 & 3 & 8 & 9 & Denver, $\mathrm{CO}$ & 85 & 45 & 22 & 5 & 6 & 7 & 4 \\
\hline Cleveland, $\mathrm{OH}$ & 219 & 145 & 51 & 16 & 4 & 3 & - & Las Vegas, NV & 237 & 157 & 53 & 16 & 9 & 2 & 10 \\
\hline Columbus, $\mathrm{OH}$ & 196 & 133 & 46 & 9 & 2 & 6 & 13 & Ogden, UT & 26 & 19 & 2 & 2 & 1 & 2 & 1 \\
\hline Dayton, $\mathrm{OH}$ & 161 & 115 & 36 & 8 & - & 2 & 9 & Phoenix, AZ & 171 & 101 & 41 & 16 & 9 & 4 & 8 \\
\hline Detroit, MI & 179 & 86 & 59 & 21 & 9 & 4 & 8 & Pueblo, CO & 37 & 32 & 2 & 3 & - & - & 4 \\
\hline Evansville, IN & 49 & 34 & 11 & 3 & 1 & - & 2 & Salt Like City, UT & 147 & 109 & 21 & 11 & 3 & 3 & 9 \\
\hline Fort Wayne, IN & 79 & 61 & 13 & 3 & 2 & - & $\begin{array}{l}2 \\
6\end{array}$ & Tucson, AZ & 163 & 108 & 29 & 19 & 4 & 3 & 7 \\
\hline Gary, IN & 18 & 6 & 7 & 3 & 1 & 1 & - & Pacific & 1,832 & 1,239 & 412 & 107 & 45 & 28 & 126 \\
\hline Grand Rapids, MI & 65 & 44 & 15 & 3 & 2 & 1 & 6 & Berkeley, CA & 12 & 7 & 4 & - & - & 1 & - \\
\hline Indianapolis, IN & 213 & 126 & 60 & 11 & 9 & 7 & 16 & Fresno, CA & 193 & 129 & 42 & 16 & 6 & - & 10 \\
\hline Lansing, MI & 52 & 43 & 9 & - & - & - & 3 & Glendale, CA & 21 & 18 & 3 & - & - & - & 3 \\
\hline Milwaukee, WI & 101 & 61 & 28 & 9 & 1 & 2 & 10 & Honolulu, HI & 59 & 45 & 6 & 7 & - & 1 & 一 \\
\hline Peoria, IL & 46 & 30 & 12 & 1 & 2 & 1 & 1 & Long Beach, CA & 59 & 39 & 14 & 3 & 1 & 2 & 7 \\
\hline Rockford, IL & 60 & 44 & 12 & 2 & - & 2 & 3 & Los Angeles, CA & 361 & 259 & 77 & 15 & 6 & 4 & 27 \\
\hline South Bend, IN & 61 & 43 & 12 & 4 & 2 & - & - & Pasadena, CA & 29 & 21 & 3 & 1 & 3 & 1 & 3 \\
\hline Toledo, $\mathrm{OH}$ & 89 & 61 & 17 & 6 & 2 & 3 & 6 & Portland, OR & 135 & 77 & 39 & 12 & 3 & 4 & 8 \\
\hline Youngstown, $\mathrm{OH}$ & 52 & 44 & 7 & - & 1 & - & - & Sacramento, CA & 195 & 131 & 44 & 12 & 6 & 2 & 13 \\
\hline W.N. Central & 578 & 365 & 122 & 45 & 25 & 19 & 29 & San Diego, CA & 162 & 106 & 37 & 11 & 3 & 4 & 16 \\
\hline Des Moines, IA & - & - & - & - & - & - & - & San Francisco, CA & 112 & 74 & 27 & 8 & 1 & 2 & 10 \\
\hline Duluth, MN & 31 & 22 & 8 & - & 1 & - & - & San Jose, CA & 188 & 146 & 32 & 4 & 3 & 3 & 10 \\
\hline Kansas City, KS & 42 & 25 & 11 & 3 & 2 & 1 & 4 & Santa Cruz, CA & 23 & 14 & 5 & 2 & 2 & - & - \\
\hline Kansas City, MO & 92 & 61 & 14 & 6 & 5 & 6 & 4 & Seattle, WA & 123 & 69 & 40 & 6 & 5 & 3 & 6 \\
\hline Lincoln, NE & 42 & 31 & 7 & 1 & 3 & - & 1 & Spokane, WA & 72 & 47 & 17 & 4 & 3 & 1 & 9 \\
\hline Minneapolis, MN & 62 & 35 & 11 & 8 & 5 & 3 & 5 & Tacoma, WA & 88 & 57 & 22 & 6 & 3 & 一 & 4 \\
\hline Omaha, NE & 104 & 69 & 18 & 12 & 2 & 3 & 5 & Total & $11,413^{\star *}$ & 7,486 & 2,571 & 767 & 331 & 254 & 613 \\
\hline St. Louis, MO & 79 & 40 & 27 & 5 & 4 & 2 & 6 & & & & & & & & \\
\hline St. Paul, MN & 49 & 30 & 12 & 4 & 1 & 2 & 2 & & & & & & & & \\
\hline Wichita, KS & 77 & 52 & 14 & 6 & 2 & 2 & 2 & & & & & & & & \\
\hline
\end{tabular}

U: Unavailable. - No reported cases.

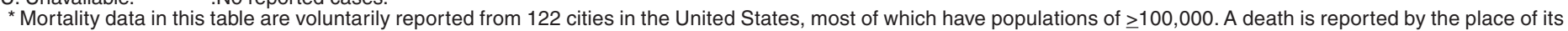
occurrence and by the week that the death certificate was filed. Fetal deaths are not included.

† Pneumonia and influenza.

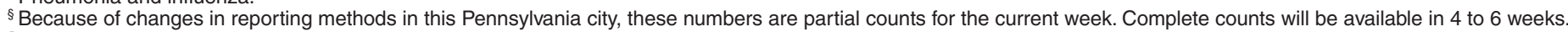

"Because of Hurricane Katrina, weekly reporting of deaths has been temporarily disrupted.

** Total includes unknown ages. 
FIGURE I. Selected notifiable disease reports, United States, comparison of provisional 4-week totals July 15, 2006, with historical data

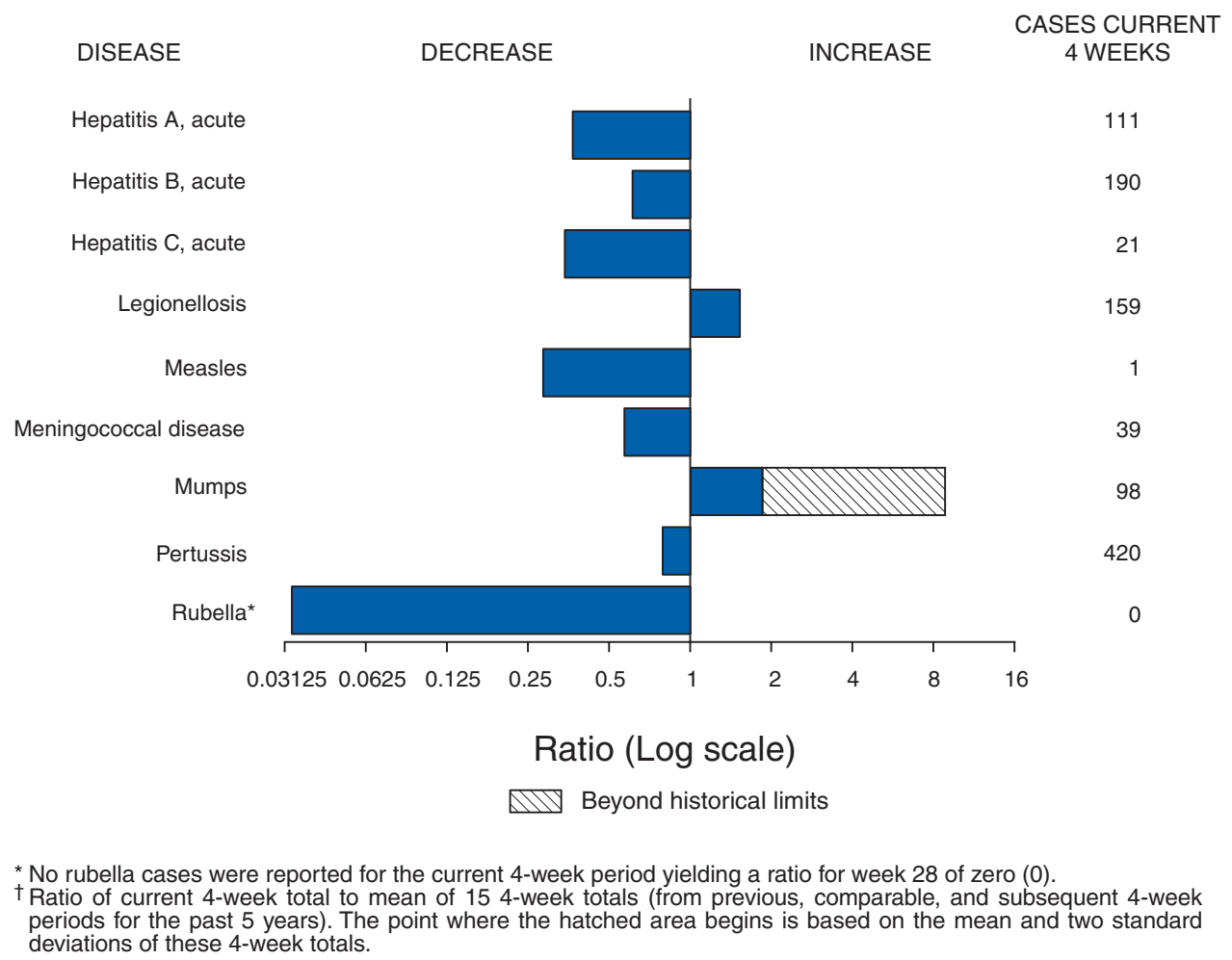

Notifiable Disease Morbidity and 122 Cities Mortality Data Team Patsy A. Hall

Deborah A. Adams Rosaline Dhara

Willie J. Anderson Vernitta Love

Lenee Blanton Pearl C. Sharp 
The Morbidity and Mortality Weekly Report (MMWR) Series is prepared by the Centers for Disease Control and Prevention (CDC) and is available free of charge in electronic format. To receive an electronic copy each week, send an e-mail message to listserv@listserv.cdc.gov. The body content should read SUBscribe mmwrtoc. Electronic copy also is available from CDC's Internet server at http://www.cdc.gov/mmwr or from CDC's file transfer protocol server at $f t p: / / f t p . c d c$. gov/pub/ publications/mmwr. Paper copy subscriptions are available through the Superintendent of Documents, U.S. Government Printing Office, Washington, DC 20402; telephone 202-512-1800.

Data in the weekly MMWR are provisional, based on weekly reports to CDC by state health departments. The reporting week concludes at close of business on Friday; compiled data on a national basis are officially released to the public on the following Friday. Data are compiled in the National Center for Public Health Informatics, Division of Integrated Surveillance Systems and Services. Address all inquiries about the MMWR Series, including material to be considered for publication, to Editor, MMWR Series, Mailstop E-90, CDC, 1600 Clifton Rd., N.E., Atlanta, GA 30333 or to www.mmwrq@cdc.gov.

All material in the MMWR Series is in the public domain and may be used and reprinted without permission; citation as to source, however, is appreciated.

Use of trade names and commercial sources is for identification only and does not imply endorsement by the U.S. Department of Health and Human Services.

References to non-CDC sites on the Internet are provided as a service to $M M W R$ readers and do not constitute or imply endorsement of these organizations or their programs by CDC or the U.S. Department of Health and Human Services. CDC is not responsible for the content of these sites. URL addresses listed in $M M W R$ were current as of the date of publication. 